EVELYN THAÍS FANTOZZI

HORMÔNIOS SEXUAIS FEMININOS COMO MODULADORES DA GERAÇÃO DE MEDIADORES INFLAMATÓRIOS EM MODELO EXPERIMENTAL DE ISQUEMIA E REPERFUSÃO INTESTINAL

Dissertação apresentada ao Programa de Pós-Graduação em Farmacologia do Instituto de Ciências Biomédicas da Universidade de São Paulo, para obtenção do Título de Mestre em Ciências. 
EVELYN THAÍS FANTOZZI

\section{HORMÔNIOS SEXUAIS FEMININOS COMO MODULADORES DA GERAÇÃO DE MEDIADORES INFLAMATÓRIOS EM MODELO EXPERIMENTAL DE ISQUEMIA E REPERFUSÃO INTESTINAL}

Dissertação apresentada ao Programa de PósGraduação do Instituto de Ciências Biomédicas da Universidade de São Paulo, para obtenção do Título de Mestre em Ciências.

Área de Concentração: Farmacologia

Orientador: Prof. Dr.Wothan Tavares de Lima

Versão original 
DADOS DE CATALOGAÇÃO NA PUBLICAÇÄO (CIP)

Serviço de Biblioteca e Informação Biomédica do

Instituto de Cièncias Biomédicas da Universidade de São Paulo

O reproduçăo total

Fantozzi, Evelyn Thaís.

Hormônios sexuais femininos como moduladores da geraçäo de mediadores inflamatórios em modelo experimental de isquemia e reperfusäo intestinal / Evelyn Thaís Fantozzi. -- São Paulo, 2013.

Orientador: Prof. Dr. Wothan Tavares de Lima.

Dissertaçäo (Mestrado) - Universidade de São Paulo. Instituto de Ciências Biomédicas. Departamento de Farmacologia. Área de concentraçäo: Farmacologia. Linha de pesquisa: Isquemia e reperfusäo intestinal.

Versão do título para o inglês: Female sex hormones modulates the generation of inflammatory mediators in experimental model of intestinal ischemia and reperfusion.

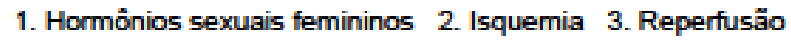

4. Inflamação 5. Intestino delgado 6. Ratos Wistar L. Lima, Prof. Dr.

Wothan Tavares de II. Universidade de São Paulo. Instituto de Ciências Biomédicas. Programa de Pós-Graduaçäo em Farmacologia III. Título. 
UNIVERSIDADE DE SÃO PAULO

INSTITUTO DE CIÉNCIAS BIOMÉDICAS

Candidato(a):

Título da Dissertação:

Hormônios sexuais femininos como moduladores da geração de mediadores inflamatórios em modelo experimental de isquemia e reperfusão intestinal.

Orientador(a): $\quad$ Prof. Dr. Wothan Tavares de Lima.

A Comissão Julgadora dos trabalhos de Defesa da Dissertação de Mestrado, em sessão pública realizada a .. .J................, considerou
( ) Aprovado(a)
( ) Reprovado(a)

$\begin{array}{ll}\text { Examinador(a): } & \begin{array}{l}\text { Assinatura: } \\ \text { Nome: } \\ \text { Instituição: }\end{array} \\ \text { Examinador(a): } & \begin{array}{l}\text { Assinatura: } \\ \text { Nome: } \\ \text { Instituição: }\end{array} \\ \text { Presidente: } & \begin{array}{l}\text { Assinatura: } \\ \text { Nome: } \\ \text { Instituição: }\end{array}\end{array}$ 


\section{Certificado}

Certificamos que o protocolo registrado sob $n^{\circ} \mathbf{0 3 9}$ nas fls. 101 do livro 02 para uso de animais em experimentação, sob a responsabilidade do Prof(a) Dr(a)) Wothan Tavares de Lima, Coordenador(a) da Linha de pesquisa "Papel dos sinais de perigo na modulação da lesão pulmonar aguda decorrente da isquemia e reperfusão intestinal: Importância dos hormônios sexuais femininos" do qual participam o(s) alunos Evelyn Thais Fantozzi, Luana Beatriz Vitoretti, Daniel Romero, Adriana Silva Rodrigues e os pesquisadores Ricardo Martins de Oliveira Filho, Ana Cristina Breithaup Faloppa, Patrícia Castelucci, está de acordo com os Princípios Éticos de Experimentação Animal adotado pela Sociedade Brasileira de Ciência de Animais de Laboratório (SBCAL) e foi aprovado pela COMISSÃO DE ÉTICA NO USO DE ANIMAIS (CEUA) em 24.03.2011, com validade de 3 anos.

São Paulo, 25 de março de 2011.
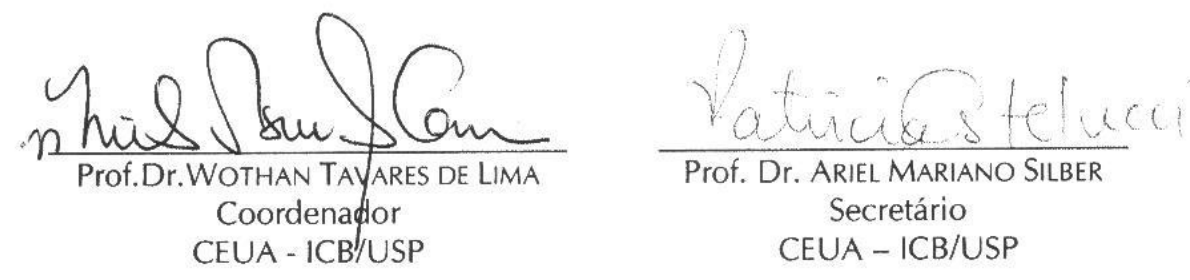
Decl. CEUA.035/2012

\section{DECLARA Ç ÃO}

Em adendo ao Certificado 039/11/CEUA, aprovado em 24.03.11, informo que o título do Projeto foi alterado para "Hormônios sexuais femininos como moduladores da geração de mediadores inflamatórios em modelo experimentais de isquemia e reperfusão intestinal", sem alteração da metologia empregada.

São Paulo, 25 de julho de 2012

Atenciosamente,

$$
\text { E) Wuik }
$$

Prof. Dr. Anderson de Sá Nunes Vice-Coordenador-CEUA ICB/USP 
Aos meus pais pelo amor incondicional, apoio, dedicação, confiança e incentivo constante para a minha formação.

Obrigada! 


\section{AGRADECIMENTOS}

A Deus, por guiar meu caminho e me dar saúde e perseverança para segui-lo.

A meus pais, Paulo e Sandra, por todo carinho, amor, confiança, incentivo, dedicação, parceria e apoio financeiro. E principalmente, pelo suporte em caminhos árduos que sem a presença de vocês seria impossível vencer qualquer batalha.

A minha família, pelo suporte, carinho e apoio durante toda minha vida.

Ao meu namorado, Bruno, por estar comigo nessa fase e entender a importância desta etapa. Sofrendo, vibrando e torcendo comigo. Obrigada por todo amor, carinho, respeito e companheirismo.

Ao meu orientador, Wothan, pela paciência, confiança, apoio e dedicação. Obrigada por fazer o meu jardim florir com muito mais beleza.

A Ana Cristina, pela enorme ajuda e ensinamentos fundamentais para meu crescimento e desenvolvimento científico. Aqui, não caberiam palavras para descrever minha gratidão!

Aos amigos de laboratório, Daniel, Adriana, Fernanda e Maria Beatriz, por tornarem a minha jornada menos árdua e mais alegre. Obrigada por toda amizade, ajuda e dedicação!

Ao Laboratório de Fisiopatologia da Inflamação Experimental do Instituto de Ciências Biomédicas, incluindo alunos, técnicos e professores, agradeço imensamente pelo apoio, auxílio e convivência.

Ao CNPq e a FAPESP pelo apoio financeiro.

Aos amigos e amigas conquistados ao longo da vida.

A todos que de alguma maneira foram importantes e fundamentais para a execução desse trabalho. 
“Cada sonho que você deixa para trás, é um pedaço do seu futuro que deixa de existir." Steve Jobs 


\section{RESUMO}

FANTOZZI, E. T. Hormônios sexuais femininos como moduladores da geração de mediadores inflamatórios em modelo experimental de isquemia e reperfusão intestinal. 2013. 115 f. Dissertação (Mestrado em Farmacologia) - Instituto de Ciências Biomédicas, Universidade de São Paulo, São Paulo, 2013.

A isquemia e reperfusão intestinal (I/R-i) pode causar inflamação pulmonar aguda caracterizada por infiltrado de neutrófilos e aumento da permeabilidade microvascular. Evidências clínicas e experimentais mostram que os hormônios sexuais femininos (HSF) exercem efeito protetor do pulmão após trauma seguido por choque hemorrágico. Apesar do mencionado o papel modulador dos HSF sobre as repercussões pulmonares e sistêmicas em modelo de I/R-i ainda não foi totalmente identificado. Neste estudo investigamos o papel dos HSF na modulação da inflamação pulmonar, sistêmica e no intestino em modelo experimental de I/R-i. Para tanto, ratas (Wistar, 60 dias, $160 \mathrm{~g}$ ) foram ovariectomizadas (OVx) e 7 dias após foram submetidas a I/R-i por meio da oclusão da artéria mesentérica superior (45min), seguida por $2 \mathrm{~h}$ de reperfusão intestinal. Em paralelo, ratas OVx receberam dose única de estradiol $(280 \mu \mathrm{g} / \mathrm{kg}$, s.c.) ou de progesterona $(200 \mu \mathrm{g} / \mathrm{kg}$, s.c.) $24 \mathrm{~h}$ antes da indução da I/R-i. Como controle foram utilizadas ratas Não-OVx, ratas OVx falsamente submetidas à I/R-i (Sham) e ratas não manipuladas (Basal). As repercussões pulmonares da $\mathrm{I} / \mathrm{R}$ intestinal foram avaliadas por meio da quantificação do extravasamento do corante azul de Evans (AE), do recrutamento de células inflamatórias, citocinas (IL-1 $\beta$, IL-6, IL-10, INF- $\gamma$ e VEGF), concentração de nitritos, expressão de moléculas de adesão e do receptor $\mathrm{P} 2 \mathrm{X}_{7}$ no endotélio vascular pulmonar. Também avaliamos os efeitos sistêmicos causados pela I/R-i quantificando ácido úrico, ATP, fosfatase alcalina, LDH, leucograma, mielograma, AMPc e TNF- $\alpha$. Por fim, caracterizamos a inflamação intestinal causada pela I/R-i quantificando o extravasamento do cortante AE e da atividade de MPO intestinal. Os dados obtidos revelaram que o pulmão de ratas OVx aumentou significativamente a geração de IL-1 $\beta$ e VEGF, a quantidade de neutrófilos e extravasamento do corante $\mathrm{AE}$ em relação ao observado no grupo Não-OVx. Ainda, no pulmão de animais OVx observamos redução de IL-10, nitritos e da expressão de PECAM-1 e do receptor $\mathrm{P}_{2} \mathrm{X}_{7}$ em relação ao grupo Não-OVx. As ratas OVx submetidas à I/R-i apresentaram maior recrutamento celular e aumento da concentração sérica dos sinais de perigo ( $\mathrm{LDH}$, fosfatase alcalina e ATP) em relação ao grupo Não-OVx. O tratamento dos animais OVx com estradiol ou progesterona preveniu o recrutamento celular e permeabilidade vascular, o aumento de citocinas, a geração dos sinais de perigo, a expressão das moléculas de adesão e do $\mathrm{P}_{2} \mathrm{X}_{7}$, observados nos animais $\mathrm{OVx}$ após $\mathrm{I} / \mathrm{R}-\mathrm{i}$. Nossos resultados indicam que o estradiol e a progesterona alteram a síntese de mediadores inflamatórios no pulmão e também exercem influência endógena na expressão de moléculas de adesão endoteliais, do receptor $\mathrm{P}_{2} \mathrm{X}_{7}$ e na concentração de fosfatase alcalina. Tomados em conjunto os dados apresentados permitem sugerir que os HSF exercem efeito protetor das repercussões pulmonares e sistêmicas causada pela I/R-intestinal.

Palavras-chave: Hormônios sexuais femininos. Inflamação pulmonar. Isquemia e reperfusão intestinal. Ratas. 


\begin{abstract}
FANTOZZI, E. T. Female sex hormones modulates the generation of inflammatory mediators in experimental model of intestinal ischemia and reperfusion. 2013. 115 p. Masters thesis (Pharmacology) - Instituto de Ciências Biomédicas, Universidade de São Paulo, São Paulo, 2013.
\end{abstract}

Intestinal Ischemia/Reperfusion (I/R-i) causes acute lung injury with neutrophil infiltration and increase microvascular permeability. Clinical and experimental evidences indicate that female sex hormones (FSH) may have a protective effect after trauma hemorrhagic shock. Despite the mentioned modulatory role of FSH on the pulmonary and systemic effects on model of I/R-i has not been fully identified. We investigated the effects of FSH modulating lung, systemic and intestine in an experimental model of I/R-i.For this, female rats (Wistar, 60 days, $160 \mathrm{~g}$ ) were ovariectomized (OVx) and after 7 days were subjected to I/R-i through the superior mesenteric artery occlusion ( $45 \mathrm{~min}$ ), followed by 2 hours of reperfusion. In parallel, OVxrats received a single dose of estradiol $(280 \mu \mathrm{g} / \mathrm{kg}$,s.c.) or progesterone $(200 \mu \mathrm{g} / \mathrm{kg}$,s.c. $) 24$ hours before induction of I/R-i. As a control rats were used Non-OVx, OVx rats falsely subjected to I/R-i (Sham) and non-manipulated rats (Naïve). The pulmonary effects caused by I/R-i were evaluated by quantifying the extravasation of Evans Blue dye (EB), recruitment of inflammatory cells, cytokines (IL-1 $\beta$, IL-6, IL-10, INF- $\gamma$ and VEGF), concentration of nitrites, expression of adhesion molecules and $\mathrm{P}_{2} \mathrm{X}_{7}$ receptor in pulmonary vascular endothelium. We also evaluate the systemic effects caused by I/R-i quantifying uric acid, ATP, alkaline phosphatase, LDH, WBC, bone marrow, cAMP and TNF- $\alpha$. Finally, we characterize the intestinal inflammation caused by I/R-i quantifying intestinal extravasation of EB dye and MPO activity. The data obtained revealed that the lungs of OVx rats significantly increased the generation of VEGF and IL-1 $\beta$, the amount of neutrophil and the extravasation of the EB dye compared to that observed in Non-OVx group. Still in the lung of OVxrats we observed reduction of IL-10, nitrites and expression of PECAM-1 and $\mathrm{P}_{2} \mathrm{X}_{7}$ receptor in comparison with Non-OVx group. The OVx rats subjected to I/R-i showed higher cell recruitment and increased serum concentrations of danger signs (LDH, alkaline phosphatase and ATP) in relation to the Non-OVx group. Treatment of OVx animals with estradiol or progesterone prevented cell recruitment and vascular permeability, increased cytokine generation of danger signs, expression of adhesion molecules and $\mathrm{P} 2 \mathrm{X}_{7}$ observed in $\mathrm{OVx}$ animals after I/R-i. Our results indicate that estradiol and progesterone affect the synthesis of inflammatory mediators in the lung and also influence endogenous the expression of endothelial adhesion molecules, and $\mathrm{P}_{2} \mathrm{X}_{7}$ receptor in the concentration of alkaline phosphatase. Taken together the data presented may suggest that the FSH exert protective effect of pulmonary and systemic effects caused by I/R-i.

Keywords: Female sex hormones. Lung injury.Ischemia and reperfusion.Female rats. 


\section{LISTA DE FIGURAS}

Figura 1 - Perfil temporal do curso da SDRA

Figura 2 - Valores de estradiol (painel superior) e progesterona (painel inferior) no soro de ratas com os ovários intactos ou 7 dias após a ovariectomia $(\mathrm{OVx})$ e após tratamento dos animais com estradiol $(280 \mu \mathrm{g} / \mathrm{kg})$ ou progesterona $(200 \mu \mathrm{g} / \mathrm{kg}) . \mathrm{O}$ sangue foi coletado pela artéria aorta após a eutanásia dos animais e processado para obtenção do soro. Os valores foram obtidos por radioimunoensaio e representam a média \pm EPM entre 7 a 10 amostras. ${ }^{*} P<0,05$ em relação ao respectivo grupo controle

Figura 3 - Efeito da OVx sobre o extravasamento do corante azul de Evans pulmonar. As ratas OVx ou não foram submetidas ou não (Sham) à isquemia (45 min) e reperfusão intestinal ( 2 horas - I/R intestinal). Valores basais foram obtidos de ratas não manipuladas. $\mathrm{O}$ corante $\mathrm{AE}(20 \mathrm{mg} / \mathrm{kg})$ foi injetado $20 \mathrm{~min}$ antes do término da reperfusão. Os dados representam a média $\pm \mathrm{EPM}$ de 5 animais. No gráfico $\mathrm{A},{ }^{*} P<$ 0,05 em relação ao grupo basal; ${ }^{\phi} P<0,05$ em relação ao grupo I/R não-OVx. No gráfico $\mathrm{B},{ }^{*} P<0,05$ em relação ao grupo sham; ${ }^{\phi} P<0,05$ em relação ao grupo I/R OVx.

Figura 4 -Atividade da enzima MPO em homogenatos de pulmão. As ratas OVx foram submetidas ou não (Sham) à isquemia (45 min) e reperfusão intestinal (2 horas - I/R intestinal). Valores basais foram obtidos de ratas não manipuladas. Os dados representam a média $\pm \mathrm{EPM}$ de 5 animais. No gráfico $\mathrm{A} * P<0,05$ em relação ao grupo não OVx. No gráfico $\mathrm{B} * P<0,05$ em relação ao grupo Sham e ${ }^{\phi} P<0,05$ em relação ao grupo OVx I/R

Figura 5 - Porcentagem de neutrófilos, células mononucleares e eosinófilos no pulmão processado para digestão com colagenase. As ratas OVx foram submetidas ou não (Sham) à isquemia (45 min) e reperfusão intestinal (2 horas - I/R intestinal). Valores basais foram obtidos de ratas não manipuladas. Os dados representam a média \pm EPM de 5 animais. Nos gráficos $* P<0,05$ em relação ao grupo sham e ${ }^{\phi} P<$ 0,05 em relação ao grupo OVx I/R

Figura 6 - Fotomicrografia mostrando o efeito da OVx e do tratamento dos animais com hormônios sexuais femininos sobre a expressão de ICAM-1 nos vasos pulmonares por imunohistoquímica. As ratas OVx foram submetidas ou não (sham) à isquemia (45 $\mathrm{min}$ ) e reperfusão intestinal ( 2 horas - I/R intestinal). Fotomicrografia basal representa corte de pulmão de rata não manipulada

Figura 7 - Efeito da OVx e do tratamento dos animais com hormônios sexuais femininos sobre a expressão de ICAM-1 nos vasos pulmonares por imunohistoquímica. As ratas OVx foram submetidas ou não (sham) à isquemia (45 min) e reperfusão intestinal ( 2 horas - I/R intestinal). Valores basais foram obtidos de ratas não manipuladas. Os dados representam a média $\pm \mathrm{EPM}$ de 5 animais. No gráfico $\mathrm{A} * P<0,05$ em relação ao grupo basal. No gráfico $\mathrm{B}{ }^{\phi} P<0,05$ em relação ao grupo I/R OVx

Figura 8 - Fotomicrografia mostrando o efeito da OVx e dos hormônios sexuais femininos sobre a expressão de PECAM-1 nos vasos pulmonares por imunohistoquímica. As ratas $\mathrm{OVx}$ foram submetidas ou não (sham) à isquemia (45 min) e reperfusão intestinal ( 2 horas - I/R intestinal). Fotomicrografia basal representa corte de pulmão de rata não manipulada.

Figura 9 - Efeito da OVx e dos hormônios sexuais femininos sobre a expressão de PECAM-1 nos vasos pulmonares por imunohistoquímica. As ratas OVx foram submetidas ou não (sham) à isquemia (45 min) e reperfusão intestinal (2 horas - I/R 
intestinal). Valores basais foram obtidos de ratas não manipuladas. Os dados representam a média \pm EPM de 5 animais. No gráfico $\mathrm{A}^{*} P<0,05$ em relação ao grupo basal, ${ }^{\phi} P<0,05$ em relação ao grupo I/R não-OVx. No gráfico $\mathrm{B}{ }^{*} P<0,05$ em relação ao grupo sham, ${ }^{\phi} P<0,05$ em relação ao grupo I/R OVx....

Figura 10 - Fotomicrografia mostrando o efeito da OVx e dos hormônios sexuais femininos sobre a expressão de VCAM no tecido pulmonar por imunohistoquímica. As ratas OVx foram submetidas ou não (sham) à isquemia (45 min) e reperfusão intestinal (2 horas - I/R intestinal). Fotomicrografia basal representa corte de pulmão de rata não manipulada.

Figura 11 - Efeito da OVx e dos hormônios sexuais femininos sobre a expressão de VCAM no endotélio vascular pulmonar por imunohistoquímica. As ratas OVx foram submetidas ou não (sham) à isquemia (45 min) e reperfusão intestinal (2 horas - I/R intestinal). Valores basais foram obtidos de ratas não manipuladas. Os dados representam a média \pm EPM de 5 animais. No gráfico $B{ }^{\phi} P<0,05$ em relação ao grupo $\mathrm{I} / \mathrm{R} \mathrm{OVx}$

Figura 12 - Fotomicrografias mostrando o efeito da OVx e dos hormônios sexuais femininos sobre a expressão do receptor $\mathrm{P} 2 \mathrm{X}_{7}$ nos vasos pulmonares por imunofluorescência. As ratas $\mathrm{OVx}$ foram submetidas ou não (basal) à isquemia (45 min) e reperfusão intestinal (2 horas - I/R intestinal). Valores basais foram obtidos de ratas não manipuladas. As imagens representam a atividade do receptor $\mathrm{P}_{2} \mathrm{X}_{7}$ nos vasos pulmonares

Figura 13 - Efeito da OVx e dos hormônios sexuais femininos sobre a quantificação do receptor $\mathrm{P}_{2} \mathrm{X}_{7}$ nos vasos pulmonares por imunofluorescência. As ratas $\mathrm{OVx}$ foram submetidas ou não (basal) à isquemia $(45 \mathrm{~min})$ e reperfusão intestinal (2 horas - I/R intestinal). Valores basais foram obtidos de ratas não manipuladas. Os dados representam a média \pm EPM de 5 animais. No gráfico $\mathrm{A}:{ }^{*} P<0,05$ em relação ao grupo basal, ${ }^{\phi} P<0,05$ em relação ao grupo I/R Não-OVx. No gráfico B: $* P<0,05$ em relação ao grupo sham, ${ }^{\phi} P<0,05$ em relação ao grupo I/R OVx.

Figura 14 - Fotomicrografias representando a atividade do receptor $\mathrm{P}_{2} \mathrm{X}_{7}$ nos vasos pulmonares. As figuras da esquerda representam as imagens com autofluerência em verde. As imagens da direita mostrando a autofluorescência verde transformada em vermelho após incubação com azul de pontamina. $\mathrm{E}$ as imagens centrais mostram a atividade do receptor $\mathrm{P} 2 \mathrm{X}_{7}$ após tratamento com azul de pontamina.

Figura 15 - Efeito da OVx e dos hormônios sexuais femininos sobre a geração de IL$1 \beta$ em explante de pulmão de ratas (cultura de $24 \mathrm{~h}$ ) após a I/R intestinal. A I/R intestinal foi induzida 7 dias após a remoção dos ovários $(\mathrm{OVx})$ e em ratas não-OVx. O grupo basal consistiu de animais OVx, e o grupo sham de animais falsamente operados. O tratamento hormonal ocorreu $24 \mathrm{~h}$ antes da indução da I/R intestinal. Os dados representam a média \pm EPM de 5 animais. No gráfico $A * P<0,05$ em relação ao grupo não OVx I/R. No gráfico B . ${ }^{*} P<0,05$ em relação ao grupo Sham; ${ }^{\phi} P<0,05 \mathrm{em}$ relação ao grupo OVx I/R

Figura 16 - Efeito da OVx e dos hormônios sexuais femininos sobre a geração de IL10 em explante de pulmão (cultura de $24 \mathrm{~h}$ ) de ratas submetidas à $\mathrm{I} / \mathrm{R}$ intestinal. A I/R intestinal foi induzida 7 dias após a remoção dos ovários $(\mathrm{OVx})$ bem como em ratas não-OVx. O grupo basal consistiu de animais $O V x$, e o grupo sham de animais falsamente operados. O tratamento hormonal ocorreu $18 \mathrm{~h}$ antes do procedimento de I/R intestinal. Os dados representam a média $\pm E P M$ de 5 animais. No gráfico $\mathrm{A}, * P<$ 0,05 em relação ao grupo basal; ${ }^{\phi} P<0,05$ em relação ao grupo $\mathrm{I} / \mathrm{R}$ não-OVx. No gráfico $\mathrm{B}, * P<0,05$ em relação ao grupo sham; ${ }^{\phi} P<0,05$ em relação ao grupo I/R $\mathrm{OVX}$ 
Figura 17 - Efeito da OVx e dos hormônios sexuais femininos sobre a geração de VEGF em explante de pulmão (cultura de $24 \mathrm{~h}$ ) de ratas submetidas à I/R intestinal. A I/R intestinal foi induzida 7 dias após a remoção dos ovários $(\mathrm{OVx})$ bem como em ratas não $\mathrm{OVx}$. O grupo basal consistiu de animais $\mathrm{OVx}$, e o grupo sham de animais falsamente operados. O tratamento hormonal ocorreu $18 \mathrm{~h}$ antes do procedimento de I/R intestinal. Os dados representam a média \pm EPM de 5 animais No gráfico A $* P<$ 0,05 em relação ao grupo não $\mathrm{OVx}$. No gráfico, $* P<0,05$ em relação ao grupo Sham; ${ }^{\phi} P<0,05$ em relação ao grupo $\mathrm{OVx} \mathrm{I} / \mathrm{R}$

Figura 18 - Efeito da OVx e dos hormônios sexuais femininos sobre a geração de IL6 em explante de pulmão (cultura de $24 \mathrm{~h}$ ) de ratas submetidas à I/R intestinal. A I/R intestinal foi induzida 7 dias após a remoção dos ovários $(\mathrm{OVx})$ bem como em ratas não OVx. O grupo basal consistiu de animais $\mathrm{OVx}$, e o grupo sham de animais falsamente operados. $\mathrm{O}$ tratamento hormonal ocorreu $18 \mathrm{~h}$ antes do procedimento de $\mathrm{I} / \mathrm{R}$ intestinal. Os dados representam a média \pm EPM de 5 animais.

Figura 19 - Efeito da OVx e dos hormônios sexuais femininos sobre a geração de INF- $\gamma$ em explante de pulmão de ratas (cultura de $48 \mathrm{~h}$ ) após a I/R intestinal. A I/R intestinal foi induzida 7 dias após a remoção dos ovários (OVx) e em ratas não-OVx. $\mathrm{O}$ grupo basal consistiu de animais não manipulados, e o grupo sham de animais $\mathrm{OVx}$ falsamente operados. O tratamento hormonal ocorreu $24 \mathrm{~h}$ antes da indução da I/R intestinal. Os dados representam a média \pm EPM de 5 animais. No gráfico $\mathrm{B}{ }^{\phi} P<0,05$ em relação ao grupo OVx I/R.

Figura 20 - Efeito da OVx e dos hormônios sexuais femininos sobre a geração de nitritos em explante de pulmão de ratas após a I/R intestinal. A I/R intestinal foi induzida 7 dias após a remoção dos ovários $(\mathrm{OVx})$ e em ratas não OVx. O grupo basal consistiu de animais não manipulados, e o grupo sham de animais falsamente operados. O tratamento hormonal ocorreu $24 \mathrm{~h}$ antes da indução da I/R intestinal. Os dados representam a média \pm EPM de 5 animais. No gráfico $\mathrm{A} * P<0,05$ em relação ao grupo basal, ${ }^{\phi} P<0,05$ em relação ao grupo não-OVx. No gráfico $\mathrm{B} * P<0,05 \mathrm{em}$ relação ao grupo Sham; ${ }^{\phi} P<0,05$ em relação ao grupo $\mathrm{OVx}$.

Figura 21 - Número de leucócitos totais na medula óssea em grupos de ratas ovariectomizadas $(\mathrm{OVx})$ ou não (não $\mathrm{OVx}$ ), submetidas a $\mathrm{I} / \mathrm{R}$ intestinal ou não (basal). Há também animais OVx falsamente submetidos a I/R intestinal (sham). Os dados representam a média \pm EPM de 5-8 experimentos. No gráfico $\mathrm{A}, * P<0,05 \mathrm{em}$ relação ao grupo basal; ${ }^{\phi} P<0,05$ em relação ao grupo I/R não-OVx. No gráfico $\mathrm{B}$,

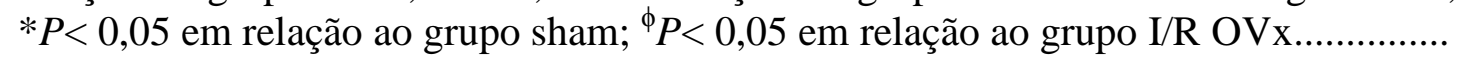
Figura 22 - Número de leucócitos totais circulantes em grupos de ratas ovariectomizadas $(O V x)$ ou não (não $O V x$ ), submetidas a $I / R$ intestinal ou não (basal). Há também animais OVx falsamente submetidos a I/R intestinal (sham). Os dados representam a média \pm EPM de 5-8 animais. ${ }^{*} P<0,05$ em relação ao respectivo grupo controle (antes da I/R intestinal). ${ }^{\Phi} P<0,05$ em relação ao grupo sham. ${ }^{\Delta} P<0,05$ em relação ao grupo I/R intestinal OVx....

Figura 23 - Número de mononucleares (A), neutrófilos (B) e eosinófilos (C) circulantes em grupos de ratas ovariectomizadas (OVx) ou não (não $O V x$ ), submetidas a I/R intestinal ou não (basal). Há também animais OVx falsamente submetidos a I/R intestinal (sham). Os dados representam a média \pm EPM de 5-8 experimentos. ${ }^{*} P<0,05$ em relação ao respectivo grupo controle (antes da $\mathrm{I} / \mathrm{R}$ intestinal). ${ }^{\Phi} P<0,05$ em relação ao grupo sham. ${ }^{\Delta} P<0,05$ em relação ao grupo I/R intestinal $\mathrm{OVX}$.

Figura 24 - Efeito da OVx e dos hormônios sexuais femininos sobre os níveis de TNF- $\alpha$ no soro de ratas. As ratas OVx ou não foram submetidas ou não (Sham) à 
isquemia (45 min) e reperfusão intestinal (2 horas - I/R intestinal). Valores basais foram obtidos de ratas não manipuladas. Os dados representam a média $\pm E P M$ de 5 animais. No gráfico A, $* P<0,05$ em relação ao grupo basal; ${ }^{\phi} P<0,05$ em relação ao grupo I/R não-OVx. No gráfico $\mathrm{B},{ }^{*} P<0,05$ em relação ao grupo sham; ${ }^{\phi} P<0,05 \mathrm{em}$ relação ao grupo I/R OVx.

Figura 25 - Efeito da OVx e dos hormônios sexuais femininos sobre os níveis de LDH no soro de ratas. As ratas OVx ou não foram submetidas ou não (Sham) à isquemia (45 min) e reperfusão intestinal ( 2 horas - I/R intestinal). Valores basais foram obtidos de ratas não manipuladas. Os dados representam a média $\pm \mathrm{EPM}$ de 5 animais. No gráfico A, $* P<0,05$ em relação ao grupo basal; ${ }^{\phi} P<0,05$ em relação ao grupo I/R não-OVx. No gráfico $\mathrm{B},{ }^{*} P<0,05$ em relação ao grupo sham; ${ }^{\phi} P<0,05 \mathrm{em}$ relação ao grupo I/R OVx.

Figura 26 - Efeito da OVx e dos hormônios sexuais femininos sobre os níveis de fosfatase alcalina no soro de ratas. As ratas OVx ou não foram submetidas ou não (Sham) à isquemia (45 min) e reperfusão intestinal (2 horas - I/R intestinal). Valores basais foram obtidos de ratas não manipuladas. Os dados representam a média $\pm E P M$ de 5 animais. No gráfico $\mathrm{A} * P<0,05$ em relação ao grupo não $\mathrm{OVx}$. No gráfico $\mathrm{B}$, ${ }^{*} P<0,05$ em relação ao grupo Sham; ${ }^{\phi} P<0,05$ em relação ao grupo OVx I/R.

Figura 27 - Efeito da OVx e dos hormônios sexuais femininos sobre os níveis de ácido úrico no soro de ratas. As ratas $\mathrm{OVx}$ ou não foram submetidas ou não (Sham) à isquemia (45 min) e reperfusão intestinal (2 horas - I/R intestinal). Valores basais foram obtidos de ratas não manipuladas. Os dados representam a média $\pm E P M$ de 5 animais. No gráfico A, $* P<0,05$ em relação ao grupo basal; ${ }^{\phi} P<0,05$ em relação ao grupo I/R não-OVx. No gráfico $\mathrm{B},{ }^{*} P<0,05$ em relação ao grupo sham; ${ }^{\phi} P<0,05 \mathrm{em}$ relação ao grupo I/R OVx

Figura 28 - Efeito da OVx e dos hormônios sexuais femininos sobre os níveis de AMPc no soro de ratas. As ratas OVx foram submetidas ou não (Sham) à isquemia (45 min) e reperfusão intestinal ( 2 horas - I/R intestinal). Valores basais foram obtidos de ratas não manipuladas. Os dados representam a média \pm EPM de 5 animais. No gráfico $\mathrm{A} * P<0,05$ em relação ao grupo não $\mathrm{OVx}$

Figura 29 - Atividade da enzima MPO em homogenatos de intestino. As ratas OVx foram submetidas ou não (Sham) à isquemia (45 min) e reperfusão intestinal (2 horas - I/R intestinal). Valores basais foram obtidos de ratas não manipuladas. Os dados representam a média \pm EPM de 5 animais. No gráfico $\mathrm{A}, * P<0,05$ em relação ao grupo basal; ${ }^{\phi} P<0,05$ em relação ao grupo I/R não-OVx. No gráfico $\mathrm{B},{ }^{*} P<0,05 \mathrm{em}$ relação ao grupo sham; ${ }^{\phi} P<0,05$ em relação ao grupo I/R OVx....

Figura 30 - Efeito da OVx sobre o extravasamento do corante AE intestinal. As ratas OVx ou não foram submetidas ou não (Sham) à isquemia (45 min) e reperfusão intestinal ( 2 horas - I/R intestinal). Valores basais foram obtidos de ratas não manipuladas. Os dados representam a média \pm EPM de 5 animais. No gráfico $\mathrm{A},{ }^{*} P<$ 0,05 em relação ao grupo basal; ${ }^{\phi} P<0,05$ em relação ao grupo $\mathrm{I} / \mathrm{R}$ não-OVx. No gráfico $\mathrm{B}, * P<0,05$ em relação ao grupo sham; ${ }^{\phi} P<0,05$ em relação ao grupo I/R OVx. 


\section{LISTA DE ABREVIATURAS E SIGLAS}

AE: Azul de Evans

AKT: Proteína quinase B

AMPc: Adenosina monofasfato cíclico

AP-1: Proteína Ativadora tipo 1

ATP: Trifosfato de adenosina

BML-111: agonista do receptor A-4 para lipoxina

CD40: Proteína coestimulatória

DAMPs: Moléculas padrões de células lesionadas

DMEM: Dulbecco'sModifiedEagle'sMedium

DO: Densidade Óptica

EDTA: Ácido etilenodiamino tetra-acético

eNOS: óxido nítrico sintase

EPM: Erro padrão da média

Explante: Cultura de tecido pulmonar

HMGB-1: Proteínas de alta mobilidade do grupo 1

HUVECs: Células endoteliais humanas de cordão umbilical

I/R: Isquemia e Reperfusão

ICAM-1: Moléculas de adesão intracelular tipo 1

IL: Interleucina

IMOS: Insuficiência múltipla de órgãos e sistemas

i.m.: administração via intramuscular

INF $\gamma$ : Interferon gama

i.p.: administração via intraperitoneal

LDH: Desidrogenase lática 
LV: Lavado vaginal

LPA: Lesão pulmonar aguda

LTB4: leucotrieno B4

M1: Macrófago tipo 1

M2: Macrófago tipo 2

MMP-8: metoproteinase de matrix8

MPO: Mieloperoxidase

NF- $\kappa$ B: Fator nuclear kappa B

NO: Óxido nítrico

NOS: Óxido nítrico sintase

NOX: enzima produtora de espécies reativas de oxigênio

OVx: Ovariectomia

P2: Receptor purinérgico tipo 2

$\mathrm{P} 2 \mathrm{X}_{7 \text { : }}$ Receptor purinérgico tipo 2, subtipo X 7

P2Y 6: Receptor purinérgico tipo 2, subtipo Y 6

p38: Proteína quinase ativadora de mitógeno

PAF: Fator ativador de plaquetas

PAMPs: Moléculas padrões associadas aos patógenos

PECAM-1: Moléculas de adesão plaqueta-endotélio tipo 1

PBS: Phosphate Buffered Saline

PGE: Prostaglandina

PGF2 $\alpha$ : Prostaglandina F2 alfa

PMN: Polimorfonucleares

PRRs: Receptores de padrão de reconhecimento

s.c.: administração via subcutânea 
SFB: soro fetal bovino

SDRA: Síndrome do Desconforto Respiratório Agudo

TFM: Tissue Freezing Medium

TLR-9: receptor toll-like tipo 9

TNF- $\alpha$ : Fator de necrose tumoral alfa

UTI: Unidade de Terapia intensiva

VCAM: Molécula de adesão vascular

VEGF: Vascular Endothelial Growth Factor 


\section{SUMÁRIO}

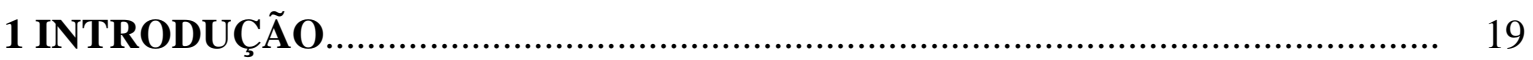

1.1 Isquemia e Reperfusão (I/R) intestinal e repercussões...................................... 19

1.2 Síndrome do Desconforto Respiratório Agudo (SDRA) .................................... 23

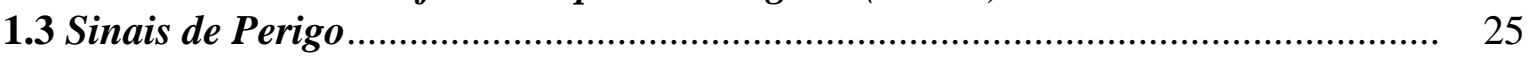

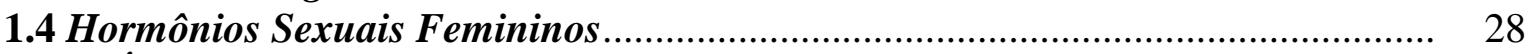

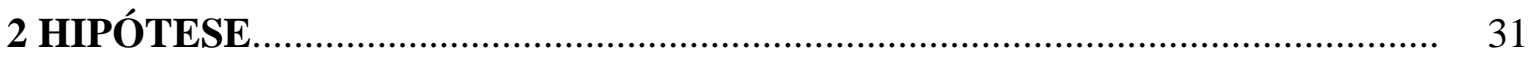

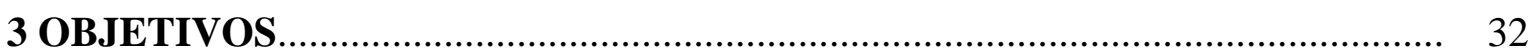

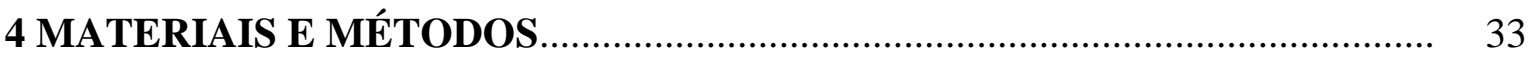

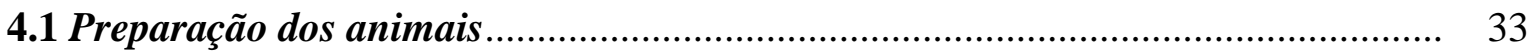

4.2 Determinação do número de leucócitos circulantes e da medula óssea ................ 34

4.3 Cultura de tecido pulmonar (explante) ................................................................. 34

4.4 Caracterização dos efeitos pulmonares da I/R intestinal e marcadores da lesão isquêmica ............................................................................................................ 35

4.5 Análise dos mediadores inflamatórios gerados pela I/R intestinal...................... 37

4.6 Quantificação da geração de sinais de perigo..................................................... 37

4.7 Estudo da expressão das moléculas de adesão (ICAM-1, PECAM-1 e VCAM) no tecido pulmonar .................................................................................................. 38

4.8 Estudo do receptor $P 2 X_{7}$ no tecido pulmonar........................................................ 39

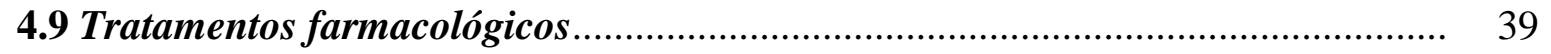

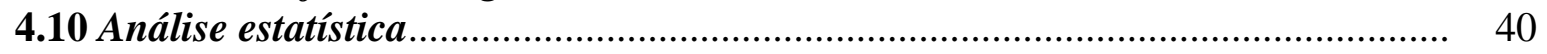

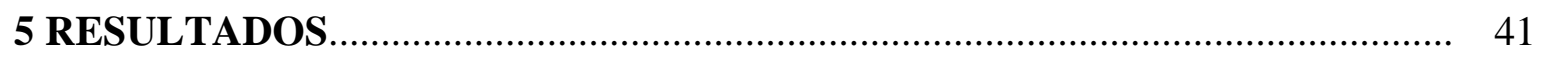

5.1 Determinação dos níveis séricos hormonais....................................................... 41

5.2 Caracterização dos efeitos pulmonares e da remoção dos ovários $n a I / R$ intestinal.

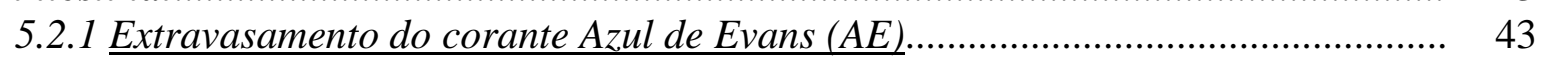

5.2 .2 Recrutamento de células inflamatórias.................................................................. 45

5.2.3 Expressão das moléculas de adesão (ICAM-1, PECAM-1 e VCAM).................... 49

5.2 .4 Expressão dos receptores $P 2 X_{7}$............................................................................ 55

5.2.5 Quantificação dos mediadores inflamatórios em explante pulmonar.................... 58

5.3. Caracterização dos efeitos sistêmicos causados pela I/R intestinal....................... 68

5.3.1 Contagem de leucócitos totais na medula óssea.................................................... 68

5.3.2 Contagem total e diferencial dos leucócitos circulantes........................................ 69

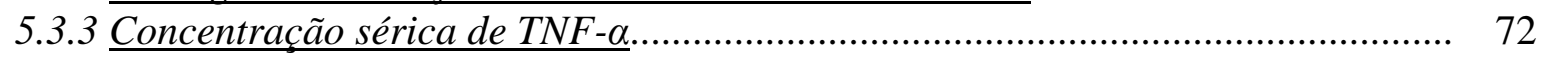

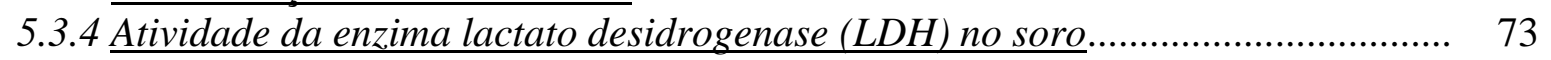

5.3.5 Concentração de fosfatase alcalina no soro.......................................................... 74

5.3.6 Concentração de ácido úrico no soro.................................................................... 75

5.3.7 Concentração de trifosfato de adenosina (ATP) no soro......................................... 76

5.4 Caracterização da lesão local causada pela I/R intestinal ..................................... 77

5.4.1 Atividade da enzima mieloperoxidase (MPO)...................................................... 77

5.4.2 Extravasamento do corante Azul de Evans (AE) no intestino................................. 79

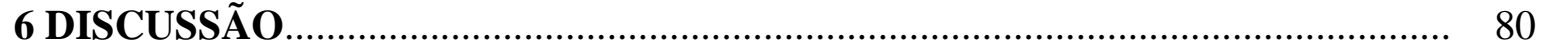

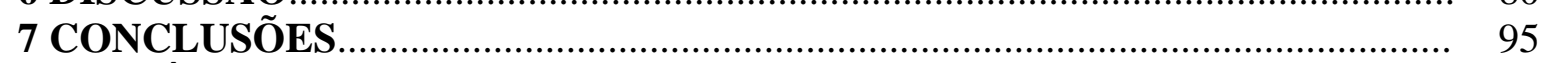

REFERÊNCIAS 


\section{INTRODUÇÃO}

\subsection{Isquemia e Reperfusão (I/R) intestinal e repercussões}

A isquemia é definida como a perda do suprimento de sangue e de oxigênio para um determinado órgão por diminuição da luz de artérias, arteríolas ou capilares. Por consequência, este órgão sofre diversas alterações do metabolismo, resultando no acúmulo de metabólitos tóxicos, redução de reservas energéticas e eventualmente necrose tecidual (SCARABELLI et al., 2002; SUN et al., 1999).

Ainda não está totalmente esclarecido se apenas a isquemia é condição suficiente para a indução de lesão tecidual. Todavia, sabe-se que durante o quadro de isquemia e reperfusão as alterações metabólicas e funcionais nas células que podem ser reconhecidas pelo sistema imune inato. De fato, a hipóxia tecidual e a redução de nutrientes causadas pela isquemia levam ao dano celular, sendo que a posterior fase de reperfusão pode ser considerada como fator de contribuição para a ativação celular e o desencadeamento de resposta inflamatória exacerbada a estímulos subsequentes (WAXMAN, 1996).

Por exemplo, a hipóxia causada pela I/R intestinal ativa o NF- $\kappa B$ (fator nuclear kappa B) nas células do epitélio intestinal, levando um aumento do TNF- $\alpha$ (fator de necrose tumoral tipo $\alpha$ ), uma citocina pro-inflamatória. Esta citocina se eleva no soro e se acumula na mucosa intestinal estimulando simultaneamente a apoptose epitelial (CHEN et al., 2003).

Contudo, o período de reperfusão parece ser o mais crucial para a lesão intestinal. Estudos elaborados por Parks e Granger (1986) mostram que o intestino de animais submetidos à $3 \mathrm{~h}$ de isquemia e $1 \mathrm{~h}$ de reperfusão estava mais lesionado que o intestino de animais que foram submetidos à $4 \mathrm{~h}$ de isquemia. Este dado pode ser explicado pelas espécies reativas de oxigênio presentes no fluxo sanguíneo que volta a circular no intestino resultando na ativação de leucócitos e sua adesão ao endotélio (MC CORD, 1985). Por consequência há um aumento de permeabilidade vascular, perda da integridade endotelial, formação de edema intersticial com aumento da pressão intersticial. Este aumento de pressão não permite que o conteúdo microvascular retorne ao vaso gerando um aumento da hemoconcentração intravascular e trombose, disfunção vasomotora, aumento das células endoteliais e edema (MENGER; RÜCKER; VOLLMAR, 1997). Então se pode inferir que a lesão na microvascularização intestinal é crucial para os danos intestinais e consequentemente sistêmicos causados pela I/R intestinal (VOLLMAR; MENGER, 2011). A ação lesiva da reperfusão aparentemente reside na disseminação sistêmica dos produtos tóxicos gerados 
durante o evento, que tem suas consequências geradas ainda na fase de isquemia e também durante reperfusão tecidual, quando ocorre o restabelecimento da oxigenação interrompido pela isquemia (BERTHIAUME; LESUR; DAGENAIS, 1999; ELTZSCHIG; CARMELIET, 2011; GIRN et al., 2007).

Como consequência da $\mathrm{I} / \mathrm{R}$ intestinal pode ocorrer o aparecimento de inflamação pulmonar aguda a qual pode evoluir, em casos mais graves para a síndrome do desconforto respiratório agudo, inflamação sistêmica e falência múltipla de órgãos e sistemas (BARON et al.,1994; HSIEH et al., 2011; JAMES et al., 2010; TURNAGE; GUICE; OLDHAM, 1994).

Evidências experimentais mostram que a I/R intestinal causa ativação de neutrófilos, aumento de permeabilidade vascular, edema pulmonar, indução de necrose e apoptose (CHOPRA; KEUBEN; SHARMA, 2009; GRACE, 1994; GRANGER; KORTHUIS, 1995; MAXWELL; LIP, 1997). Do ponto de vista das células efetoras, neutrófilos e macrófagos exercem papel importante na inflamação pulmonar causada pela I/R intestinal. Um aspecto interessante associando os neutrófilos à inflamação pulmonar experimental, refere-se aos dados indicando que a redução do seu número no pulmão diminui a gravidade da lesão pulmonar aguda causada pela I/R intestinal (MATSUO et al., 2013). Ainda, as vias de sinalização intracelular constituem alvos importantes para o controle do tráfego de neutrófilos para o pulmão. Neste sentido a p38 (proteína quinase ativadora de mitógeno), AKT (proteína quinase B) e NF-kB representam importantes alvos para o controle da atividade funcional dos neutrófilos, pois reduzem a toxicidade e hemorragia causada pela inflamação pulmonar aguda (ABRAHAM, 2003).

Em decorrência da I/R intestinal, os neutrófilos cruzam a barreia endotelial migram para o pulmão, liberam diversas enzimas proteolíticas e espécies reativas do oxigênio, razão pela qual a interação leucócito-endotélio é relevante para que o processo inflamatório pulmonar se estabeleça. De fato, o recrutamento de neutrófilos para locais de injúria tecidual é evento crítico para a defesa do hospedeiro contra estímulos lesivos e para a reparação de tecidos (BAUMANN; GAULDIE, 1994). A ação dos neutrófilos é iniciada e potencializada por diversos mediadores, tais como as interleucinas (IL) IL-1 $\beta$, IL-6, IL-8, o TNF- $\alpha$ e os mediadores lipídicos como eicosanóides e PAF (Fator Ativador de Plaquetas), e receptores do tipo toll-like (IKAI et al., 1996; KOIKE et al., 2000; VICTONI et al., 2010).

Durante a isquemia, a hipóxia o metabolismo anaeróbico estimula as vias das xantinas por consequência da depleção dos níveis de trifosfato de adenosina (ATP), que é metabolizado até se transformar em hipoxantina que, com a restauração do fluxo de sangue, favorece a formação de radicais de oxigênio. Estes por sua vez, podem produzir injúria celular 
através de reações de peroxidação lipídica das membranas mitocondriais, lisossômicas e plasmáticas, alterando, então, a estrutura e a função dessas membranas (MCCORD, 1985). Muitos estudos acreditam que a maior fonte de radicais de oxigênio seja através da vida da xantina-oxidase, enzima presente em muitos tecidos que converte a hipoxantina em radicais de oxigênio (JAESCHKE; WOOLBRIGHT, 2012). Nesse contexto, a inibição da ação da xantina-oxidase reduz a atividade funcional de neutrófilos e o dano pulmonar ocasionados pela I/R intestinal (KOIKE et al., 1993; SEEKAMP; WARD, 1993; TÜRÜT et al., 2009). De forma geral, os neutrófilos medeiam as alterações funcionais em órgãos submetidos à isquemia e reperfusão, bem como aquelas observadas em órgãos distantes do local onde o evento isquêmico teve origem. Além dos neutrófilos, os macrófagos, mastócitos e linfócitos também medeiam as lesões teciduais causadas pela I/R intestinal. Ainda, células estruturais das vias aéreas também favorecem o desencadeamento da lesão pulmonar aguda causada pela I/R intestinal. De fato, esta bem estabelecido que células musculares das vias aéreas são potenciais geradoras de mediadores pro-inflamatórios (XIA et al., 2012). Portanto fica claro que a lesão pulmonar aguda (LPA) causada pela I/R intestinal é um evento multimediado, justificando a dificuldade de tratamento farmacológico efetivo e a inexistência de terapia única e definitiva.

Recentemente mostramos que a I/R intestinal aumenta a expressão de moléculas de adesão plaquetária do tipo 1 (PECAM-1) no pulmão e que, possivelmente, esta molécula esteja associada aos efeitos lesivos dos neutrófilos sobre o pulmão (BREITHAUPTFALOPPA et al., 2012). Estudos anteriores do nosso grupo revelaram o envolvimento da enzima óxido nítrico sintase (NOS) constitutiva no controle do recrutamento de neutrófilos para o pulmão após a I/R intestinal em ratos (CAVRIANI et al., 2004). Estes dados indicam que um complexo sistema de sinalização intracelular pode mediar os eventos pulmonares observados após a I/R intestinal.

Macrófagos alveolares liberam grande contingente de mediadores e fatores que regulam a inflamação pulmonar. Em um pulmão sadio a população de macrófagos é elevada. Assim, estas células representam a primeira linha de defesa no pulmão. Evidências mostram que macrófagos podem constituir populações distintas de células na dependência da natureza do mediador que os estimule. Nesse sentido são reconhecidos macrófagos do tipo 1 (M1) e do tipo 2 (M2) (para revisão ver LASKIN et al., 2011). Estas células como mencionado, estão presentes em grande quantidade no tecido pulmonar e, quando estimuladas, liberam amplo espectro de mediadores, tais como TNF- $\alpha$, INF $\gamma$ (interferon gama), LTB4 (leucotrieno B4), radicais livres de oxigênio, óxido nítrico e eicosanóides os quais podem induzir ou 
potencializar o processo inflamatório (CHOPRA; KEUBEN; SHARMA, 2009; DAVIDSON et al., 2004; MUKUNDAN et al., 2001; OHKUBO et al., 2013; POULTER et al., 1994; SOUZA et al., 2000). Dados publicados por Moraes et al. (2008) mostram que em modelo de I/R intestinal em ratos machos, os macrófagos alveolares são essenciais para 0 desencadeamento da inflamação pulmonar. Ainda, é interessante notar que os neutrófilos quando ativados interagem com os macrófagos e induzem estas células a liberarem quantidades apreciáveis da citocina anti-inflamatória IL-10 (BORJESSON et al., 2000; MORAIS et al., 2008). Esta interação se torna interessante uma vez que estas células são encontradas de forma exacerbada no modelo de I/R intestinal, assim como pode ser observada a presença de IL-10 (DE LIMA et al., 2013; BREITHAUPT-FALOPPA et al., 2012; MATSUO et al., 2013; PAMUK et al., 2010; XIA; MARTIN; BERNER, 2003).

Embora esteja bem estabelecido que eventos isquêmicos intestinais podem causar a inflamação pulmonar, persistem dúvidas acerca dos sinais que medeiam a indução/controle da resposta inflamatória pulmonar após a I/R intestinal. Estudos revelam que citocinas e interleucinas geradas no intestino durante o estresse provocado pelo choque hemorrágico, um modelo que possui efeitos semelhantes ao da I/R intestinal, são disseminadas sistemicamente e concorrem para a lesão inflamatória pulmonar (DEITCH et al., 2001). A lesão intestinal causada pela isquemia resulta em diminuição da função intestinal e consequentemente, favorece a translocação bacteriana (VOLLMAR; MENGER, 2011). Existe, também, evidência de translocação bacteriana para o sistema linfático mesentérico após a I/R intestinal (Foex, 2005). A translocação bacteriana ocorre quando há lesão da barreira intestinal e passagem das bactérias do trato gastrointestinal através da mucosa epitelial para outros locais, como, por exemplo, os linfonodos mesentéricos (BERG; OWENS, 1979). Diversos estudos mostram que a I/R intestinal promove a translocação bacteriana em modelos animais de trauma intestinal (HONGGANG et al., 2012; KÜÇÜKAYDIN et al., 2000; LU et al., 2012; XING et al., 2005) Por outro lado, estudos comprovaram que em humanos após o trauma intestinal não ocorre translocação bacteriana (MOORE et al., 1991; MOORE et al., 1992).

Em conclusão, a I/R intestinal é um problema clínico que se associa ao desenvolvimento de inflamação sistêmica e disfunção da microcirculação pulmonar que pode ocasionar uma lesão pulmonar aguda (CARDEN; YOUNG; GRANGER, 1993; CATY et al., 1990; HARWARD et al., 1993; HE et al., 2012; HILL et al., 1992; XIAO et al., 1997). Nesse sentido, a despeito de seus efeitos benéficos inquestionáveis, a reperfusão tecidual subsequente aos quadros de isquemia, é importante fator de risco para o desencadeamento de lesões teciduais generalizadas, geralmente fatais, onde o pulmão é o principal órgão afetado. 


\subsection{Síndrome do Desconforto Respiratório Agudo (SDRA)}

Como mencionado a I/R intestinal é fator de indução de lesão pulmonar aguda que, em casos mais graves, pode desencadear a síndrome do desconforto respiratório agudo (SDRA). Considerando que a SDRA é um dos primeiros eventos na insuficiência múltipla de órgãos e sistemas (IMOS) (BIFFL; MOORE, 1996), a lesão intestinal ocasionada pelo trauma pode ser considerada motor da IMOS e consequentemente da lesão pulmonar aguda (DEITCH et al., 2001). Desta forma, a geração de mediadores inflamatórios pelo intestino, quando este se encontra sob o estresse de redução de perfusão (isquemia) pode mediar/modular a inflamação pulmonar (LPA/SDRA).

Conceitualmente, a SDRA é uma síndrome clínica grave caracterizada por lesão pulmonar aguda decorrente de intensa inflamação pulmonar onde há hipoxemia grave (BERNARD, 2005). Os sinais clínicos são caracterizados por: hipoxemia $\left(\mathrm{PaO}_{2} / \mathrm{FiO}_{2}<300\right.$ para LPA e < 200 para SDRA), infiltrado bilateral pulmonar sugerindo edema, sem sinais clínicos de falência cardíaca e, nenhuma outra explicação para esses sintomas (RUBENFELD et al., 2005).

Durante a SDRA diversos mediadores inflamatórios são potenciais candidatos à mediação das lesões, dentre eles o TNF $\alpha$, a IL-1 e a IL-8 ocupam lugar de destaque. Embora possa ter início agudamente (6-48 horas após o insulto lesivo), a SDRA pode persistir por dias e até semanas (HUDSON et al., 1995). A SDRA apresenta uma fase denominada de exsudativa, onde pode ser observada a liberação de amplo espectro de mediadores, exsudação, edema intersticial e presença de membrana hialina. Além desta, observa-se a fase proliferativa, na qual ocorre infiltração de miofibroblastos e deposição de colágeno. Por fim, em pacientes com doença prolongada observa-se prejuízo da arquitetura pulmonar, fibrose difusa e formação de edema (Figura 1). 
Figura 1 - Perfil temporal do curso da SDRA.

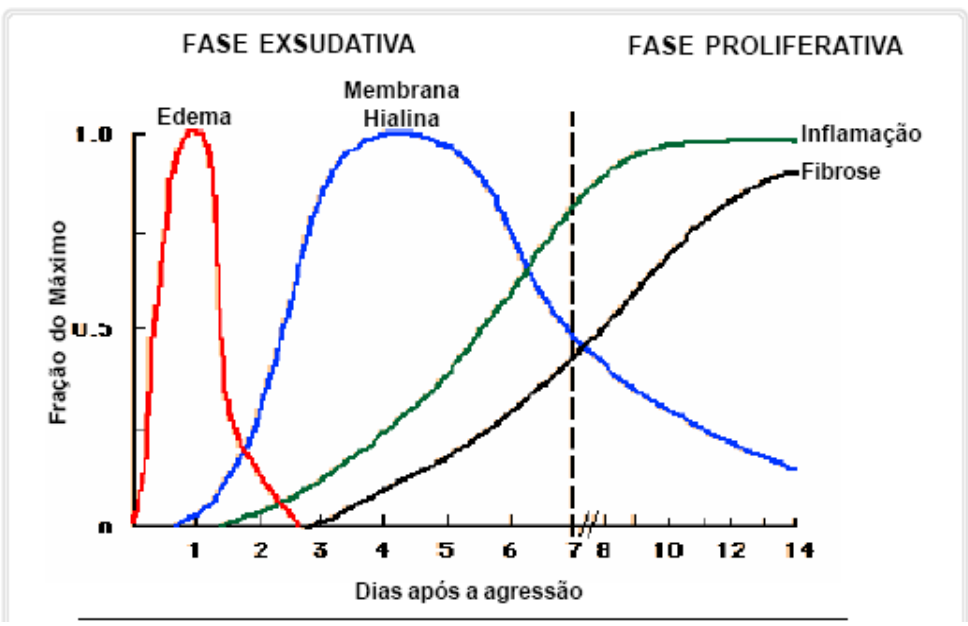

Fonte: Galhardo e Martinez, 2003

A SDRA atinge de 10 a $15 \%$ dos pacientes na UTI (Unidade de Terapia Intensiva) e cerca de $20 \%$ dos pacientes que estão em ventiladores mecânicos, nos EUA foram relatados cerca de 190.000 casos por ano (WARE; MATTHAY, 2000). A mortalidade em casos severos (maior hipoxemia) de SDRA é superior a 50\% (BRAUNE; KLUGE, 2013).

Foram evidenciadas mais de sessenta causas para a SDRA, estas caracterizadas como sendo de origem direta ou indireta. As de origem direta são ocasionadas por eventos pulmonares como a pneumonia e aspiração de conteúdo gástrico. Já as de origem indireta são consequentes de uma resposta inflamatória sistêmica como a sepse e o trauma grave com choque (GALHARDO; MARTINEZ, 2003). Ferguson et al. (2007) concluiu que as causas diretas de se contrair a SDRA são mais frequentes do que as causas de origem indireta contudo, o trauma é a causa mais severa.

O quadro clínico dos pacientes com SDRA consiste em insuficiência respiratória aguda de horas ou até dias após a lesão (BERNARD et al., 1994). Com isso, há o aparecimento de sinais físicos como dispnéia, cianose, taquipnéia, uso da musculatura acessória da respiração. Ainda, pode ser observado um infiltrado alveolar difuso e bilateral no exame radiológico. Contudo, não há um tratamento específico para a SDRA e busca-se aliviar os sintomas subjacentes (STEINBERG; HUDSON, 2000). É digno de nota que o prognóstico é de 35 a 40\% dos pacientes diagnosticados com SDRA chegam ao óbito (LUHR et al., 1999; MILBERG et al., 1995). 


\subsection{Sinais de Perigo}

A resposta inflamatória de defesa tem como função combater a infecção e o dano tecidual. Várias células como macrófagos, neutrófilos, células dendríticas, e leucócitos reconhecem as células afetadas a partir de receptores de padrão de reconhecimento (PRRs). Estes receptores detectam padrões moleculares associados a patógenos (PAMPs - Pathogenassociated molecular pattern molecules) como as lipoproteínas de bactérias, e também padrões moleculares associados ao dano celular (DAMPs - Damage-associated molecular patterns). Uma vez ativado, os PRRs induzem uma cascata de eventos celulares que promovem a síntese de diversos fatores que participam, por exemplo, do recrutamento celular para a área lesada (BIANCHI, 2007; NEWTON; DIXIT, 2012).

A I/R intestinal pode ativar o sistema complemento e ativar a síntese de DAMPs. A ligação dos DAMPs aos receptores presentes em células associadas à resposta imune inata leva a uma resposta inflamatória estéril, a qual em conjunto com a ativação do sistema complemento, aumenta o dano tecidual. Esta inflamação estéril também induz maturação de células apresentadoras de antígeno (por exemplo, macrófagos e células dendríticas) que uma vez ativadas, medeiam o recrutamento de linfócitos (THAUNAT, 2011).

No caso de pacientes com inflamação sistêmica, a resposta imune inata libera moléculas conhecidas como PAMPs, que são expressas por uma grande variedade de patógenos. Após o dano tecidual são liberadas as moléculas endógenas de origem celular, os DAMPs. Os PAMPs e DAMPs induzem uma resposta imune inata semelhante mesmo sem a presença de microorganismos (IWASAKI; MEDZHITOV, 2010).

No caso de uma inflamação estéril os DAMPs ganham destaque com a liberação de muitas moléculas endógenas, como o ATP, IL-1, ácido úrico, HMGB-1(proteínas de alta mobilidade do grupo 1) (BIANCHI, 2009). Alguns DAMPs, incluindo o HMGB1 e as proteínas S100, são rapidamente liberados na corrente sanguínea de pacientes após o trauma. Altas concentrações de HMGB1 são associadas à falência de órgãos após o trauma (COHEN et al., 2009; MOLLEN et al., 2006).

Logo após a necrose tecidual, o DNA mitocondrial é liberado na circulação assim como os peptídeos formilados, considerados como DAMPs, e atuam ativando neutrófilos iniciando a resposta imune inata. Este estímulo molecular além de ativar os neutrófilos através do receptor de membrana para peptídeos formilados também promove uma resposta inflamatória através da fosforilação e liberação de mediadores inflamatórios como a IL-8 e a MMP-8 
(metaloproteinase de matriz 8). O DNA mitocondrial também é capaz de ativar a p38 MAP kinase através da ligação com o receptor toll-like tipo 9 (TLR9) presente na superfície dos neutrófilos (PITTMAN; KUBES, 2013; ZHANG et al., 2010).

Em modelo animal, Zhang et al. (2010), observou que ao se administrar na via circulatória de ratos DAMPs mitocondriais eles desenvolveram lesão pulmonar aguda, a maior causa de falência respiratória em pacientes na UTI (WARE; MATTHAY, 2000). Mesmo a LPA causada pelos DAMPs não sendo grave, ela pode explicar como os DAMPs podem atuar como primeiro estímulo para a LPA e agravar a inflamação pulmonar após um segundo estímulo inflamatório, como transfusões sanguíneas ou infecções (LOONEY et al., 2009).

Os sinais de perigo são moléculas ou estruturas moleculares, liberadas ou produzidas por células sob estresse e que são detectadas por células do sistema imune podendo desencadear a resposta imune (GALLUCCI; MATZINGER, 2001). Dentre os sinais de perigo considerados clássicos estão o ligante de CD40 (proteína coestimulatória), TNF $\alpha$, IL-1 $\beta$, acidose extracelular (RAJAMÄKI et al., 2013; SALLUSTO et al., 1995). No que tange ao CD40, o aumento de sua expressão nas células dendríticas está associado à indução da resposta imune adaptativa, pois este pode controlar a comunicação das células $\mathrm{T}$ com as células B e com as células dendríticas (O’SULLIVAN; THOMAS, 2003). Por outro lado, em condições onde ocorre lesão tecidual, o aumento da expressão de CD40 em plaquetas, por exemplo, se relaciona com a sinalização para células dendríticas e o desencadeamento da resposta imune inata (LAPCHAK et al., 2012). Vale ressaltar que adicionalmente aos mediadores sintetizados, componentes intracelulares são igualmente potenciais sinais de perigo. Portanto os DAMPs também são considerados sinais de perigo.

$\mathrm{Na}$ vigência de hipóxia, isquemia e estresse mecânico celular, nucleotídeos como o ATP podem ser liberados. O ATP isoladamente ou em sinergismo com o TNF- $\alpha$ pode ser indutor de estimulação do sistema imune (SCHNURR et al., 2000). Como dito anteriormente, a isquemia reduz o suprimento sanguíneo e isto causa hipóxia no sítio inflamado. Nesta condição é possível que ocorra a liberação celular de ATP (LUTZ; THURMEL; HEEMANN, 2010). O ATP se acopla a receptores purinérgicos do tipo 2 (P2) (BURNSTOCK et al., 2012). Conforme o subtipo ( $\mathrm{X}$ ou $\mathrm{Y}$ ) de receptor de ATP ativado um distinto efeito pode ser observado. Nesse contexto o ATP quando interage a seu receptor $\mathrm{P}_{2} \mathrm{Y}_{6}$ pode causar resposta imunossupressora (GIANNATTASIO et al., 2011) e quando estimula o $\mathrm{P}_{2} \mathrm{X}_{7}$ determina eventos associados a um efeito pró-inflamatório (BOOTH; TAM; UNWIN, 2012). 
É interessante notar que o ATP presente no espaço extracelular se acopla ao receptor purinérgico tipo 2, subtipo $\mathrm{X}(\mathrm{P} 2 \mathrm{X})$. Este receptor possui distintas subunidades, dentre elas o $\mathrm{P} 2 \mathrm{X}_{7}$. O P2X $\mathrm{X}_{7}$ encontra-se bem distribuído no organismo podendo ser encontrado no endotélio vascular, vias aéreas, linfócitos, músculo liso, entre outros sítios (NORTH, 2002). Ainda, nas vias aéreas, foi encontrada a expressão de $\mathrm{P}_{2} \mathrm{X}_{7}$ nos mastócitos humanos (WAREHAM et al., 2009).

O sistema nervoso entérico é composto pelos plexos mioentérico e submucoso, que controlam a motilidade, o transporte de fluidos através da mucosa e o fluxo sanguíneo local (FURNESS, 2000; FURNESS, 2006). A família do receptor P2X esta presente em cerca de 80 a 90\% dos neurônios no plexo mioentérico (BARAJA-LÓPEZ et al., 1996). Este receptor é importante para a motilidade intestinal (BIAN; BERTRAND; BORNSTEIN, 2000; GALLIGAN et al., 2000; GALLIGAN 2002). Contudo, estudos mostraram que a I/R intestinal reduz o numero de neurônios entéricos (LINDESTROM; EKBLAD, 2004; PIAO et al., 1999). Estudos realizados em colaboração com a Prof. Patricia Castelucci do Departamento de Anatomia do ICB/USP revelaram redução da expressão de receptores $\mathrm{P} 2 \mathrm{X}_{2}$ e P2X $\mathrm{X}_{7}$ em neurônios entéricos de ratos submetidos a I/R intestinal. Este estudo mostrou que os efeitos da I/R intestinal nos neurônios entéricos são dependentes do subtipo de receptor, e que há redução na expressão dos receptores $\mathrm{P}_{2} \mathrm{X}_{2}$ e alterações na densidade e tamanho dos neurônios entéricos observados no plexo mioentérico e submucoso (PAULINO et al., 2011).

Embora potencialmente agressivas, as repercussões locais e sistêmicas da I/R intestinal devem estar sob alguma forma de controle endógeno, o que concorre para minimizar suas eventuais complicações. Nesse sentido é razoável postular que o organismo lance mão de mecanismos que se contraponham aos efeitos dos sinais de perigo. Desta maneira, admite-se a existência de indução de mecanismos que informem ao organismo a necessidade de antagonizar o risco de uma estimulação acentuada do sistema imune originada pelos sinais de perigo. Tais mecanismos devem gerar condições para o estabelecimento de uma atividade anti-inflamatória. Nesse sentido, estudos realizados por Serhan et al. (2008) acerca das ações anti-inflamatórias das lipoxinas e seus similares têm recebido destaque como controladores endógenos da resposta inflamatória. As lipoxinas compõem um grupo de mediadores derivados da família dos eicosanoides que podem exercer efeito modulador do curso da resposta inflamatória. Estudos recentes mostram que animais tratados com um agonista do receptor A-4 para lipoxina (BML-111) reduziram a lesão pulmonar aguda causada pelo modelo de trauma seguido por choque hemorrágico (GONG et al., 2012; LI et al., 2013). 


\subsection{Hormônios sexuais femininos}

Embora existam evidências de que a modulação da resposta imune (inata e adaptativa) difira entre homens e mulheres, o dimorfismo sexual não recebe atenção merecida como fator para o entendimento das diferentes respostas imunes observadas entre homens e mulheres (FISH, 2008). O perfil dominante da resposta imune (Th1 ou Th2) depende da variação hormonal durante o ciclo sexual feminino estudos que visem a esclarecer qual o efeito ou ações dos hormônios sexuais femininos nesses perfis são de interesse.

De acordo com Fish (2008) o perfil Th1 da resposta tende a ser dominante durante a menstruação e na fase lútea do ciclo sexual. Por outro lado, na fase folicular, o padrão Th2 se sobrepõe ao Th1. Com esta percepção sugere-se que os hormônios sexuais femininos, ao exercerem atividade moduladora do sistema imune, podem igualmente interferir com o curso da resposta inflamatória. De fato, estudos clínicos revelam que mulheres apresentam menor incidência de pneumonia, sepse e falência de múltiplos órgãos em relação a homens (DEITCH et al., 2007; GROSSMANN, 1985; MEES et al., 2008; OLSEN; KOVACS, 1996; SCHRODER et al., 2000, SPERRY et al., 2008) Distúrbios cardiovasculares são também mais graves em mulheres na pós-menopausa (STANGL et al., 2002). A incidência de asma em mulheres é maior do que em homens (DEMARCO et al., 2000).

São vários os dados de literatura relatando a participação dos hormônios sexuais femininos na mediação das repercussões causadas pelo trauma seguido de choque hemorrágico (ANGELE et al., 2000; ANGELE; FRANTZ; CHAUDRY, 2006; CHAUDRY et al., 2003; FRINK et al., 2007; HILDEBRAND et al., 2006; KNÖFERL et al., 2001; KNÖFERL et al., 2002; MELDRUM, 2006; MOEINPOUR et al., 2007).

Evidências clínicas mostram que mulheres sob trauma intestinal geram menores concentrações séricas de citocinas inflamatórias, e que isso reduz o índice de falência múltipla de órgãos (FRINK et al., 2007). É interessante notar que em modelo experimental de choque hemorrágico, roedores machos, sob tratamento com estradiol desenvolvem lesões menos intensas (DEITCH et al., 2001). Nesse contexto, fêmeas também preservam melhor os parâmetros hemodinâmicos após o choque hemorrágico (DEITCH et al., 2008a; DEITCH et al., 2008b). De acordo com esses autores é possível que o estradiol exerça efeitos protetores por meio da preservação da circulação sanguínea intestinal.

Durante a I/R intestinal, ocorre redução da taxa de geração de NO e aumento de permeabilidade microvascular no intestino. Em roedores machos, a magnitude do recrutamento celular para o pulmão e das lesões vasculares intestinais depende de alterações 
(aumento/redução) na atividade das NOS (constitutiva ou induzida) (WARD et al., 2000). Vale lembrar que existem estudos indicando que o estradiol exerce papel protetor da função endotelial (MA et al., 2001) e que no intestino este esteroide medeia o aumento da expressão de NOS induzida em modelo de I/R intestinal (XIAO et al., 2004). Neste contexto, é razoável supor que os hormônios sexuais femininos possam modular a geração de mediadores envolvidos com a homeostasia intestinal. Na medida em que a $I / R$ intestinal induz recrutamento de células inflamatórias, então os hormônios sexuais femininos podem interferir com a expressão de moléculas de adesão.

Estudos conduzidos por Cavriani et al. (2005) revelaram que a obstrução do fluxo linfático atenua a inflamação pulmonar causada pela $\mathrm{I} / \mathrm{R}$ intestinal em ratos. Assim, em fêmeas os efeitos nocivos da hipoperfusão intestinal no pulmão, podem ser menos expressivos por causa de uma maior proteção do leito intestinal em gerar mediadores inflamatórios que uma vez transportados pela linfa até os pulmões puderam induzir inflamação pulmonar aguda (ADAMS et al., 2000). Assim, o controle hormonal no compartimento intestinal pode ser relevante para o desencadeamento das lesões em órgãos distantes do local de origem do trauma intestinal (ANANTHAKRISHNAN et al., 2005).

Os efeitos dos hormônios sexuais resultam primariamente da sua interação com receptores localizados em diversos tecidos e células. Basicamente os receptores para estradiol são classificados em $\alpha$ e $\beta$. Tais receptores podem ser encontrados na superfície da membrana celular ou no núcleo. Ao se acoplar com seu receptor ocorre ativação seguida por uma dimerização do receptor, que aumenta sua afinidade com o DNA. Ao se ligar ao DNA, o complexo receptor+DNA recruta uma cascata de coativadores e proteínas para a região promotora dos genes-alvo. Esse tipo de interação do hormônio com o DNA é chamado de via genômica (GOODMAN; GILMAN, 2010). Alguns dos efeitos do estradiol ocorrem após minutos de sua administração. Por isso estes efeitos não podem ocorrer através da transcrição e síntese de proteínas (MEYER; HAAS; BARTON, 2006). Estas ações ocorrem por vias enzimáticas e canais de íons em receptores presentes na membrana celular, esta via é conhecida como não-genômica (BOONVARRATANAKORNKIT; EDWARDS, 2007). Porém, vale ressaltar que os efeitos não-genômicos e genômicos não devem ser separados, uma vez que as ações intra-celulares ativam fatores de transcrição nucleares (BJORNSTROM; SJOBERG, 2005). Além disso, existem evidências da influência do estradiol na expressão de fatores de transcrição envolvidos no processo inflamatório, como o NF-kB e o AP-1 (proteína ativadora 1) após o choque hemorrágico experimental (SHIMIZU et al., 2007). 
Os receptores de progesterona são classificados em A e B, que variam sua quantidade e tipo conforme o tecido que se encontra. Estes receptores usam dois promotores distintos dependentes de estrogênio, permanecem no núcleo como um monômero inativo. Ao se ligar a progesterona formam homo e heterodímeros que se ligam com alta afinidade aos elementos responsivos nos genes-alvo. O subtipo B medeia as ações estimuladoras da progesterona, já o subtipo A inibe a ação de B (GOODMAN; GILMAN, 2010).

Embora ainda não totalmente elucidada a distribuição dos receptores de estradiol no intestino e no pulmão é heterogênea. Neste contexto, existem relatos de que em modelo de trauma seguido de choque hemorrágico os receptores do subtipo $\alpha$ e $\beta$ medeiam os efeitos protetores do estradiol no intestino enquanto no pulmão somente os receptores do subtipo $\beta$ modulam suas ações protetoras (YU; CHAUDRY, 2009).

Tomados em conjunto os dados apresentados indicam que os hormônios sexuais femininos podem interferir com o curso da resposta inflamatória além de exercer importante efeito na homeostasia. Todavia, ainda não existem dados conclusivos acerca do papel desses hormônios sobre a inflamação pulmonar causada pelo evento isquêmico intestinal ou se os hormônios sexuais afetam a capacidade do pulmão de gerar mediadores inflamatórios. Como os mediadores gerados no intestino, durante a isquemia, na reperfusão tem acesso ao pulmão e podem atuar, por exemplo, na interação leucócito-endotélio, na modulação da atividade das células do sistema imune na alteração da matriz extracelular, na geração adicional de mediadores inflamatórios, então mecanismos endógenos que regulem a produção desses fatores podem contribuir para a manutenção da homeostasia pulmonar.

Considerando que nossos estudos convergem para a percepção do pulmão como sensível e propulsor da inflamação sistêmica, então a compreensão dos sensores e sinalizadores endógenos da inflamação após a I/R intestinal, num contexto controlado pelos hormônios sexuais femininos pode ser de interesse. 


\section{HIPÓTESE}

Os hormônios sexuais femininos medeiam a magnitude da inflamação pulmonar aguda por meio do controle da indução de mediadores inflamatórios gerados no pulmão em decorrência do estimulo da I/R intestinal. 


\section{OBJETIVOS}

$\rightarrow$ Avaliar o papel dos hormônios sexuais femininos na inflamação pulmonar causada pela $\mathrm{I} / \mathrm{R}$ intestinal

$\rightarrow$ Investigar se os hormônios sexuais femininos exercem algum papel indução da geração de sinais de perigo (ATP, ácido úrico e fosfatase alcalina), mediadores inflamatórios $(\mathrm{TNF}-\alpha)$ e recrutamento celular.

$\rightarrow$ Investigar se os hormônios sexuais femininos exercem algum papel na geração de mediadores inflamatórios (IL-1 $\beta$, IL-10, IL-6, INF- $\gamma$ e VEGF) e expressão de moléculas de adesão (ICAM-1, PECAM-1 e VCAM) no compartimento pulmonar após a I/R intestinal.

$\rightarrow$ Analisar a interação dos hormônios sexuais femininos com a expressão dos receptores $\mathrm{P} 2 \mathrm{X}_{7}$ no tecido pulmonar após a indução da I/R intestinal. 


\section{MATERIAIS E MÉTODOS}

\subsection{Preparação dos animais}

Animais: Foram utilizadas ratas Wistar adultas com peso entre 160 e $180 \mathrm{~g}$, provenientes do Biotério Central do Instituto de Ciências Biomédicas da Universidade de São Paulo. Os estudos que foram realizados nesta proposta estão de acordo com os preceitos éticos de uso de animais em experimentação científica estabelecidos pela Comissão de Ética em Experimentação Animal do ICB/USP.

Ovariectomia $(\boldsymbol{O} \boldsymbol{V} \boldsymbol{x})$ : As ratas foram anestesiadas com isoflurano (5\% de isoflurano em $50 \%$ de oxigênio), a seguir os ovários foram removidos de acordo com o método utilizado por De Oliveira et al. (2007). Antes da cirurgia foi administrado tramadol (5 mg/kg, i.p.) para a analgesia e pentabiótico (540 mg/kg, i.m.). Após a cirurgia o tratamento com analgésico foi mantido por 3 dias com paracetamol na água de beber $(0,53 \mathrm{mg} / \mathrm{ml}$, v.o. $)$.

Validação da ovariectomia: Decorridos 7 dias da cirurgia, a eficácia da ovariectomia foi avaliada pela detecção de redução no peso do útero e pela análise do padrão morfológico das células presentes no lavado vaginal (LV). Para tanto, com o auxílio de um conta-gotas, solução salina tamponada com fosfato (PBS) foi introduzida na vagina e o LV retirado. Amostras do LV foram colocadas sobre lâmina de vidro e a seguir diluídas em $5 \mu 1$ de corante azul de metileno (5\%) para serem observadas por microscopia óptica. Somente fêmeas ovariectomizadas em diestro e com redução da massa uterina foram incluídas no estudo.

Determinação dos níveis séricos hormonais: Após os procedimentos cirúrgicos $(\mathrm{OVx})$ e a indução da I/R intestinal, as dosagens hormonais (estrógeno e progesterona) foram realizadas em soro, utilizando kits de radioimunoensaio seguindo as instruções do fabricante.

Indução da I/R intestinal: Decorridos 7 dias da $\mathrm{OVx}$, os animais foram anestesiados com pentobarbital sódico $(50 \mathrm{mg} / \mathrm{kg})$ e antes da cirurgia foi administrado tramadol $(5 \mathrm{mg} / \mathrm{kg}$, i.p. $)$ para a analgesia. A I/R intestinal foi induzida pelo pinçamento da artéria mesentérica superior por 45 min de acordo com Cavriani et al. (2004). O período de 7 dias após a remoção dos ovários para utilização dos animais baseia-se em estudos do laboratório nos quais demonstramos que nesse período ocorre a redução da massa uterina e a manutenção dos 
animais em diestro (DE-OLIVEIRA et al., 2007; LIGEIRO-DE-OLIVEIRA et al., 2004). Para tanto, após laparotomia longitudinal mediana e evicerização, a artéria foi localizada e a isquemia intestinal realizada. Os pinçamentos foram realizados com clamps cirúrgicos metálicos. Durante o período de manutenção da isquemia, o abdômen dos animais foi mantido coberto com plástico transparente $(15 \mathrm{~cm}$ x $10 \mathrm{~cm})$ para minimizar perdas de líquido e calor causadas pela incisão abdominal. Decorrido o tempo de isquemia, o clamp vascular foi retirado e a incisão mediana fechada com sutura contínua, em dois planos, com fio de algodão polifilamentar de $0,5 \mathrm{~mm}$ de espessura. Após $2 \mathrm{~h}$ de reperfusão intestinal os animais foram submetidos à eutanásia, sob anestesia profunda, por dessangramento pela aorta abdominal.

\subsection{Determinação do número leucócitos circulantes e da medula óssea}

Alíquotas de sangue $(20 \mu \mathrm{l})$ da veia caudal foram coletadas em pipeta automática e adicionadas a $380 \mu \mathrm{l}$ de líquido de Türk (3\%), agitadas por 20 segundos (Phoenix ${ }^{\circledR}$, modelo AP20) e processadas para a contagem total em câmara de Neubauer em microscópio óptico comum. A contagem diferencial de leucócitos foi realizada em extensões sanguíneas coradas pelo método Giemsa/May-Grünwald, diferenciando-se os tipos celulares (neutrófilos, mononucleares e eosinófilos).

Para obtenção das células da medula óssea, após a eutanásia o fêmur esquerdo dos animais foi cirurgicamente removido. Ambas as extremidades foram abertas e o canal medular foi perfundido com $10 \mathrm{ml}$ de PBS a partir da extremidade distal. Para tanto $10 \mathrm{ml}$ de PBS foi injetado no canal medula com o auxilio de uma agulha (26G x 1/2") acoplada a uma seringa plástica. A suspensão medular foi homogeneizada como o auxílio de uma pipeta automática e a seguir o as células foram quantificadas em câmara de Neubauer utilizando microscopia óptica. Para tanto, $90 \mu 1$ da amostra do lavado medular foram acrescidos de $10 \mu 1$ de cristal violeta $(0,2 \%)$. A seguir a amostra foi diluída 10 vezes em PBS.

\subsection{Cultura de tecido pulmonar (explante)}

Os animais foram sacrificados e a circulação pulmonar perfundida a partir da artéria pulmonar com PBS. Os pulmões foram retirados e fragmentos de tamanho homogêneo (1x1 $\mathrm{mm}$ ) foram cultivados em placa de 24 poços, 4 fragmentos por poço, em $1 \mathrm{ml}$ de meio DMEM (Dulbecco's Modified Eagle's Medium), permanecendo incubados a $37{ }^{\circ} \mathrm{C}$ em atmosfera contendo $5 \%$ de $\mathrm{CO}_{2}$ por períodos de $24 \mathrm{~h}$ ou $48 \mathrm{~h}$. 


\subsection{Caracterização dos efeitos pulmonares da I/R intestinal e marcadores da lesão isquêmica}

Determinação do extravasamento plasmático pulmonar e intestinal e da atividade de mieloperoxidase (MPO): A avaliação da permeabilidade vascular foi feita por meio da técnica de determinação da concentração do corante azul de Evans (AE) extravasado no parênquima pulmonar e no intestino de acordo com Cavriani et al. (2004). O corante foi injetado por via intravenosa 20 min antes do tempo da reperfusão ser completado. A eutanásia dos animais foi por dessangramento da aorta abdominal e o leito vascular perfundido com PBS pela artéria pulmonar, para remoção do sangue intravascular. Fragmentos dos tecidos foram removidos, limpos e pesados. Um fragmento de cada tecido foi colocado em formamida ( $4 \mathrm{ml} / \mathrm{g}$ de peso tecidual, a $20{ }^{\circ} \mathrm{C}$ por $24 \mathrm{~h}$ ), enquanto a outra porção foi mantida em estufa de secagem por $24 \mathrm{~h}$. A densidade óptica (DO) foi obtida em leitor de ELISA (BioTek Instruments ${ }^{\circledR}$ ) em comprimento de onda $620 \mathrm{~nm}$. A concentração de AE das amostras foi determinada gotejando os valores de DO em curva padrão de azul de Evans. Os valores foram expressos em $\mu \mathrm{g}$ de $\mathrm{AE} / \mathrm{g}$ de peso seco dos fragmentos de pulmão e intestino.

Para a determinação da atividade de MPO, tecidos (intestinal e pulmonar) foram retirados e pesados e a eles adicionado $1 \mathrm{ml}$ de tampão fosfato $\mathrm{pH} 6$ contendo brometo de hexadeciltrimetilamônio $(0,5 \%)$ na presença de $5 \mathrm{mM}$ EDTA (ácido etilenodiamino tetraacético). A seguir as amostras foram homogeneizadas em homogeneizador tecidual (Medic Tools $^{\circledR}$ ) durante $20 \mathrm{~s}$. As amostras foram centrifugadas a $12.500 \mathrm{rpm}$ durante $10 \mathrm{~min}$ à temperatura de $4{ }^{\circ} \mathrm{C}$. O sobrenadante obtido foi utilizado para determinar a atividade de MPO. O ensaio de MPO foi conduzido em placas de 96 poços (10 $\mu \mathrm{l}$ da amostra). Às amostras foram adicionados $200 \mu \mathrm{l}$ de substrato, contendo tampão fosfato $\mathrm{pH}$ 6, peróxido de hidrogênio $(0,1 \%)$ e orto-dianisidina (1,2 5\%). Decorridos 5 min, a reação foi paralisada pela adição de $50 \mu \mathrm{l}$ de azida sódica (1 \%). A leitura da absorbância foi feita em leitor de ELISA (Bio-Tek Instruments ${ }^{\circledR}$ ) em comprimento de onda de $450 \mathrm{~nm}$ e os valores expressos em atividade de MPO por mg de tecido.

Quantificação do número de células inflamatórias em amostras de pulmão: Após o período de reperfusão intestinal desejado, os animais foram profundamente anestesiados como descrito anteriormente. O tórax dos animais foi aberto e $10 \mathrm{ml}$ de PBS foram injetados por via intracardíaca para remoção do sangue intravascular pulmonar. A seguir amostras de 
fragmentos dos pulmões foram coletadas e incubadas com $3 \mathrm{ml}$ de uma solução $1 \mathrm{mg} / \mathrm{ml}$ de colagenase 1A (Sigma) em placa de Petri (35 mm de diâmetro) por 45 min à $37{ }^{\circ} \mathrm{C}$. A atividade digestiva da colagenase foi bloqueada pela adição à placa de Petri de $1 \mathrm{ml}$ de PBS contendo $20 \%$ de soro fetal bovino (SFB). Em seguida o conteúdo de cada placa foi homogeneizado, filtrado e centrifugado a $250 \mathrm{~g}$ em $10 \mathrm{ml}$ de PBS $10 \%$ SFB. O precipitado foi ressuspendido em $1 \mathrm{ml}$ de PBS para determinação da concentração celular em câmara de Neubauer. Para tanto, alíquotas da amostra $(90 \mu \mathrm{l})$ foram acrescidas de $10 \mu \mathrm{l}$ de cristal violeta 0,2 \% dissolvido em ácido acético (30\%). Para a contagem diferencial das células, alíquotas da amostra $(100 \mu \mathrm{l})$ foram centrifugadas a $1.000 \mathrm{rpm}$ por $5 \mathrm{~min}$ (citocentrífuga Citospin ${ }^{\circledR}$ Fanem). As lâminas obtidas foram coradas utilizando-se o "kit" de corantes Instant Prov $\left(\right.$ Neuprov $\left.^{\circledR}\right)$ (solução de ciclohexadienos a $0,1 \%$, solução de azobenzenosulfônicos a $0,1 \%$ e solução de fenotiazinas a $0,1 \%$ ). A contagem diferencial foi realizada em microscopia óptica comum a partir da análise de campos aleatórios com mesma área (4915200 pixels, ou 2,46

$\mathrm{mm}^{2}$ ), quantificando-se a porcentagem de cada população celular (mononucleares, neutrófilos e eosinófilos).

Dosagem de nitritos em amostras de explante pulmonar - Reação de Griess: O nitrato presente nas amostras foi reduzido a nitrito, utilizando-se a enzima nitrato redutase e NADPH. Para a reação, incubou-se $50 \mu \mathrm{l}$ da amostra ou padrão (ou de diluente para o branco), com 25 $\mu \mathrm{l}$ da solução de nitrato redutase (10 unidades dissolvidas em 16,4 ml de Tris 40mM, pH 7,4) e $25 \mu \mathrm{l}$ de solução de NADPH (6,7 mg em $50 \mathrm{ml}$ de Tris) à temperatura ambiente por $2 \mathrm{~h}$. A dosagem de nitritos foi feita pelo método de ensaio colorimétrico baseado na reação de Griess. Para a reação de Griess foram adicionados $100 \mu \mathrm{l}$ da solução de trabalho (50 \% da sol. A: $1 \%$ de sulfanilamida em ácido fosfórico a $5 \% ; 50 \%$ da sol. B: $0,1 \%$ de naftiletilenodiamina em água destilada). Após 10 min de incubação, foi feita a leitura em comprimento de onda de $595 \mathrm{~nm}$. A concentração de nitritos das amostras foi determinada gotejando os valores de DO em curva padrão. Os valores foram expressos em $\mu \mathrm{M} / \mathrm{mg}$ de peso seco dos fragmentos de pulmão cultivados no explante.

Determinação da atividade sérica de desidrogenase lática (LDH): A lactato desidrogenase é enzima expressa em praticamente todos os órgãos e tecidos. $\mathrm{Na}$ ocorrência de lesão isquêmica, ocorre perda da integridade celular e liberação da enzima. Isto resulta na redução da atividade da LDH no tecido lesado e aumento da atividade no sangue. A medida da LDH 
por este método não visa avaliar a condição metabólica do tecido, mas somente o grau da lesão sofrida. A reação é: NADH + piruvato _ NAD + lactato. Como o pico de absorbância do NADH é $340 \mathrm{~nm}$, o ensaio reflete o consumo de NADH.

Alíquotas de $10 \mu \mathrm{l}$ de soro foram adicionadas a poços de uma placa 96-well. A determinação foi realizada pela utilização do kit comercial Desidrogenase Lática LDH UV Bioclin $^{\circledR}$ (Quibasa Química Básica Ltda), seguindo instruções do fabricante.

Determinação da atividade sérica de fosfatase alcalina no soro: Alíquotas de $10 \mu \mathrm{l}$ de soro foram adicionadas a poços de uma placa 96-well. A determinação foi realizada pela utilização do kit comercial fosfatase alcalina Bioclin ${ }^{\circledR}$ (Quibasa Química Básica Ltda), seguindo instruções do fabricante.

\subsection{Análise dos mediadores inflamatórios gerados pela I/R intestinal}

Determinação dos níveis de citocinas em sobrenadante de explante pulmonar (IL-1ß, IL-10, IL-6, INF-y e VEGF): Amostras de sobrenadante dos explantes foram utilizadas para determinação dos níveis das citocinas por meio de "kits" comerciais (Duo Set, R \& D System $^{\circledR}$ ). Os ensaios foram conduzidos seguindo as especificações do fabricante e a densidade óptica obtida em leitor de ELISA em $450 \mathrm{~nm}$.

Determinação dos níveis do Fator de Necrose Tecidual (TNF- $\alpha)$ no soro: Alíquotas de 100 $\mu \mathrm{l}$ de soro foram adicionadas a poços de uma placa 96-well. A determinação foi realizada pela utilização do kit comercial RayBio ${ }^{\circledR}$ Elisa kit (RayBiotech Inc., EUA), seguindo instruções do fabricante.

\subsection{Quantificação da geração de sinais de perigo}

ATP: Amostras de soro foram processadas para a quantificação de AMPc utilizando metodologia enzimática. Para a medição foi utilizado um kit comercial seguindo as recomendações do fabricante (Enzo Life Science Inc. ${ }^{\circledR}$ ). 
Ácido Úrico: Alíquotas de $10 \mu \mathrm{l}$ de soro foram adicionadas a poços de uma placa 96-well. A determinação foi realizada pela utilização do kit comercial fosfatase alcalina Bioclin ${ }^{\circledR}$ (Quibasa Química Básica Ltda), seguindo instruções do fabricante.

\subsection{Estudo da expressão das moléculas de adesão (ICAM-1, PECAM-1 e VCAM) no tecido pulmonar}

Após a I/R intestinal e eutanásia a cavidade torácica dos animais foi aberta e o leito vascular perfundido com $20 \mathrm{ml}$ de PBS. A seguir, os pulmões preenchidos, via traquéia, com $10 \mathrm{ml}$ de TFM (Tissue Freezing Medium, Leica Instruments), diluído 1:3 em água destilada. A traquéia foi ocluída e o conjunto traquéia-pulmão removido. O lóbulo pulmonar esquerdo foi retirado, mergulhado em hexano acondicionado em gelo seco e processado para obtenção de cortes $(8 \mu \mathrm{m})$ em criostato. Os cortes foram colocados em lâminas silanizadas e subsequentemente fixados em acetona por $10 \mathrm{~min}$.

As lâminas foram lavadas com TBS-T, durante 10 min por 2 vezes. Posteriormente, foram permeabilizadas com Triton-X diluído em TBS-T (2x de 5 min), lavadas com TBS-T por 2 vezes de $5 \mathrm{~min}$. A seguir, foi realizado o bloqueio de sítios antigênicos inespecíficos utilizando Superblock ${ }^{\circledR}$ (Thermo Scientific). Foram colocados os anticorpos primários antiPECAM-1, anti-ICAM-1 e anti-VCAM diluídos em TBS-T/BSA (1:100) overnight em câmara úmida a $4{ }^{\circ} \mathrm{C}$. No dia seguinte, após três lavagens com TBS-T, as lâminas foram imersas durante 30 min em solução de peróxido de hidrogênio (1,6\%) à temperatura ambiente para o bloqueio da atividade da peroxidase endógena. Após 3 lavagens com TBST os cortes foram incubados por $2 \mathrm{~h}$ com os anticorpos secundários (1:250) conjugados à peroxidase (HRP) no escuro e em temperatura ambiente. Após esta incubação, as lâminas foram lavadas três vezes e o substrato AEC (Vector ${ }^{\circledR}$ ) foi adicionado e mantido por 10 minutos em contato com os cortes. Os cortes foram lavados em água corrente e contra-corados com hematoxilina de Mayer. As lâminas foram montadas com meio de montagem aquoso.

Os cortes foram avaliados em microscópio óptico acoplado à câmera digital e computador. As imagens obtidas foram analisadas por meio do software NIS Elements $\left(\right.$ Nikon $\left.^{\circledR}\right)$ que identificou o número de objetos marcados por área de cada vaso analisado. 


\subsection{Estudo do receptor $P 2 X_{7}$ no tecido pulmonar}

Após a I/R intestinal e eutanásia a cavidade torácica dos animais foi aberta e o leito vascular perfundido com $20 \mathrm{ml}$ de PBS. A seguir, os pulmões preenchidos, pela traquéia, com $10 \mathrm{ml}$ de TFM (Tissue Freezing Medium, Leica Instruments), diluído 1:3 em água destilada. A traquéia foi ocluída e o conjunto traquéia-pulmão removido. O lóbulo pulmonar esquerdo foi retirado, mergulhado em hexano acondicionado em gelo seco e processado para obtenção de cortes $(8 \mu \mathrm{m})$ em creostato. Os cortes foram colocados em lâminas silanizadas e subsequentemente fixados em acetona por $10 \mathrm{~min}$.

Antes das preparações serem incubadas em anticorpos primários, elas foram imersas em $10 \%$ de solução de soro normal de cavalo em 1,5\% de Triton-X (Sigma) em PBS, por 45 minutos, em temperatura ambiente. Após, foram incubadas com o anticorpo primário de coelho anti-P2X 7 (1:200, Chemicon, EUA) e permaneceram por 24 horas, à $4{ }^{\circ} \mathrm{C}$. Passado o tempo de incubação, os cortes de pulmão foram lavados em PBS por 3 vezes de 10 minutos cada. Após as lavagens as lâminas foram incubadas com o anticorpo secundário de macaco anti-Igs de coelho associado ao alexa flúor 488 (1:500, Molecular Probes, EUA) por 1hr. Ao final, as lâminas foram lavadas 3 vezes de 10 minutos cada, em PBS e montados com glicerol tamponado com 0,5 M tampão carbonato de cálcio (pH 8,6)

As imagens foram capturadas através do microscópio de fluorescência Nikon 80i, equipado com filtros para discriminar entre as fluorescências 488 (verde) e 594 (vermelho). As imagens foram analisadas com software NIS elements (Nikkon ${ }^{\circledR}$, Japão).

Para os ensaios da verificação e bloqueio da autofluorescência, foi incluída uma incubação com solução 0,5 \% de azul de pontamina (Chicago sky blue, Sigma, EUA) por 10 min seguida por 3 lavagens com PBS, imediatamente antes da incubação com o anticorpo secundário.

\subsection{Tratamentos farmacológicos}

Ratas OVx foram tratadas com $280 \mu \mathrm{g}$ de 17-ßestradiol (s.c.) ou progesterona (200 $\mu \mathrm{g}$ ) diluídos em óleo de milho, previamente $(24$ h) a indução da isquemia intestinal. 


\subsection{Análise estatística}

Os dados das amostras foram submetidos à ANOVA seguido do teste de Newman-Keuls. Para análises pareadas foi utilizado o teste " $\mathrm{t}$ " de Student. As análises estatísticas foram conduzidas utilizando GraphPad Prism 5.0. Os resultados foram expressos como média \pm EPM. Valores de $P<0,05$ serão considerados significativos. 


\section{RESULTADOS}

\subsection{Determinação dos níveis séricos hormonais}

A figura 2 representa a concentração sérica de estradiol e progesterona. No painel A encontram-se os níveis séricos de estradiol que decaem 7 dias após a remoção dos ovários e apresentam-se significativamente aumentados nos animais tratados com estradiol $(280 \mu \mathrm{g} / \mathrm{kg}$, s.c.) $24 \mathrm{~h}$ antes da indução da isquemia.

No painel B encontram-se os níveis séricos de progesterona, que também decaem 7 dias após a remoção dos ovários mas não foram reestabelecidos pelo tratamento com progesterona $(200 \mu \mathrm{g} / \mathrm{kg}$, s.c.) $24 \mathrm{~h}$ antes da indução da isquemia. 
Figura 2 - Valores de estradiol (painel superior) e progesterona (painel inferior) no soro de ratas com os ovários intactos ou 7 dias após a ovariectomia (OVx) e após tratamento dos animais com estradiol $(280 \mu \mathrm{g} / \mathrm{kg})$ ou progesterona $(200 \mu \mathrm{g} / \mathrm{kg})$. O sangue foi coletado pela artéria aorta após a eutanásia dos animais e processado para obtenção do soro. Os valores foram obtidos por radioimunoensaio e representam a média \pm EPM entre 7 a 10 amostras. ${ }^{*} P<0,05$ em relação ao respectivo grupo controle.

\section{A}

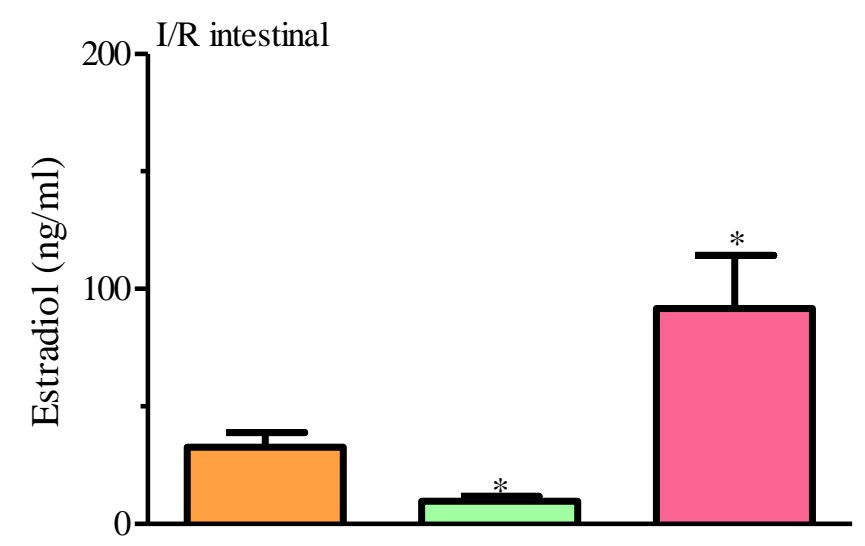

OVx

Estradiol

Progesterona

\section{B}

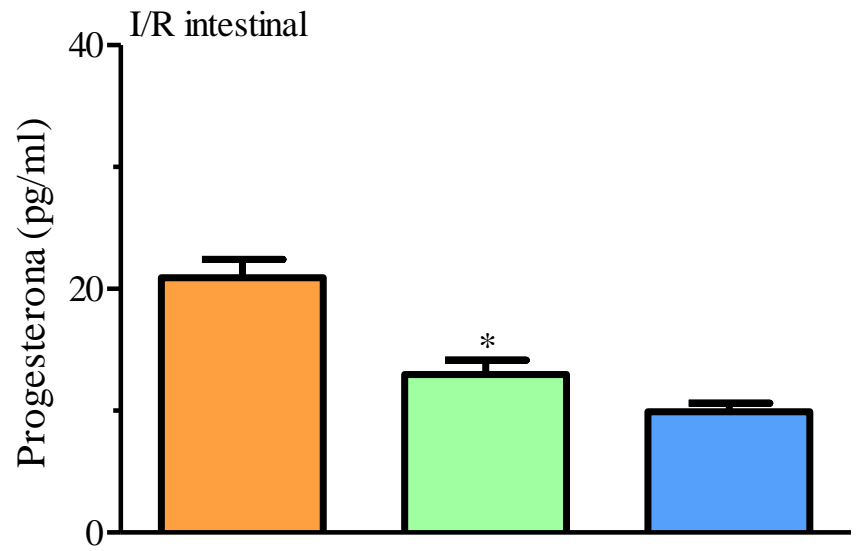

OVx

Estradiol

Progesterona

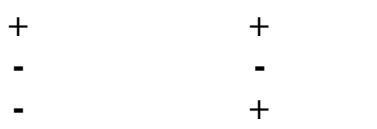




\subsection{Caracterização dos efeitos pulmonares e da remoção dos ovários na I/R intestinal}

\subsubsection{Extravasamento do corante Azul de Evans (AE)}

A permeabilidade vascular pulmonar foi avaliada por meio da técnica do extravasamento do corante azul de Evans. Os dados estão representados na figura 3. O painel A mostra significativo aumento do extravasamento do corante azul de Evans no pulmão dos animais $\mathrm{OVx}$ submetidos à $\mathrm{I} / \mathrm{R}$ intestinal quando comparado com o quantificado nos animais não OVx. O grupo não-OVx, ao ser submetido à $\mathrm{I} / \mathrm{R}$ intestinal desenvolveu aumento de permeabilidade vascular pulmonar em relação ao grupo de animais não manipulados (basal).

No painel B da figura 3, nota-se que tanto o tratamento dos animais com estradiol (280 $\mu \mathrm{g} / \mathrm{kg}$, s.c.) como com progesterona (200 $\mu \mathrm{g} / \mathrm{kg}$, s.c.) $24 \mathrm{~h}$ antes da indução da I/R intestinal, protegeu os animais submetidos à remoção dos ovários do aumento de extravasamento do corante causado pela I/R intestinal. 
Figura 3 - Efeito da OVx sobre o extravasamento do corante azul de Evans pulmonar. As ratas OVx ou não foram submetidas ou não (Sham) à isquemia (45 min) e reperfusão intestinal ( 2 horas - I/R intestinal). Valores basais foram obtidos de ratas não manipuladas. $\mathrm{O}$ corante $\mathrm{AE}(20 \mathrm{mg} / \mathrm{kg})$ foi injetado $20 \mathrm{~min}$ antes do término da reperfusão. Os dados representam a média \pm EPM de 5 animais. No gráfico $\mathrm{A},{ }^{*} P<$ 0,05 em relação ao grupo basal; ${ }^{\phi} P<0,05$ em relação ao grupo I/R não-OVx. No gráfico $\mathrm{B},{ }^{*} P<0,05$ em relação ao grupo sham; ${ }^{\phi} P<0,05$ em relação ao grupo I/R OVx.
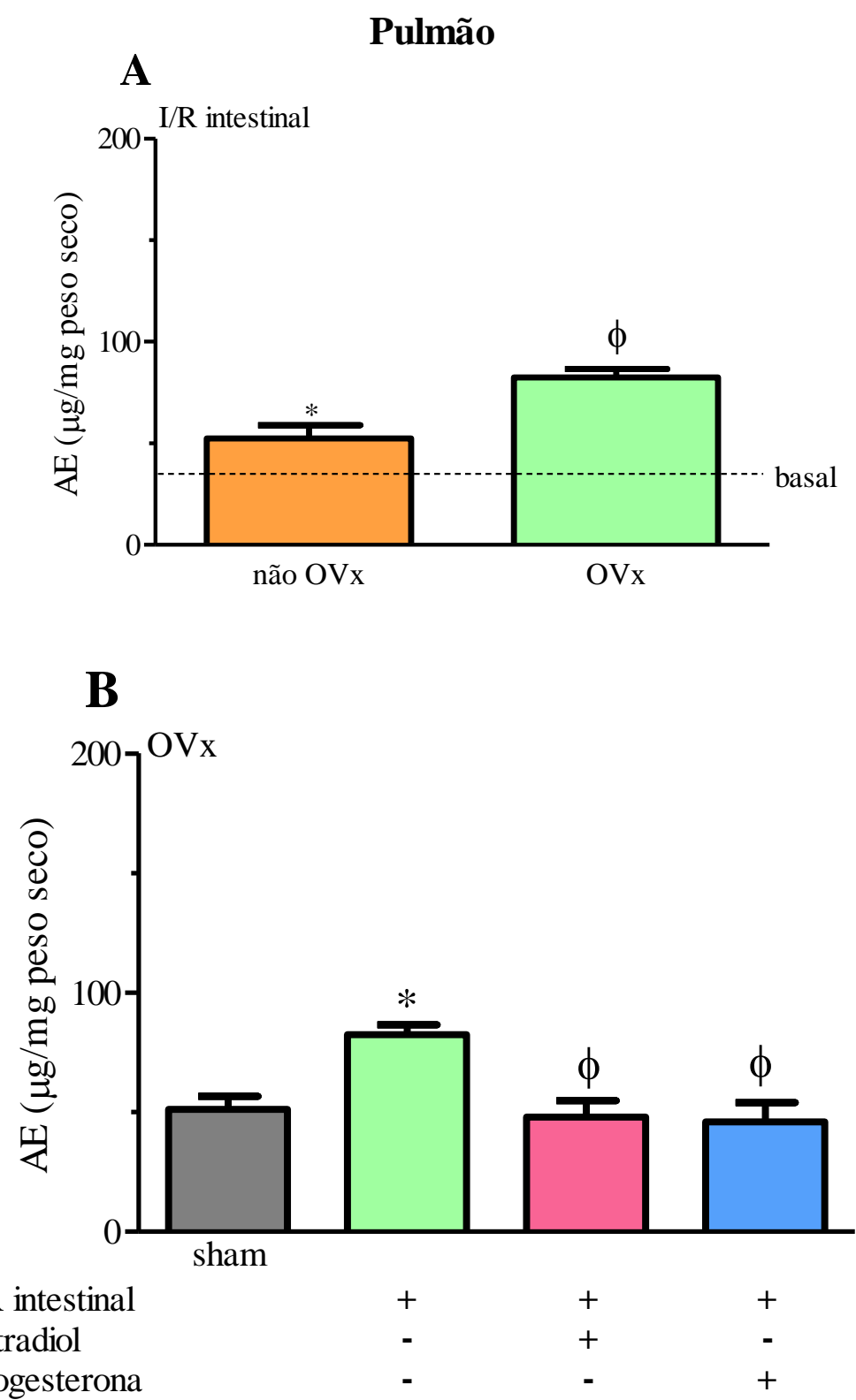


\subsubsection{Recrutamento de células inflamatórias}

- $\quad$ Atividade de enzima mieloperoxidase (MPO)

A I/R intestinal em ratas OVx causou infiltração de neutrófilos para o pulmão como indicado pelo aumento da atividade da enzima MPO quando comparado com o grupo não OVx (Fig. 4, painel A).

No painel B observamos que animais OVx submetidos à $\mathrm{I} / \mathrm{R}$ intestinal apresentaram maior atividade pulmonar de MPO em relação aos animais do grupo sham (animais OVx falsamente submetidos à $\mathrm{I} / \mathrm{R}$ intestinal). Além disso, observamos que o tratamento dos animais com progesterona potencializou a atividade MPO pulmonar quando comparada com o grupo I/R OVx. Todavia, o tratamento com estradiol não afetou a magnitude da atividade pulmonar de MPO em relação aos animais OVx não tratados. 
Figura 4 - Atividade da enzima MPO em homogenatos de pulmão. As ratas OVx foram submetidas ou não (Sham) à isquemia (45 min) e reperfusão intestinal (2 horas - I/R intestinal). Valores basais foram obtidos de ratas não manipuladas. Os dados representam a média $\pm \mathrm{EPM}$ de 5 animais. No gráfico $\mathrm{A} * P<0,05$ em relação ao grupo não $\mathrm{OVx}$. No gráfico $\mathrm{B} * P<0,05$ em relação ao grupo Sham $\mathrm{e}^{\phi} P<0,05 \mathrm{em}$ relação ao grupo OVx I/R.

\section{Pulmão}
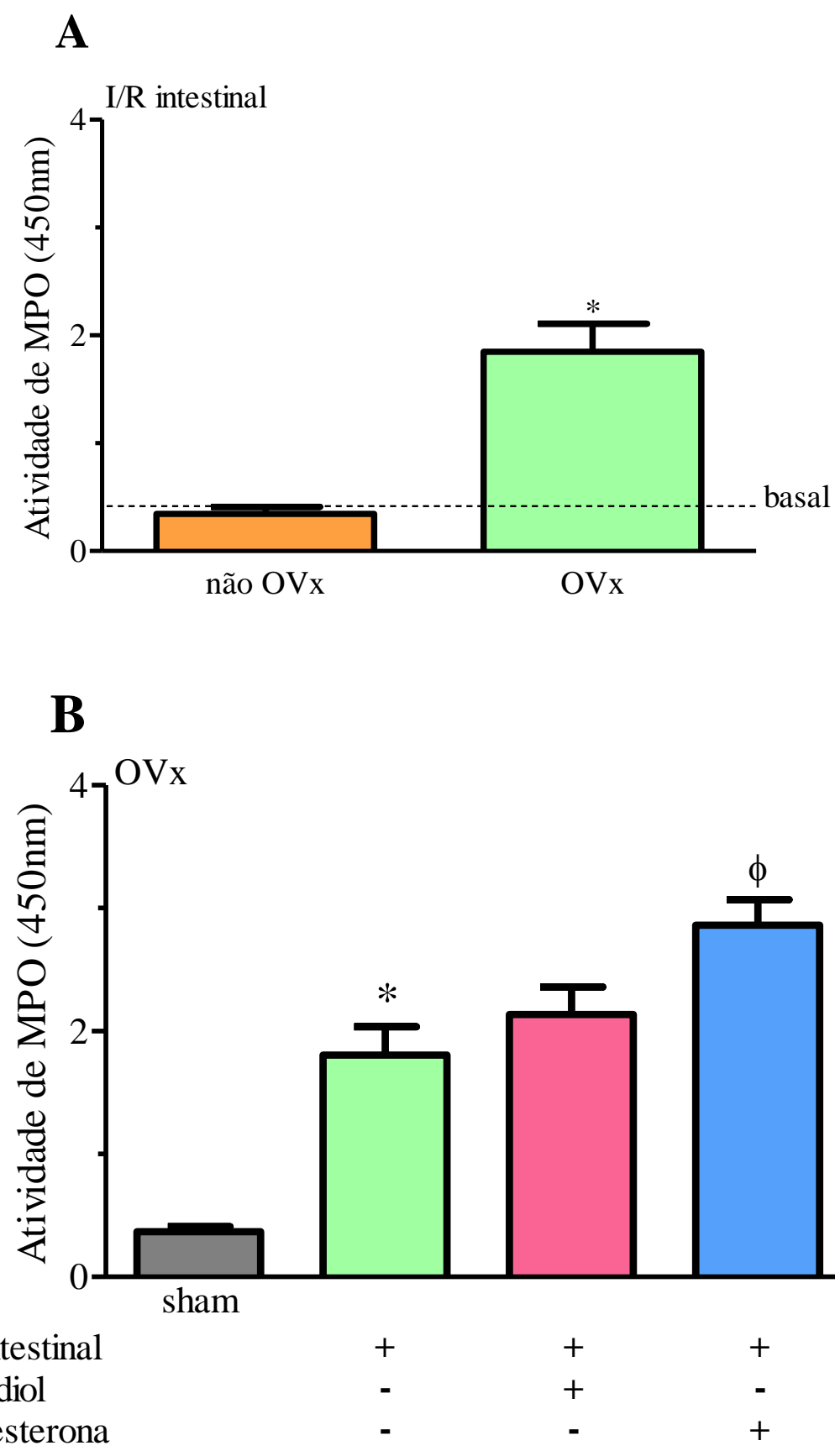

I/R intestinal
Estradiol
Progesterona

sham 
- Quantificação de células

Após a indução da $\mathrm{I} / \mathrm{R}$ intestinal, o tecido pulmonar dos animais foi digerido com colagenase e as células obtidas foram coradas em lâminas. De cada lâmina foram tiradas 3 fotomicrografias. Através destas imagens as células foram quantificadas e identificadas morfologicamente em mononucleares, neutrófilos e eosinófilos. Os dados representados na figura 5 mostram aumento na porcentagem de neutrófilos encontrados no tecido pulmonar. Nota-se no painel B da figura 5 aumento da porcentagem de neutrófilos no tecido pulmonar, redução das células mononucleares nas ratas OVx submetidas à I/R intestinal. Enquanto o número de eosinófilos não foi alterado (Fig. 5, painel C).

O tratamento prévio dos animais com estradiol (280 $\mu \mathrm{g} / \mathrm{kg}$, s.c.) ou progesterona (200 $\mu \mathrm{g} / \mathrm{kg}$, s.c.) reverteu o aumento da quantidade de neutrófilos presente nos animais $\mathrm{OVx}$ (painel A). Os tratamentos também aumentaram a quantidade de células mononucleares com relação ao grupo OVx (painel B). Contudo, em relação à porcentagem de eosinófilos encontrados no tecido pulmonar, somente os animais tratados previamente com progesterona exibiram elevação na quantidade destas células no tecido pulmonar (painel C). 
Figura 5 - Porcentagem de neutrófilos, células mononucleares e eosinófilos no pulmão processado para digestão com colagenase. As ratas OVx foram submetidas ou não (Sham) à isquemia (45 min) e reperfusão intestinal (2 horas - I/R intestinal). Valores basais foram obtidos de ratas não manipuladas. Os dados representam a média \pm EPM de 5 animais. Nos gráficos $* P<0,05$ em relação ao grupo sham e ${ }^{\phi} P$ $<0,05$ em relação ao grupo OVx I/R.

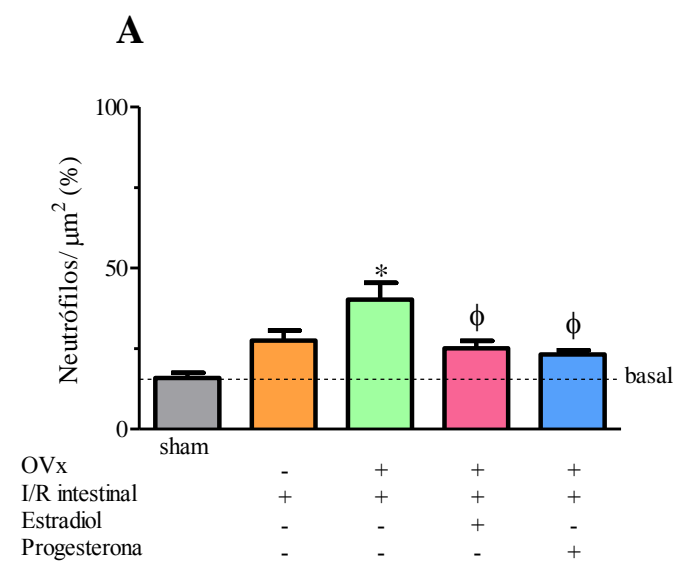

B

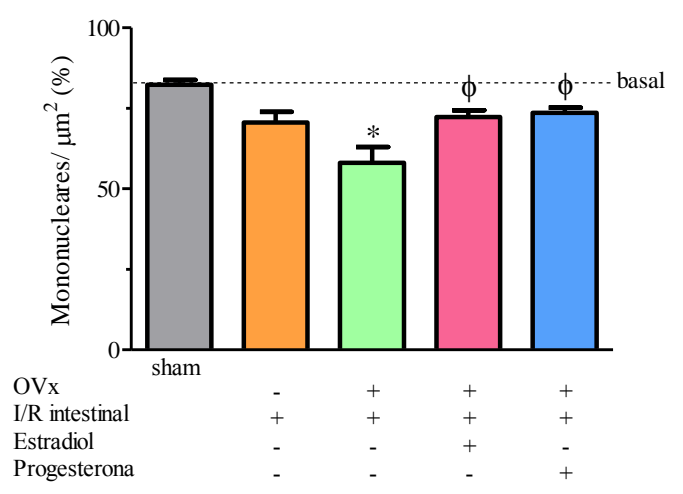

C

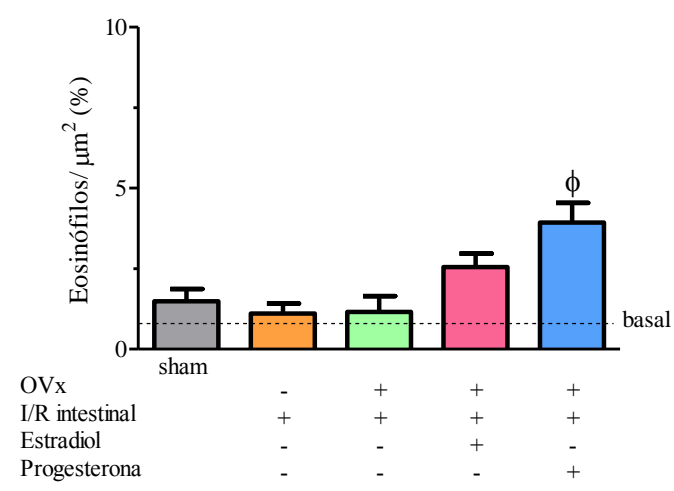




\subsubsection{Expressão das moléculas de adesão (ICAM-1, PECAM-1 e VCAM)}

A análise imunohistoquímica da expressão de moléculas de adesão no endotélio vascular pulmonar dos animais estudados revela que os animais $\mathrm{OVx}$ submetidos à $\mathrm{I} / \mathrm{R}$ intestinal não apresentaram alterações na expressão de ICAM-1 em comparação ao grupo nãoOVx (Fig. 6). A representação gráfica desta expressão encontra-se na figura 7 onde podemos observar a I/R intestinal em animais não-OVx exacerbou a expressão de ICAM-1 em relação ao grupo de animais não manipulados (basal) (painel A).

O painel B da figura 7 mostra que o tratamento prévio com estradiol (280 $\mu \mathrm{g} / \mathrm{kg}$, s.c.) e progesterona (200 $\mu \mathrm{g} / \mathrm{kg}$, s.c.) reduziram a expressão de ICAM-1 no endotélio vascular pulmonar.

Figura 6 - Fotomicrografia mostrando o efeito da OVx e do tratamento dos animais com hormônios sexuais femininos sobre a expressão de ICAM-1 nos vasos pulmonares por imunohistoquímica. As ratas $\mathrm{OVx}$ foram submetidas ou não (sham) à isquemia (45 min) e reperfusão intestinal ( 2 horas - I/R intestinal). Fotomicrografia basal representa corte de pulmão de rata não manipulada.
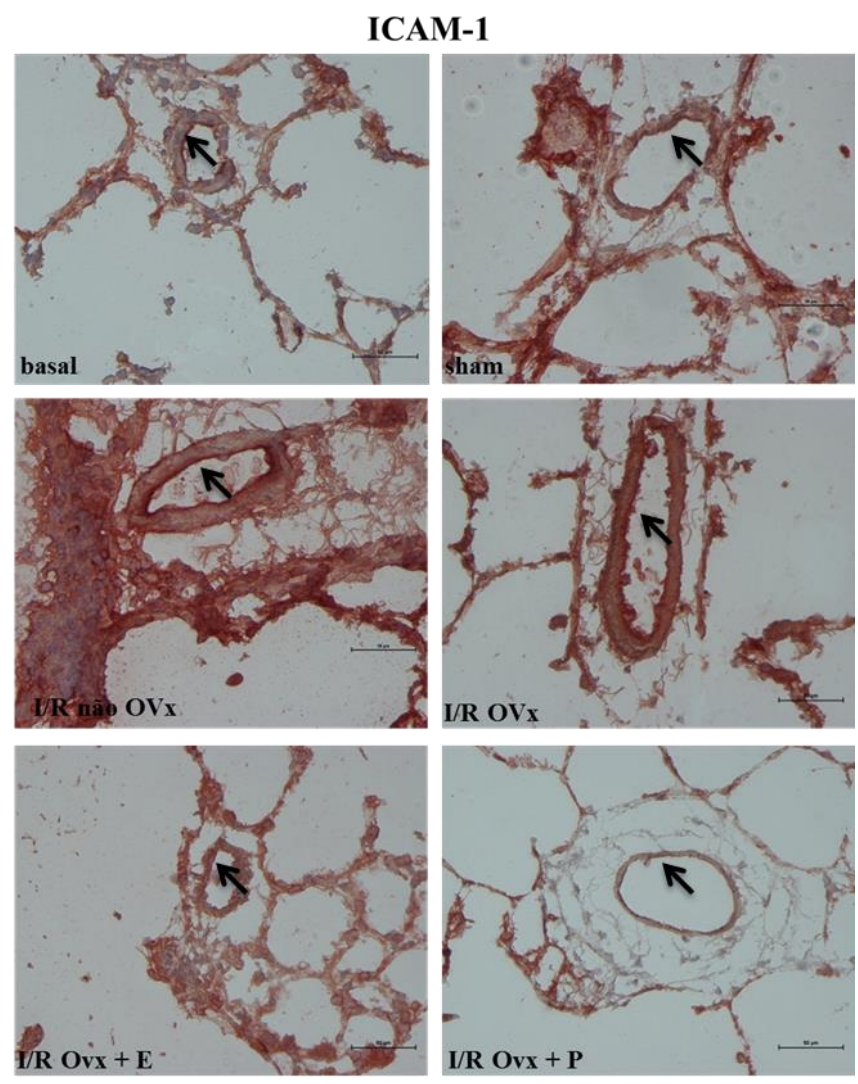
Figura 7 - Efeito da OVx e do tratamento dos animais com hormônios sexuais femininos sobre a expressão de ICAM-1 nos vasos pulmonares por imunohistoquímica. As ratas OVx foram submetidas ou não (sham) à isquemia (45 min) e reperfusão intestinal ( 2 horas - I/R intestinal). Valores basais foram obtidos de ratas não manipuladas. Os dados representam a média \pm EPM de 5 animais. No gráfico A $* P$ $<0,05$ em relação ao grupo basal. No gráfico $\mathrm{B}{ }^{\phi} P<0,05$ em relação ao grupo I/R OVx.
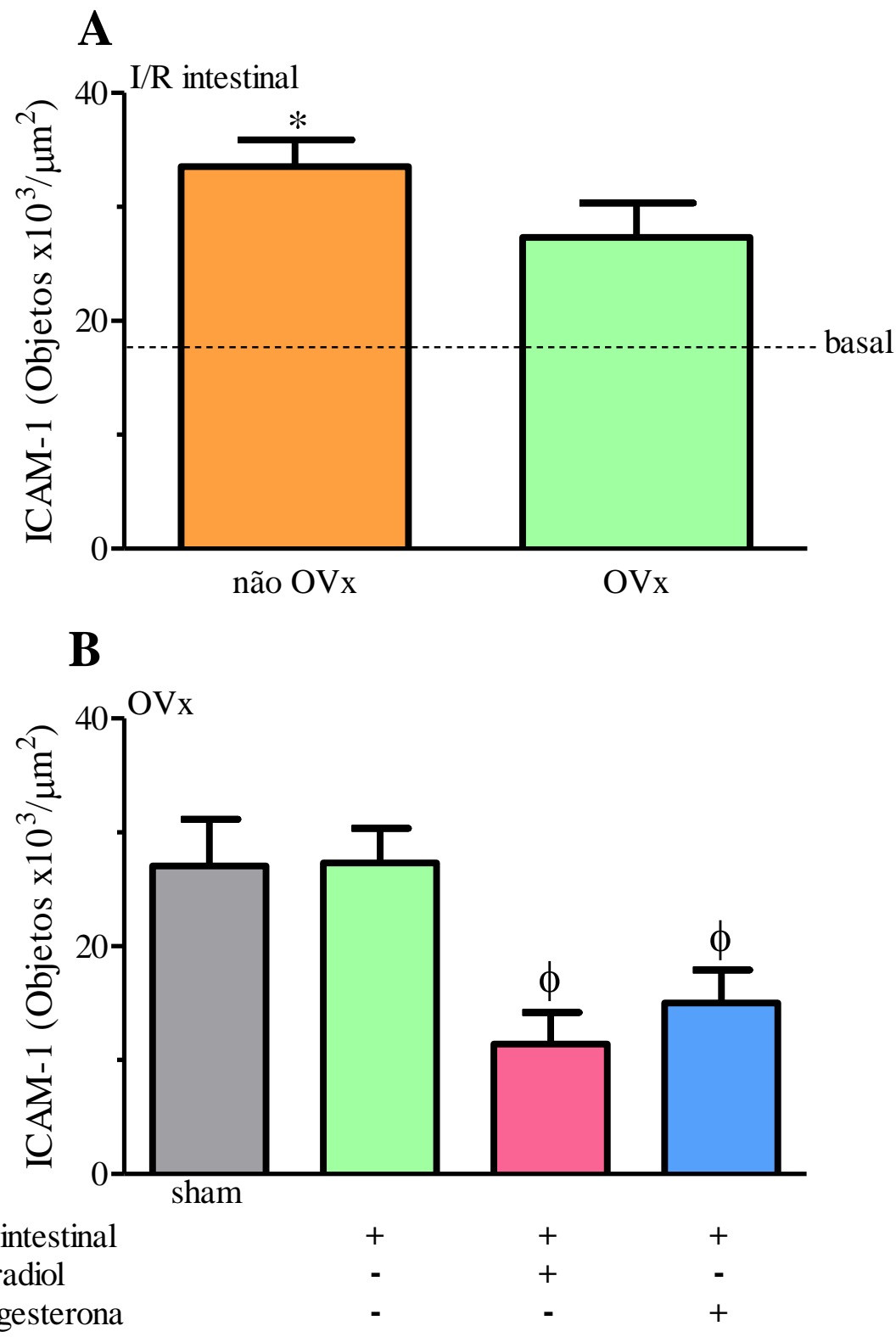
$\mathrm{Na}$ figura 8 podemos observar as fotomicrografias da expressão de PECAM-1 nos vasos pulmonares. A figura 9 mostra, após análise das imagens, o resultado da quantificação dos objetos marcados por área.

Em relação à expressão de PECAM-1 nos vasos pulmonares, notamos que há um aumento expressivo desta molécula ao compararmos o grupo basal com o grupo não-OVx I/R intestinal. A remoção dos ovários promoveu uma redução da expressão de PECAM-1 se comparada ao grupo não-OVx (Painel A, fig. 9). O tratamento prévio dos animais com estradiol (280 $\mu \mathrm{g} / \mathrm{kg}$, s.c.) ou progesterona (200 $\mu \mathrm{g} / \mathrm{kg}$, s.c.) mostrou reverter a redução da expressão de PECAM-1 observada no grupo OVx submetido à I/R intestinal (Painel B, fig. 9).

Figura 8 - Fotomicrografia mostrando o efeito da OVx e dos hormônios sexuais femininos sobre a expressão de PECAM-1 nos vasos pulmonares por imunohistoquímica. As ratas OVx foram submetidas ou não (sham) à isquemia (45 min) e reperfusão intestinal ( 2 horas - I/R intestinal). Fotomicrografia basal representa corte de pulmão de rata não manipulada.

\section{PECAM-1}
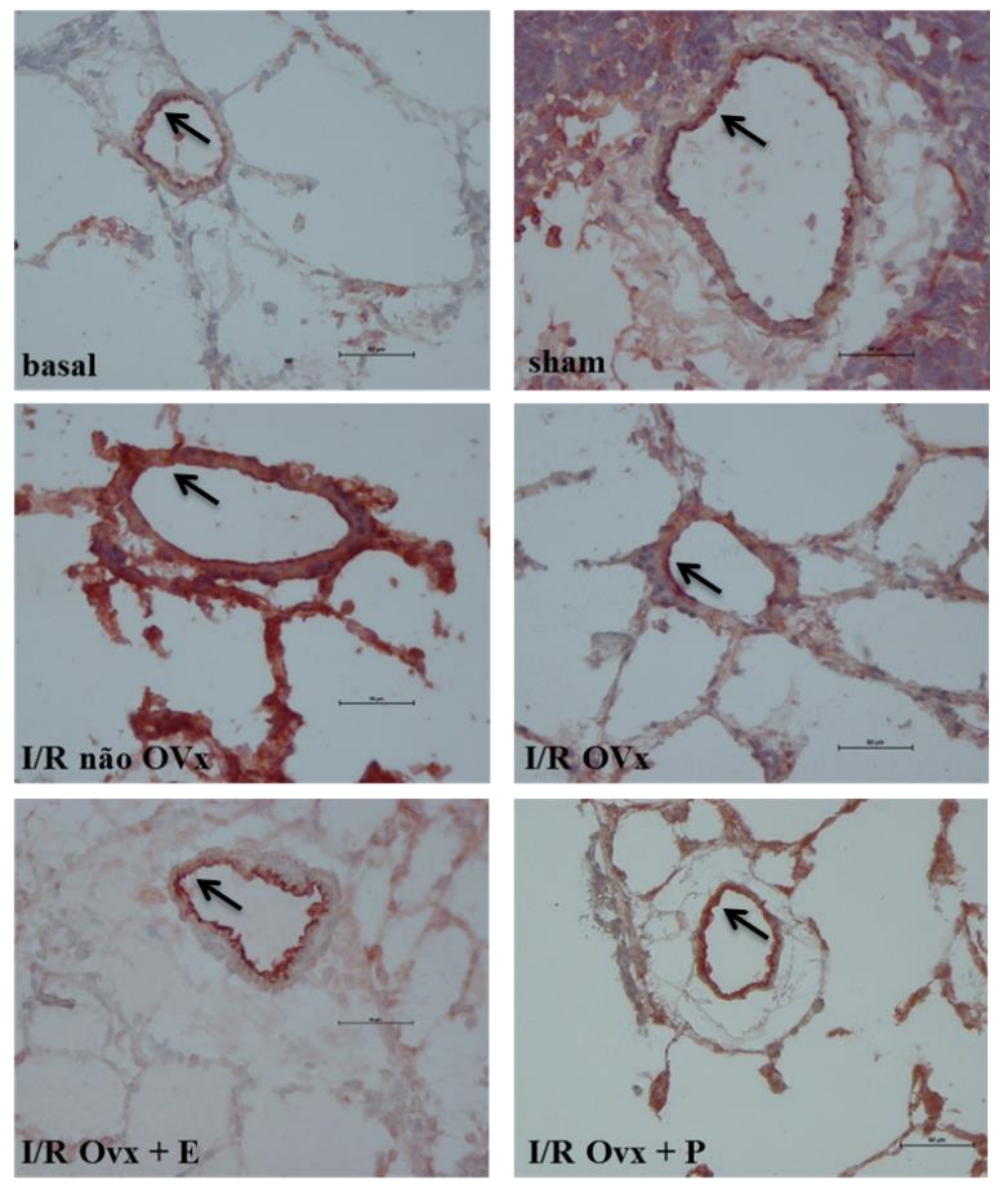
Figura 9 - Efeito da OVx e dos hormônios sexuais femininos sobre a expressão de PECAM-1 nos vasos pulmonares por imunohistoquímica. As ratas OVx foram submetidas ou não (sham) à isquemia (45 min) e reperfusão intestinal (2 horas - I/R intestinal). Valores basais foram obtidos de ratas não manipuladas. Os dados representam a média \pm EPM de 5 animais. No gráfico A ${ }^{*} P<0,05$ em relação ao grupo basal, ${ }^{\phi} P<$ 0,05 em relação ao grupo $\mathrm{I} / \mathrm{R}$ não-OVx. No gráfico $\mathrm{B}{ }^{*} P<0,05$ em relação ao grupo sham, ${ }^{\phi} P<0,05$ em relação ao grupo I/R OVx.

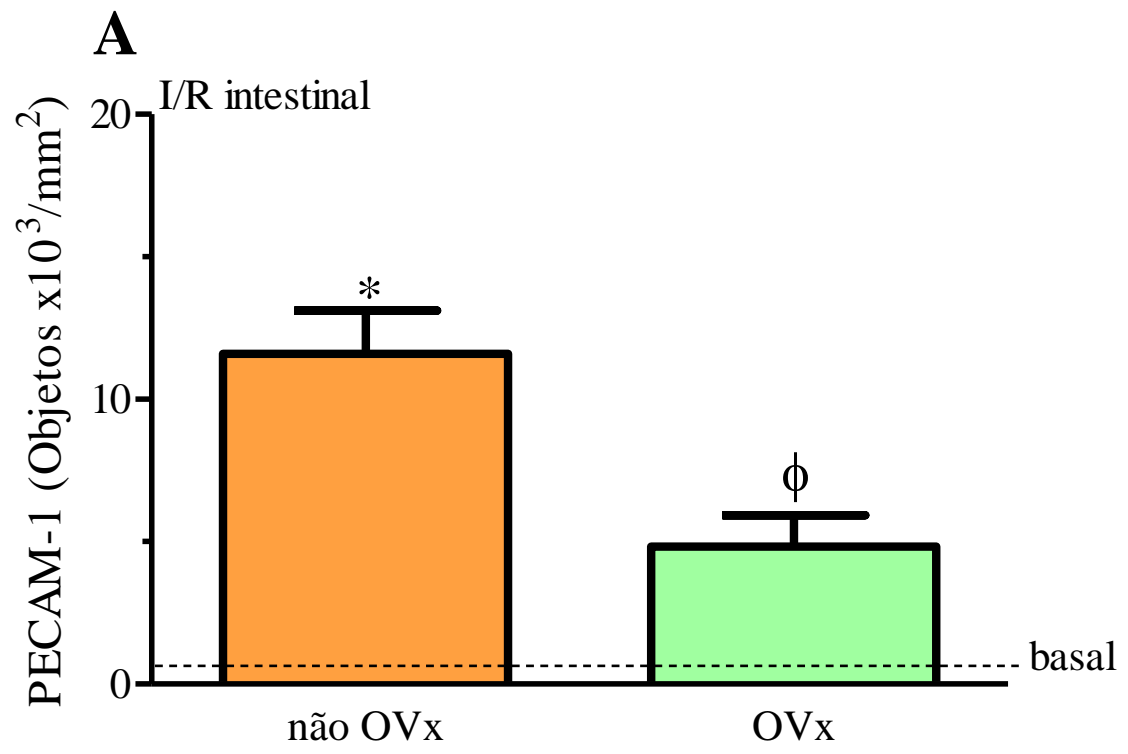

B

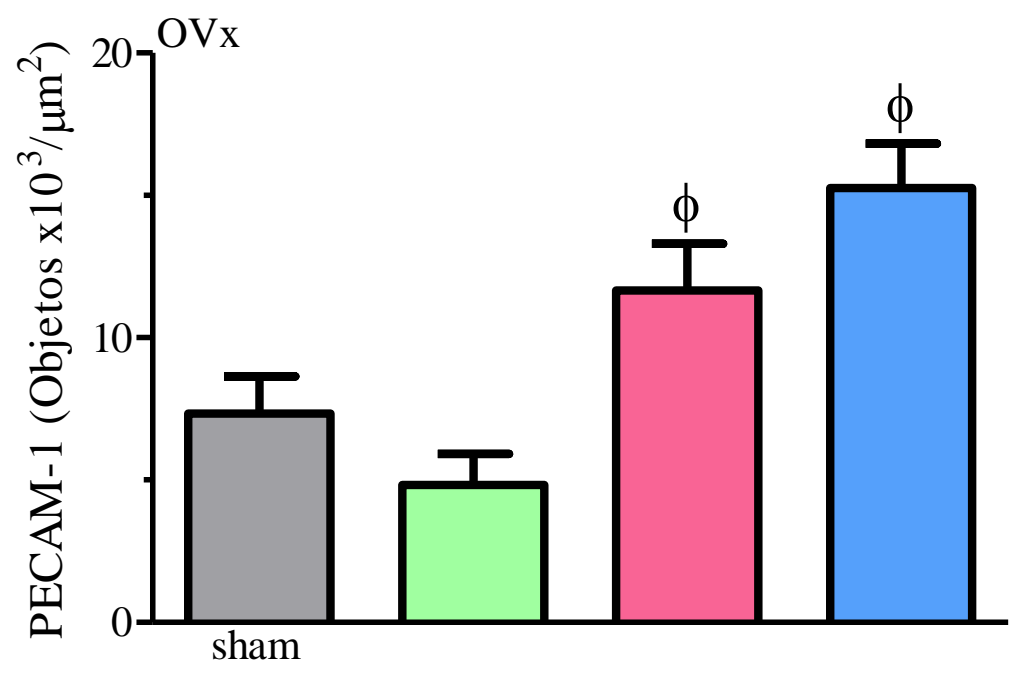

I/R intestinal

Estradiol

Progesterona

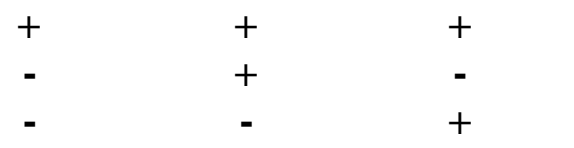


$\mathrm{Na}$ figura 10 podemos observar as fotomicrografias da expressão de VCAM no endotélio vascular pulmonar. A figura 11 mostra, após análise das imagens, o resultado da quantificação dos objetos marcados por área.

Em relação à expressão de VCAM no endotélio vascular pulmonar, notamos que há um aumento expressivo desta molécula somente no grupo de animais tratado previamente com progesterona ao compararmos com o grupo OVx I/R intestinal (Painel B, fig. 11).

Figura 10 - Fotomicrografia mostrando o efeito da OVx e dos hormônios sexuais femininos sobre a expressão de VCAM no tecido pulmonar por imunohistoquímica. As ratas OVx foram submetidas ou não (sham) à isquemia (45 min) e reperfusão intestinal ( 2 horas - I/R intestinal). Fotomicrografia basal representa corte de pulmão de rata não manipulada.

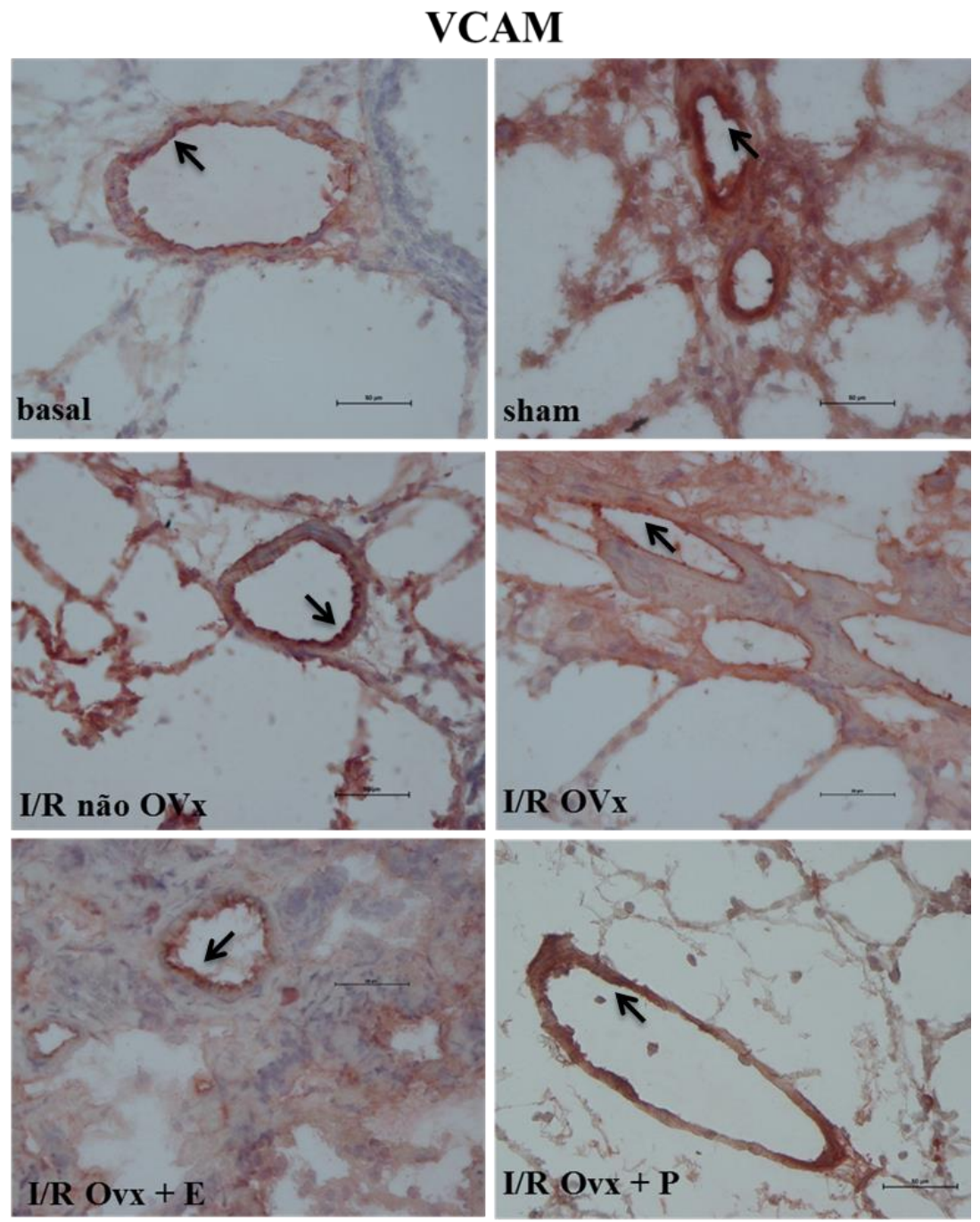


Figura 11 - Efeito da OVx e dos hormônios sexuais femininos sobre a expressão de VCAM no endotélio vascular pulmonar por imunohistoquímica. As ratas $\mathrm{OVx}$ foram submetidas ou não (sham) à isquemia (45 min) e reperfusão intestinal (2 horas - I/R intestinal). Valores basais foram obtidos de ratas não manipuladas. Os dados representam a média \pm EPM de 5 animais. No gráfico $\mathrm{B}{ }^{\phi} P<0,05$ em relação ao grupo I/R OVx.

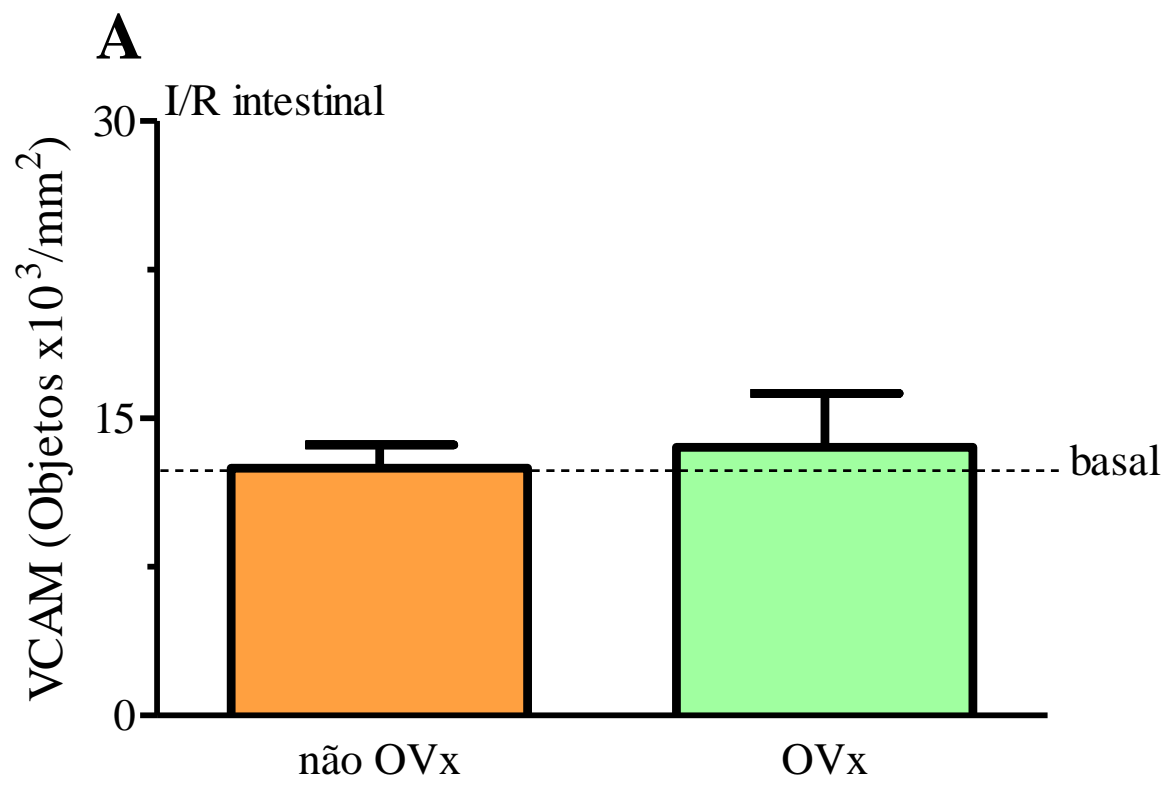

\section{B}

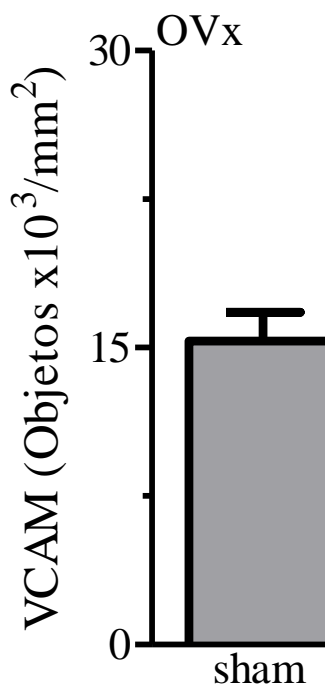

$\mathrm{I} / \mathrm{R}$ intestinal

Estradiol

Progesterona

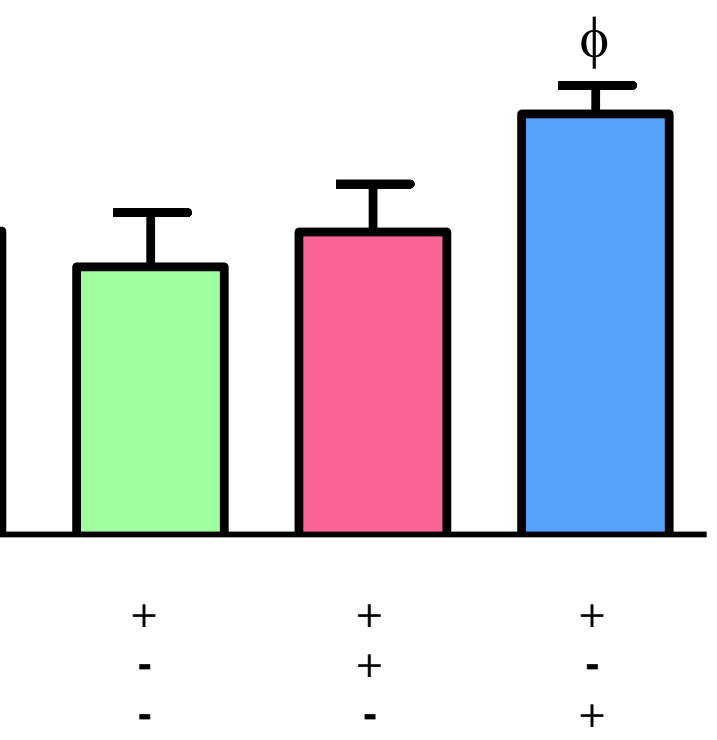




\subsubsection{Expressão dos receptores $\mathrm{P}_{2} \mathrm{X}_{Z}$}

As imagens de imunofluorescência mostrando a expressão dos receptores $\mathrm{P} 2 \mathrm{X}_{7}$ no endotélio pulmonar após a I/R intestinal estão representadas na figura 12 .

As imagens foram analisadas para quantificação da fluorescência e os dados são mostrados no gráfico (figura 13). Como pode ser observado, os resultados nos indicam que o grupo I/R intestinal não-OVx apresentou significativo aumento na expressão destes receptores em relação aos grupos de animais basal e OVx. Quando os animais receberam tratamento prévio com hormônios sexuais femininos, somente o grupo tratado com progesterona $(200 \mu \mathrm{g} / \mathrm{kg}$, s.c.) $24 \mathrm{~h}$ antes de ser submetido à $\mathrm{I} / \mathrm{R}$ intestinal, aumentou a expressão do receptor $\mathrm{P}_{2} \mathrm{X}_{7}$ no endotélio vascular pulmonar (Painel B, Fig. 13).

Figura 12 - Fotomicrografias mostrando o efeito da OVx e dos hormônios sexuais femininos sobre a expressão do receptor $\mathrm{P}_{2} \mathrm{X}_{7}$ nos vasos pulmonares por imunofluorescência. As ratas OVx foram submetidas ou não (basal) à isquemia (45 min) e reperfusão intestinal ( 2 horas - I/R intestinal). Valores basais foram obtidos de ratas não manipuladas. As imagens representam a atividade do receptor $\mathrm{P}_{2} \mathrm{X}_{7}$ nos vasos pulmonares.
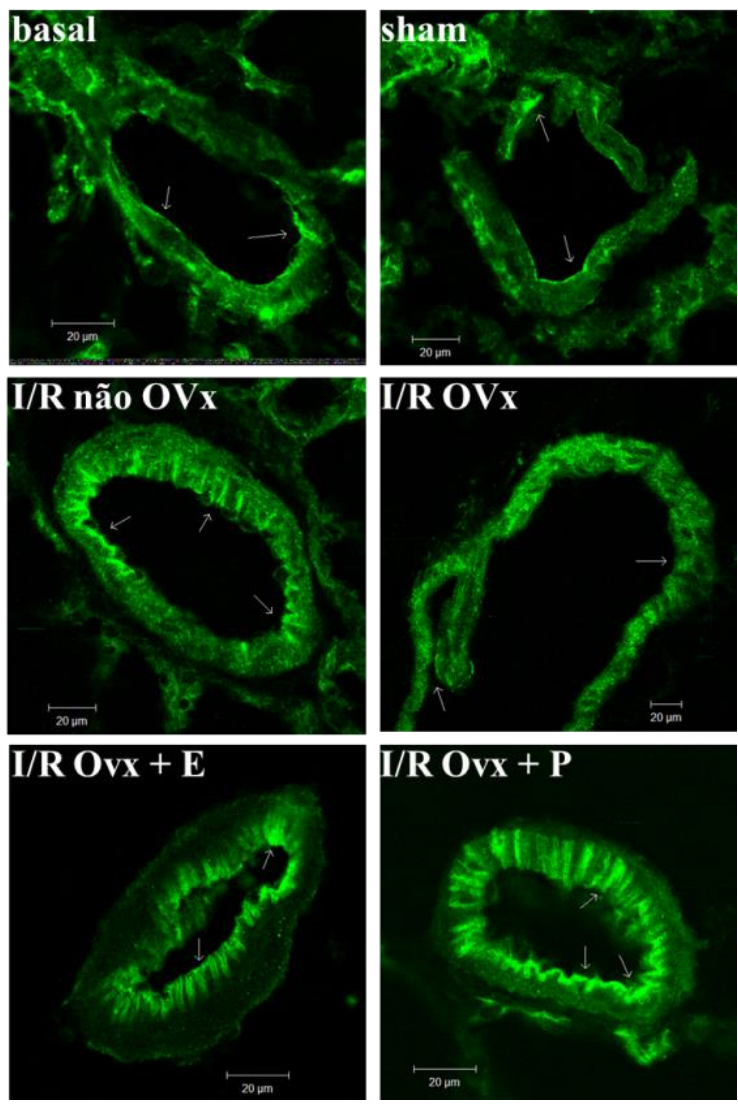
Figura 13 - Efeito da OVx e dos hormônios sexuais femininos sobre a quantificação do receptor $\mathrm{P} 2 \mathrm{X}_{7}$ nos vasos pulmonares por imunofluorescência. As ratas $\mathrm{OVx}$ foram submetidas ou não (basal) à isquemia (45 min) e reperfusão intestinal (2 horas - I/R intestinal). Valores basais foram obtidos de ratas não manipuladas. Os dados representam a média \pm EPM de 5 animais. No gráfico A: $* P<0,05$ em relação ao grupo basal, ${ }^{\phi} P<0,05$ em relação ao grupo I/R Não-OVx. No gráfico B: ${ }^{*} P<0,05$ em relação ao grupo sham, ${ }^{\phi} P<0,05$ em relação ao grupo I/R OVx.
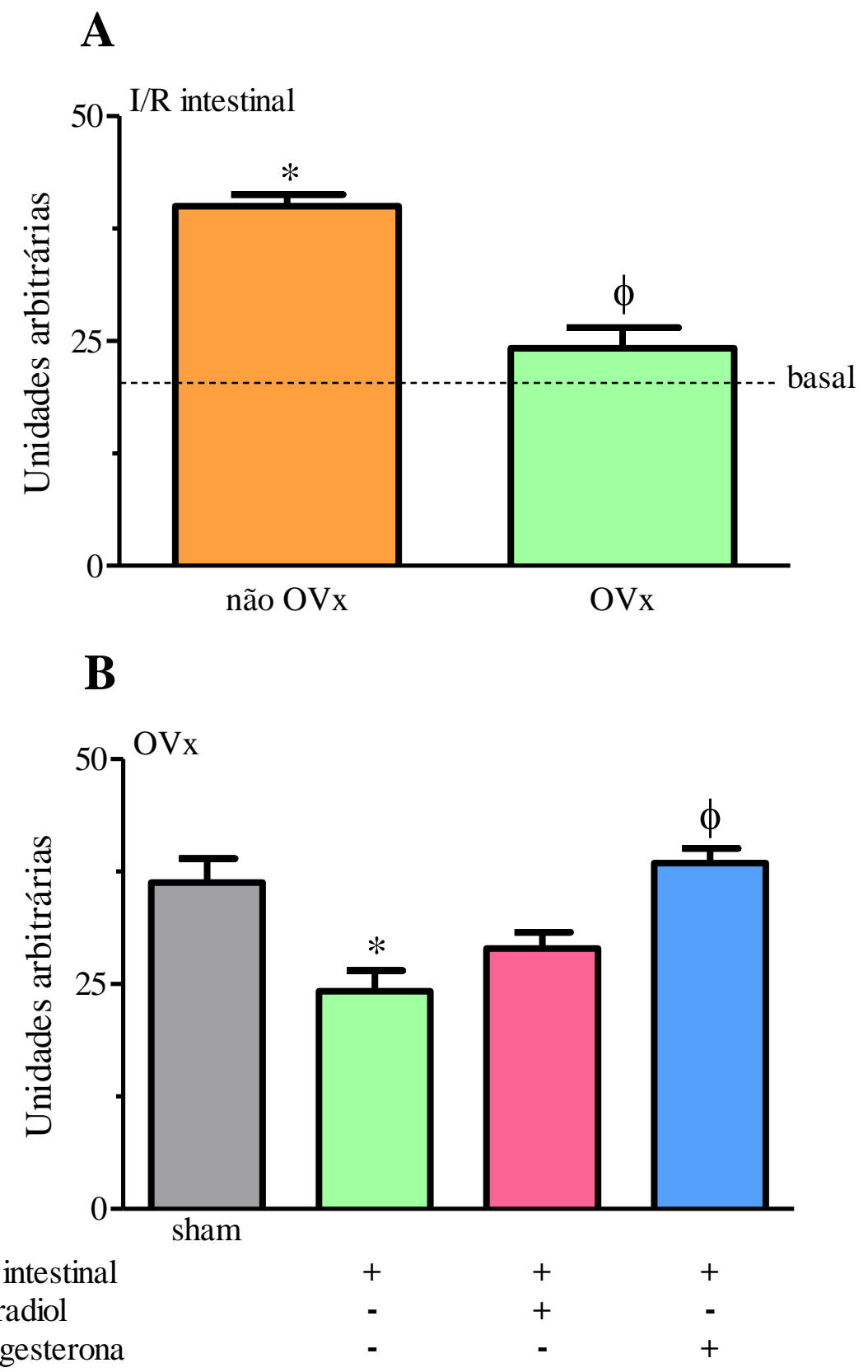
Após realizarmos a reação imunohistoquímica para avaliar a expressão dos receptores $\mathrm{P}_{2} \mathrm{X}_{7}$ com o marcador fluorescente alexa flúor 488 , de emissão verde, identificamos uma auto-fluorescência verde em nossos cortes de tecido pulmonar possivelmente pela existência da elastina e colágeno. $\mathrm{O}$ tecido pulmonar é rico nestes componentes, principalmente os vasos sanguíneos. Portanto, a fim de avaliar a presença da autofluorescência, realizamos ensaio imunohistoquímico incubando os cortes com o corante azul de pontamina (Chicago Sky Blue) antes da marcação. Este corante ao se ligar ao colágeno e à elastina altera a emissão da autofluorescência para vermelho. Os dados obtidos estão ilustrados na figura 14. Nas imagens originais (sem a incubação com o corante azul de pontamina) pode ser observada a maior intensidade do verde no tecido vascular, enquanto que nas imagens incubadas com azul de pontamina a marcação em verde se concentra apenas nos receptores. Na foto com filtro para emissão vermelha observa-se que a região vascular ficou agora evidenciada em vermelho.

Figura 14 - Fotomicrografias representando a atividade do receptor $\mathrm{P}_{2} \mathrm{X}_{7}$ nos vasos pulmonares. As figuras da esquerda representam as imagens com autofluerência em verde. As imagens da direita mostrando a autofluorescência verde transformada em vermelho após incubação com azul de pontamina. $\mathrm{E}$ as imagens centrais mostram a atividade do receptor $\mathrm{P} 2 \mathrm{X}_{7}$ após tratamento com azul de pontamina.

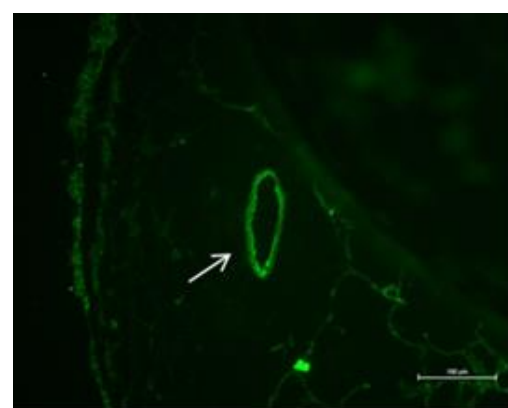

sem azul

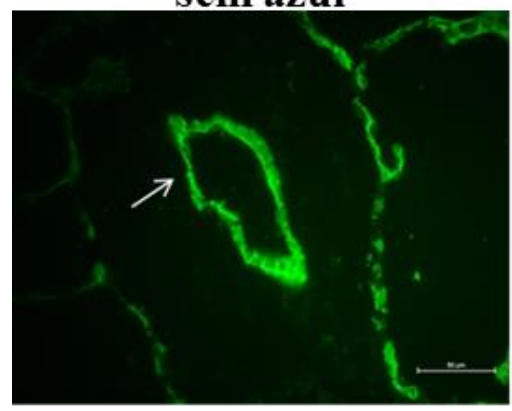

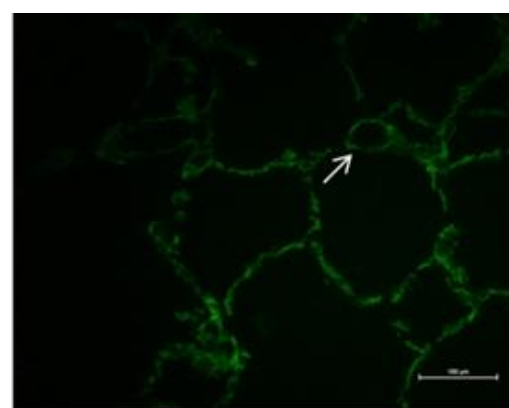

com azul

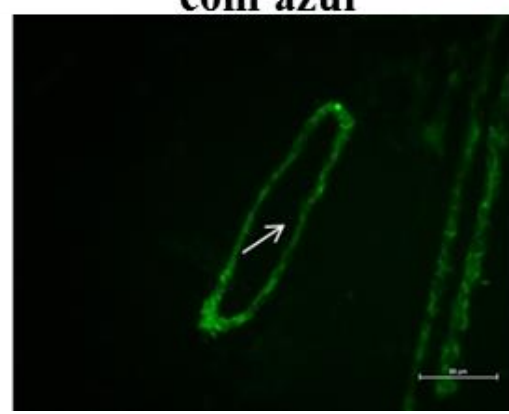

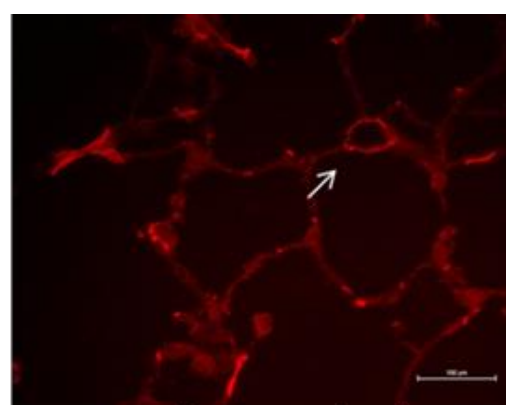

auto-fluorescência

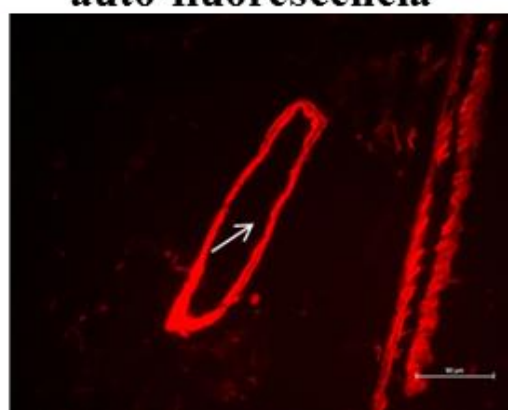




\subsubsection{Quantificação dos mediadores inflamatórios em explante pulmonar}

- Interleucina $-1 \beta$

A figura 15 (painel A) indica que a OVx elevou significativamente a concentração de IL-1 $\beta$ no grupo de animais submetidos à $\mathrm{I} / \mathrm{R}$ intestinal quando comparada com a dos animais sob I/R intestinal com ovários intactos (não OVx). O tratamento dos animais com estrógeno ou progesterona preveniu o aumento dos níveis de IL-1 $\beta$ no sobrenadante de cultura de tecido pulmonar. 
Figura 15 - Efeito da OVx e dos hormônios sexuais femininos sobre a geração de IL-1 $1 \beta$ em explante de pulmão de ratas (cultura de $24 \mathrm{~h}$ ) após a I/R intestinal. A I/R intestinal foi induzida 7 dias após a remoção dos ovários $(\mathrm{OVx})$ e em ratas não-OVx. O grupo basal consistiu de animais $\mathrm{OVx}$, e o grupo sham de animais falsamente operados. $\mathrm{O}$ tratamento hormonal ocorreu $24 \mathrm{~h}$ antes da indução da $\mathrm{I} / \mathrm{R}$ intestinal. Os dados representam a média $\pm \mathrm{EPM}$ de 5 animais. No gráfico $\mathrm{A} * P<0,05$ em relação ao grupo não $\mathrm{OVx}$ I/R. No gráfico $\mathrm{B}$. ${ }^{*} P<0,05$ em relação ao grupo Sham; ${ }^{\phi} P<0,05$ em relação ao grupo $\mathrm{OVx} \mathrm{I} / \mathrm{R}$.
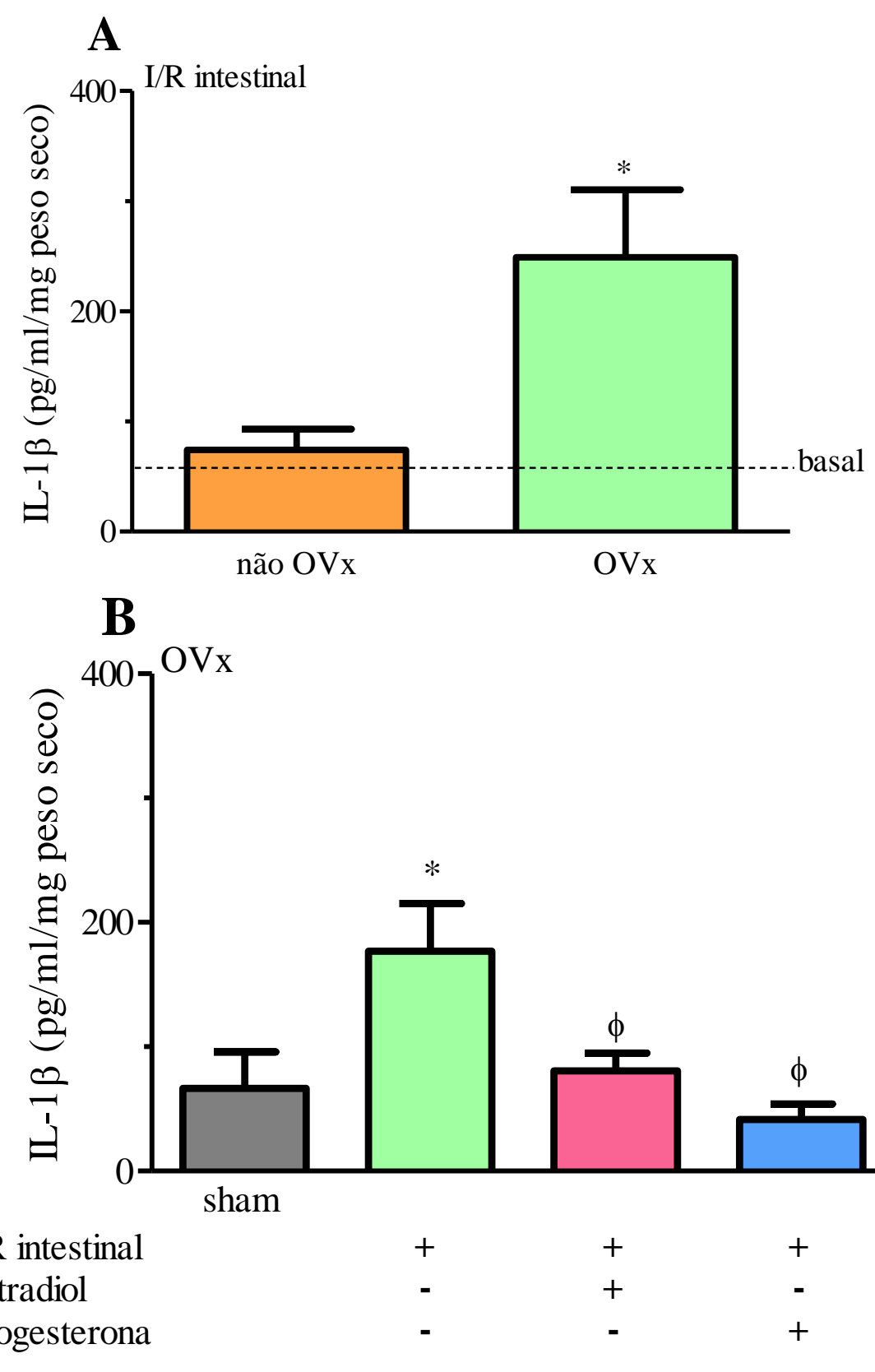
- Interleucina -10

Na figura 16 (painel A) é observado que a concentração de IL-10 no sobrenadante de cultura de explante dos animais submetidos a I/R intestinal reduziu-se significativamente em relação ao obtido no pulmão dos animais com ovários intactos. O tratamento dos animais com estradiol preveniu a geração de IL-10. Contudo o tratamento com progesterona exacerbou a geração desta citocina (painel B). 
Figura 16 - Efeito da OVx e dos hormônios sexuais femininos sobre a geração de IL-10 em explante de pulmão (cultura de $24 \mathrm{~h}$ ) de ratas submetidas à $\mathrm{I} / \mathrm{R}$ intestinal. A I/R intestinal foi induzida 7 dias após a remoção dos ovários $(\mathrm{OVx})$ bem como em ratas não-OVx. O grupo basal consistiu de animais $O V x$, e o grupo sham de animais falsamente operados. O tratamento hormonal ocorreu $18 \mathrm{~h}$ antes do procedimento de I/R intestinal. Os dados representam a média \pm EPM de 5 animais. No gráfico $\mathrm{A},{ }^{*} P$ $<0,05$ em relação ao grupo basal; ${ }^{\phi} P<0,05$ em relação ao grupo I/R não-OVx. No gráfico $\mathrm{B},{ }^{*} P<0,05$ em relação ao grupo sham; ${ }^{\phi} P<0,05$ em relação ao grupo I/R OVx.
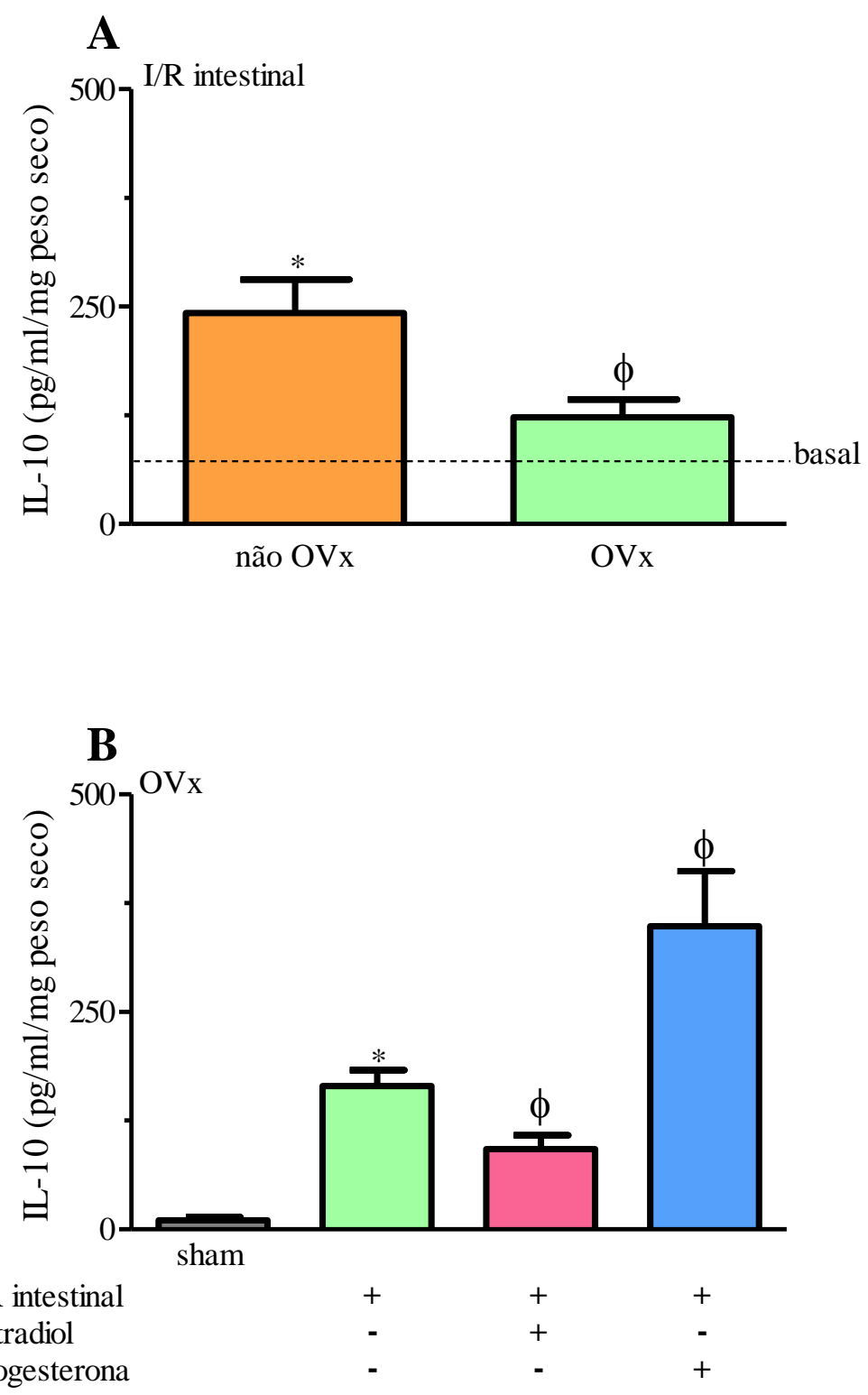
- Fator de crescimento endotelial vascular (VEGF)

A concentração de VEGF no sobrenadante do meio de cultura de explante pulmonar está representada na Figura 17. No painel A, nota-se que a indução da I/R intestinal levou a um significativo aumento do VEGF no explante pulmonar do grupo OVx, quando comparado com o grupo não OVx. No painel $\mathrm{B}$, verifica-se que o tratamento dos animais com estradiol impediu que os pulmões gerassem concentrações elevadas de VEGF em relação ao grupo de animais OVx não tratados e submetidos a I/R intestinal enquanto a progesterona não exerceu efeito significativo. 
Figura 17 - Efeito da OVx e dos hormônios sexuais femininos sobre a geração de VEGF em explante de pulmão (cultura de $24 \mathrm{~h}$ ) de ratas submetidas à $\mathrm{I} / \mathrm{R}$ intestinal. $\mathrm{A} \mathrm{I} / \mathrm{R}$ intestinal foi induzida 7 dias após a remoção dos ovários $(\mathrm{OVx})$ bem como em ratas não OVx. O grupo basal consistiu de animais $O V x$, e o grupo sham de animais falsamente operados. O tratamento hormonal ocorreu $18 \mathrm{~h}$ antes do procedimento de I/R intestinal. Os dados representam a média \pm EPM de 5 animais No gráfico $\mathrm{A}$ ${ }^{*} P<0,05$ em relação ao grupo não $\mathrm{OVx}$. No gráfico, ${ }^{*} P<0,05$ em relação ao grupo Sham; ${ }^{\phi} P<0,05$ em relação ao grupo OVx I/R.
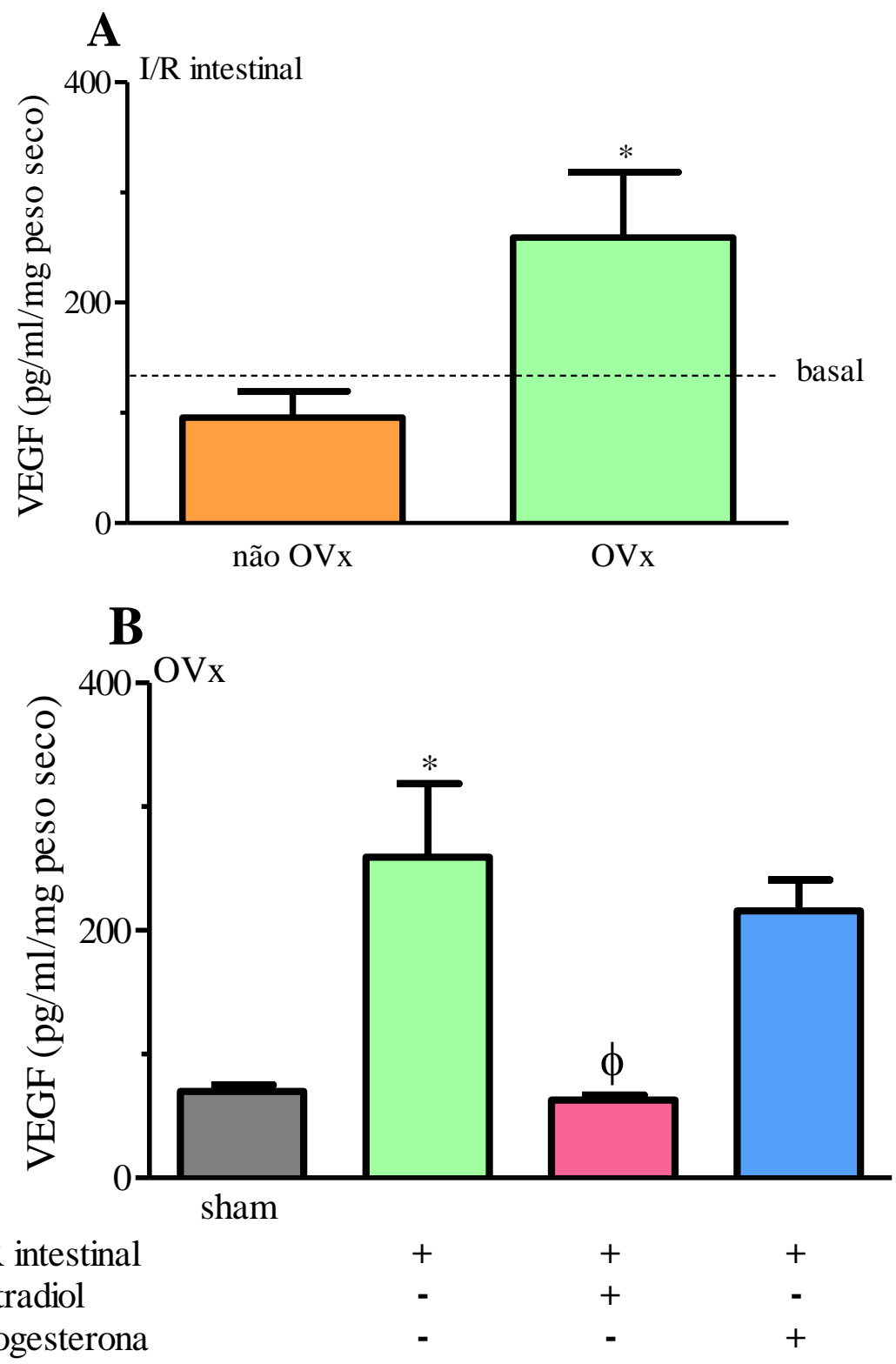

I/R intestinal

Estradiol

Progesterona 
- Interleucina 6

A concentração de IL-6 no compartimento pulmonar de animais OVx após a I/R intestinal está representada na figura 18. Como observado a I/R intestinal não determinou a geração de IL-6 no compartimento pulmonar em nenhum dos grupos investigados (painéis A e B).

Figura 18 - Efeito da OVx e dos hormônios sexuais femininos sobre a geração de IL-6 em explante de pulmão (cultura de $24 \mathrm{~h}$ ) de ratas submetidas à $\mathrm{I} / \mathrm{R}$ intestinal. A I/R intestinal foi induzida 7 dias após a remoção dos ovários $(\mathrm{OVx})$ bem como em ratas não OVx. O grupo basal consistiu de animais $O V x$, e o grupo sham de animais falsamente operados. O tratamento hormonal ocorreu $18 \mathrm{~h}$ antes do procedimento de $\mathrm{I} / \mathrm{R}$ intestinal. Os dados representam a média \pm EPM de 5 animais.
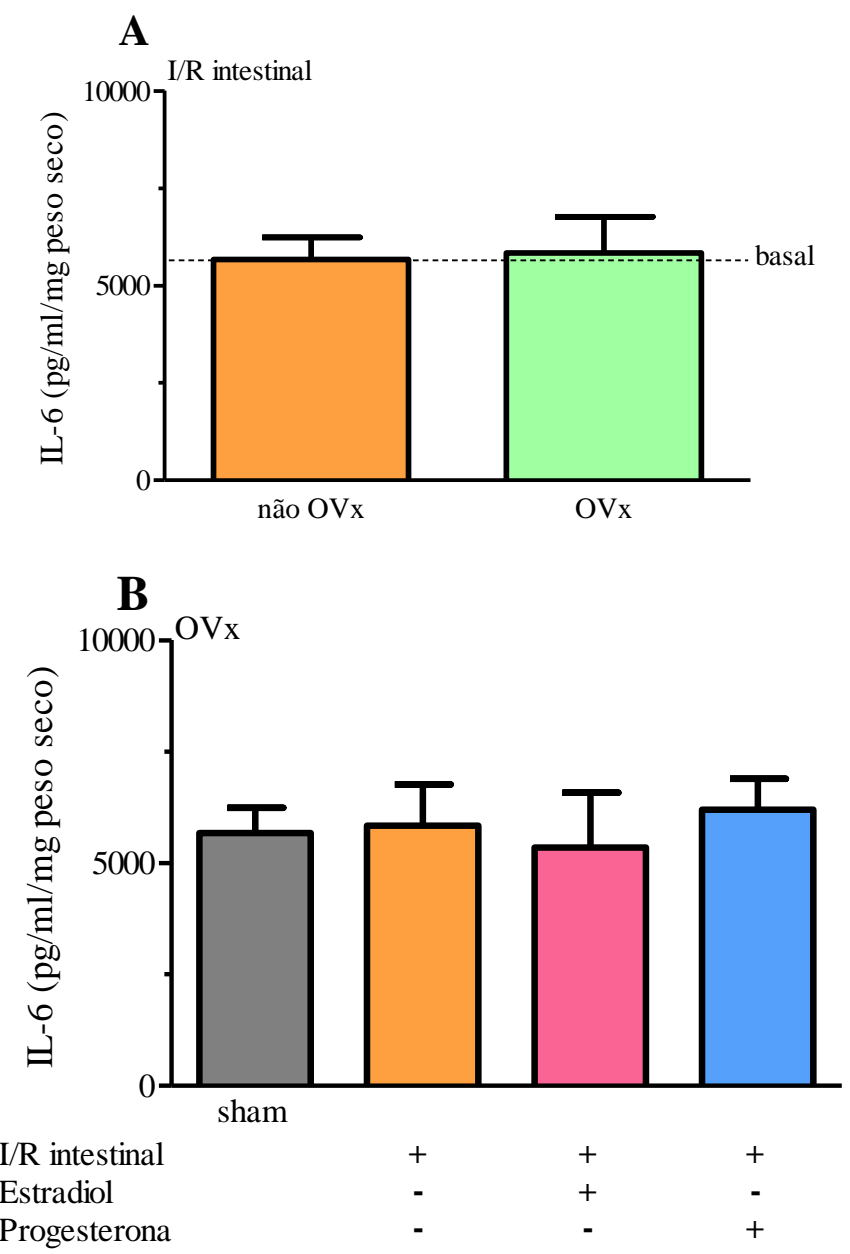
A figura 19 (painel A) indica que a I/R intestinal não alterou a concentração de INF- $\gamma$. Ainda, a remoção dos ovários não interferiu com a geração de INF- $\gamma$. Por outro lado, o tratamento dos animais com estrógeno aumentou a concentração de INF- $\gamma$ no sobrenadante de cultura de tecido pulmonar.

Figura 19 - Efeito da OVx e dos hormônios sexuais femininos sobre a geração de INF- $\gamma$ em explante de pulmão de ratas (cultura de 48h) após a I/R intestinal. A I/R intestinal foi induzida 7 dias após a remoção dos ovários (OVx) e em ratas não-OVx. O grupo basal consistiu de animais não manipulados, e o grupo sham de animais $\mathrm{OVx}$ falsamente operados. O tratamento hormonal ocorreu $24 \mathrm{~h}$ antes da indução da $\mathrm{I} / \mathrm{R}$ intestinal. Os dados representam a média \pm EPM de 5 animais. No gráfico B ${ }^{\phi} P<$ 0,05 em relação ao grupo OVx I/R.
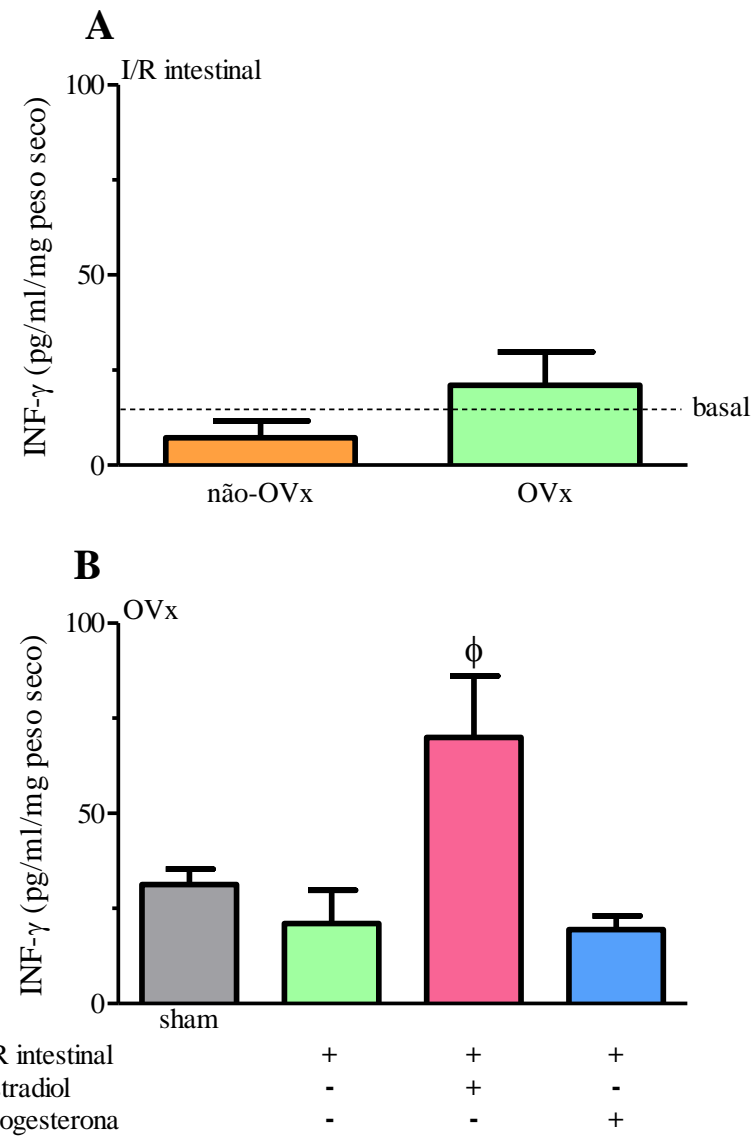
- $\underline{\text { Nitritos }}$

A geração de óxido nítrico em explante de tecido pulmonar dos animais submetidos a I/R intestinal foi avaliada pelo método de Griess. Os resultados estão representados na figura 20 revelam que o explante pulmonar de animais não-OVx submetidos à $\mathrm{I} / \mathrm{R}$ intestinal gera quantidades significantes de nitritos em relação ao quantificado em explante pulmonar de animais do grupo basal. Por outro lado, a remoção dos ovários (grupo OVx) preveniu a geração de nitritos no explante pulmonar (painel A, fig. 20).

No painel B da figura 20 podemos observar que, após $24 \mathrm{~h}$ de tratamento com estradiol $(280 \mu \mathrm{g} / \mathrm{kg}$, s.c.), o explante pulmonar gerou quantidades significantes de nitritos. Por outro lado, o explante de animais tratados previamente com progesterona $(200 \mu \mathrm{g} / \mathrm{kg}$, s.c.) não gerou nitritos após a I/R intestinal. 
Figura 20 - Efeito da OVx e dos hormônios sexuais femininos sobre a geração de nitritos em explante de pulmão de ratas após a I/R intestinal. A I/R intestinal foi induzida 7 dias após a remoção dos ovários $(\mathrm{OVx})$ e em ratas não $\mathrm{OVx}$. O grupo basal consistiu de animais não manipulados, e o grupo sham de animais falsamente operados. O tratamento hormonal ocorreu $24 \mathrm{~h}$ antes da indução da I/R intestinal. Os dados representam a média \pm EPM de 5 animais. No gráfico $\mathrm{A} * P<0,05 \mathrm{em}$ relação ao grupo basal, ${ }^{\phi} P<0,05$ em relação ao grupo não-OVx. No gráfico $\mathrm{B} * P<$ 0,05 em relação ao grupo Sham; ${ }^{\phi} P<0,05$ em relação ao grupo OVx.
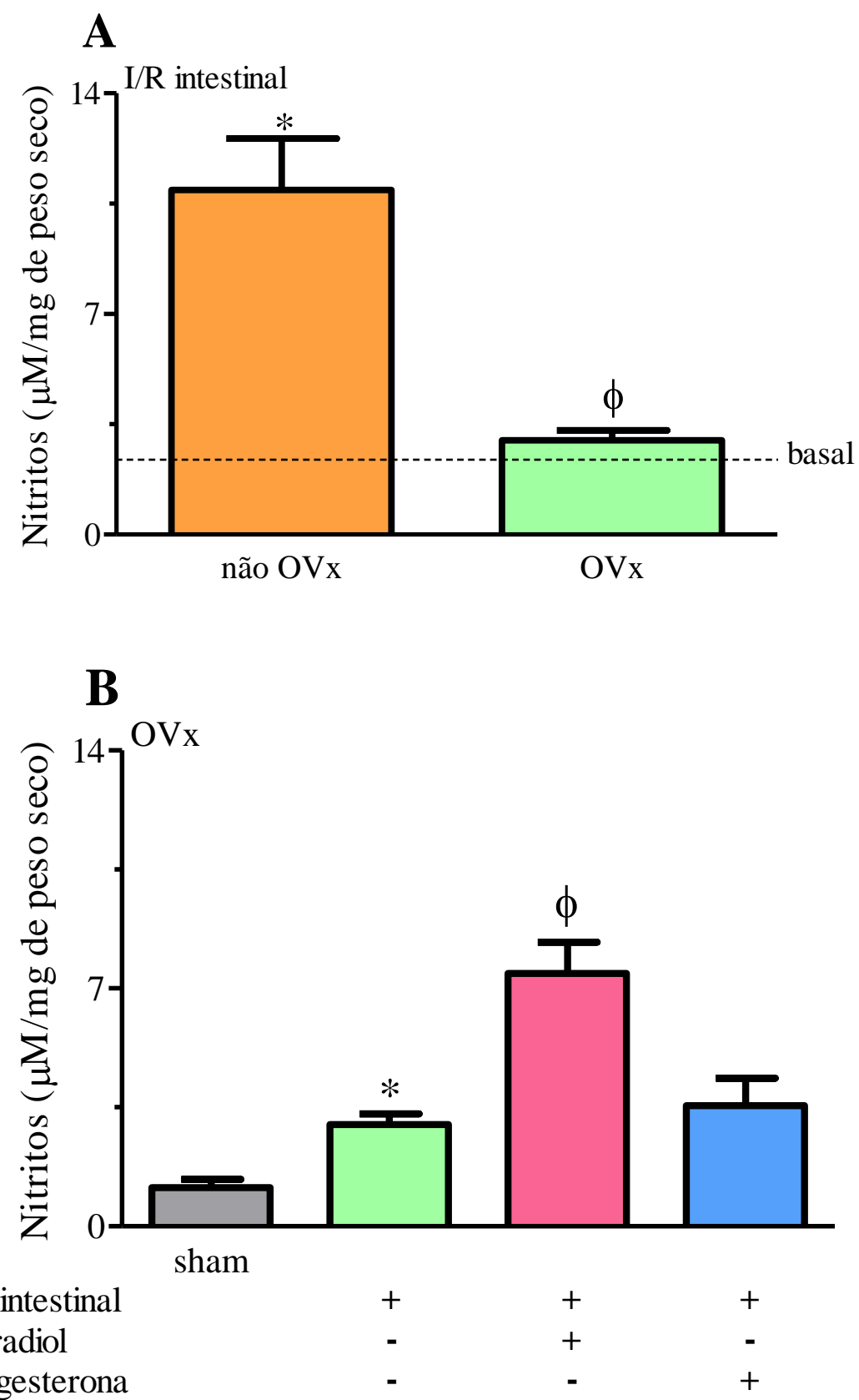


\subsection{Caracterização dos efeitos sistêmicos causados pela I/R intestinal}

\subsubsection{Contagem de leucócitos totais na medula óssea}

No contexto dos estudos sobre mobilização de células, foram obtidos dados sobre o número de células presentes na medula óssea. Os dados estão representados na figura $21 \mathrm{e}$ revelam que animais quando submetidos a $\mathrm{I} / \mathrm{R}$ intestinal com ovários intactos mostraram uma redução na quantidade de células na medula óssea, o mesmo não pode ser observado no grupo de animais OVx (painel A). Contudo, o tratamento com progesterona, mas não com estradiol, preveniu o aumento causado pela I/R intestinal nos animais $\mathrm{OVx}$, quando comparado com o grupo sham.

Figura 21 - Número de leucócitos totais na medula óssea em grupos de ratas ovariectomizadas $(\mathrm{OVx})$ ou não (não $\mathrm{OVx}$ ), submetidas a I/R intestinal ou não (basal). Há também animais OVx falsamente submetidos a I/R intestinal (sham). Os dados representam a média \pm EPM de 5-8 experimentos. No gráfico $\mathrm{A},{ }^{*} P<0,05$ em relação ao grupo basal; ${ }^{\phi} P<0,05$ em relação ao grupo I/R não-OVx. No gráfico $\mathrm{B},{ }^{*} P<0,05$ em relação ao grupo sham; ${ }^{\phi} P<0,05$ em relação ao grupo I/R OVx.
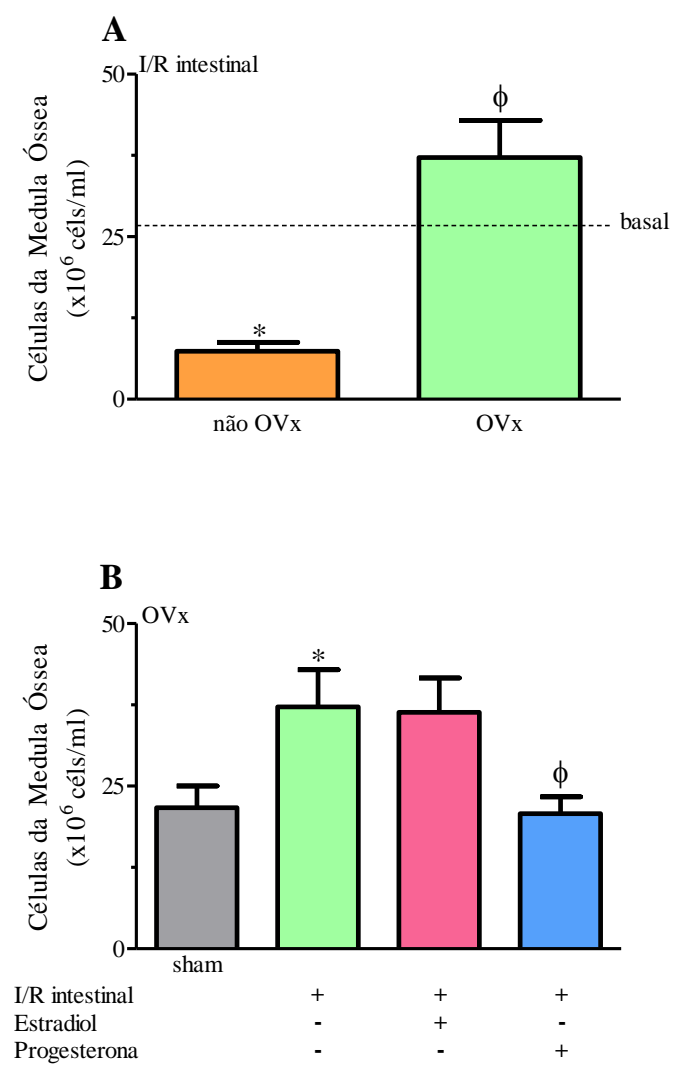


\subsubsection{Contagem total e diferencial dos leucócitos circulantes}

Com o intuito de compreender a mobilização de células causada pela I/R intestinal, quantificamos o número de leucócitos circulantes antes e após a indução da I/R intestinal. No painel A da figura 22, pode ser observado que o grupo de animais OVx apresentou elevação no número total de células circulantes após a indução da $\mathrm{I} / \mathrm{R}$ intestinal, o mesmo não foi notado no grupo de animais com ovários intactos. Este aumento observado nas ratas OVx foi prevenido tanto pelo tratamento dos animais com estradiol, como com a progesterona (painel B).

Figura 22 - Número de leucócitos totais circulantes em grupos de ratas ovariectomizadas (OVx) ou não (não $\mathrm{OVx}$ ), submetidas a $\mathrm{I} / \mathrm{R}$ intestinal ou não (basal). Há também animais OVx falsamente submetidos a I/R intestinal (sham). Os dados representam a média \pm EPM de 5-8 animais. ${ }^{*} P<0,05$ em relação ao respectivo grupo controle (antes da I/R intestinal). ${ }^{\Phi} P<0,05$ em relação ao grupo sham. ${ }^{\Delta} P<0,05$ em relação ao grupo I/R intestinal OVx.
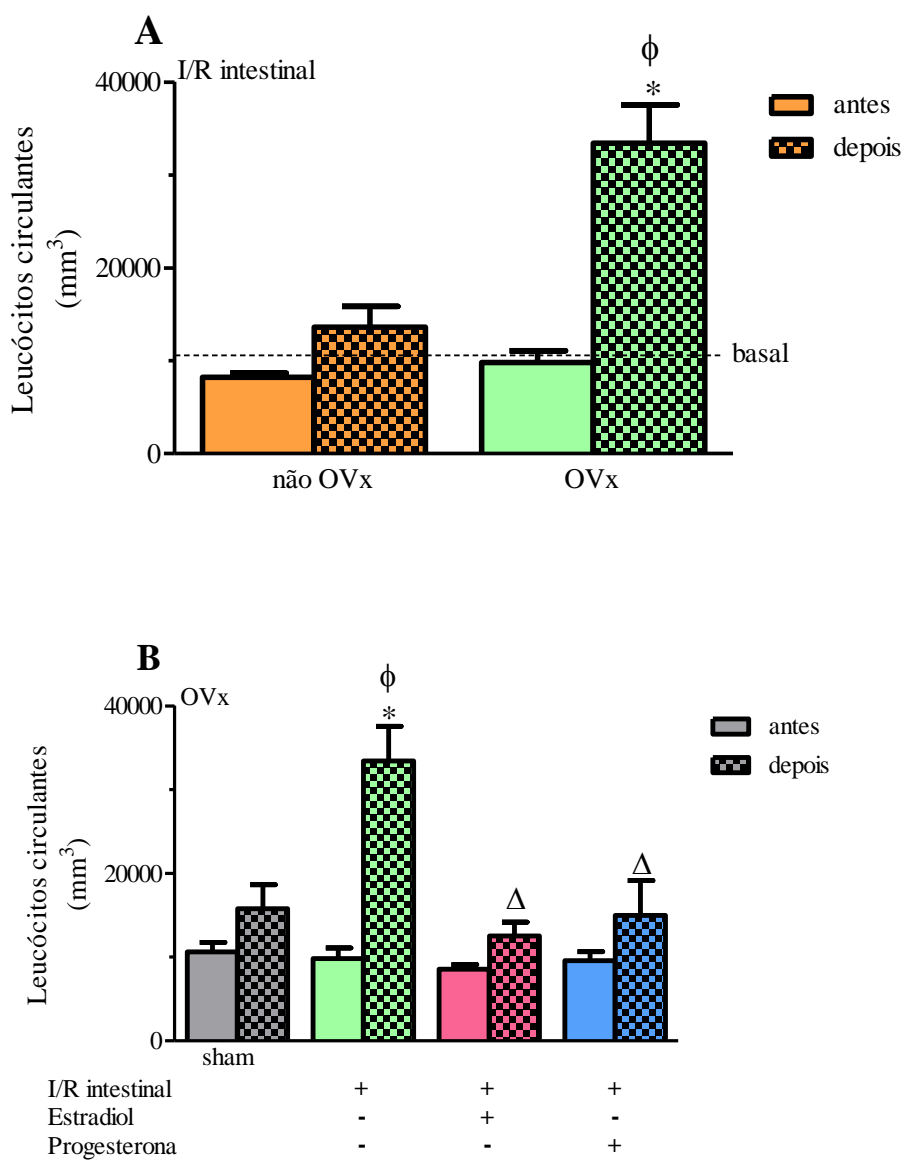
Ao analisarmos a contagem diferencial dos leucócitos circulantes, notamos aumento de mononucleares no grupo OVx após a indução da I/R intestinal. Este aumento foi prevenido pelo tratamento dos animais com estradiol ou progesterona $24 \mathrm{~h}$ antes da indução da I/R intestinal (Fig. 23, painel A).

Com relação ao aumento de neutrófilos apresentado pelo grupo OVx após a indução da $\mathrm{I} / \mathrm{R}$ intestinal em relação ao grupo não-OVx. O tratamento dos animais com estradiol $24 \mathrm{~h}$ antes da $\mathrm{I} / \mathrm{R}$ intestinal preveniu o aumento de neutrófilos em relação ao grupo OVx. $\mathrm{O}$ tratamento prévio com progesterona não preveniu o aumento de neutrófilos circulantes de maneira estatisticamente significativa ao se comparar com o grupo OVx (Fig. 23, painel B).

A contagem de eosinófilos circulantes não apresentou diferença significativa nos grupos ao compararmos o momento antes e após a indução da I/R intestinal. A remoção dos ovários também não alterou a quantificação dos eosinófilos. Por outro lado, o tratamento prévio com progesterona resultou em aumento da quantidade de eosinófilos circulantes após a I/R intestinal em relação ao grupo OVx (Fig. 23, painel C). 
Figura 23 - Número de mononucleares (A), neutrófilos (B) e eosinófilos (C) circulantes em grupos de ratas ovariectomizadas $(\mathrm{OVx})$ ou não (não $\mathrm{OVx}$ ), submetidas a $\mathrm{I} / \mathrm{R}$ intestinal ou não (basal). Há também animais $\mathrm{OVx}$ falsamente submetidos a I/R intestinal (sham). Os dados representam a média \pm EPM de 5-8 experimentos. ${ }^{*} P<0,05$ em relação ao respectivo grupo controle (antes da I/R intestinal). ${ }^{\Phi} P<0,05$ em relação ao grupo sham. ${ }^{\Delta} P<0,05$ em relação ao grupo I/R intestinal OVx.
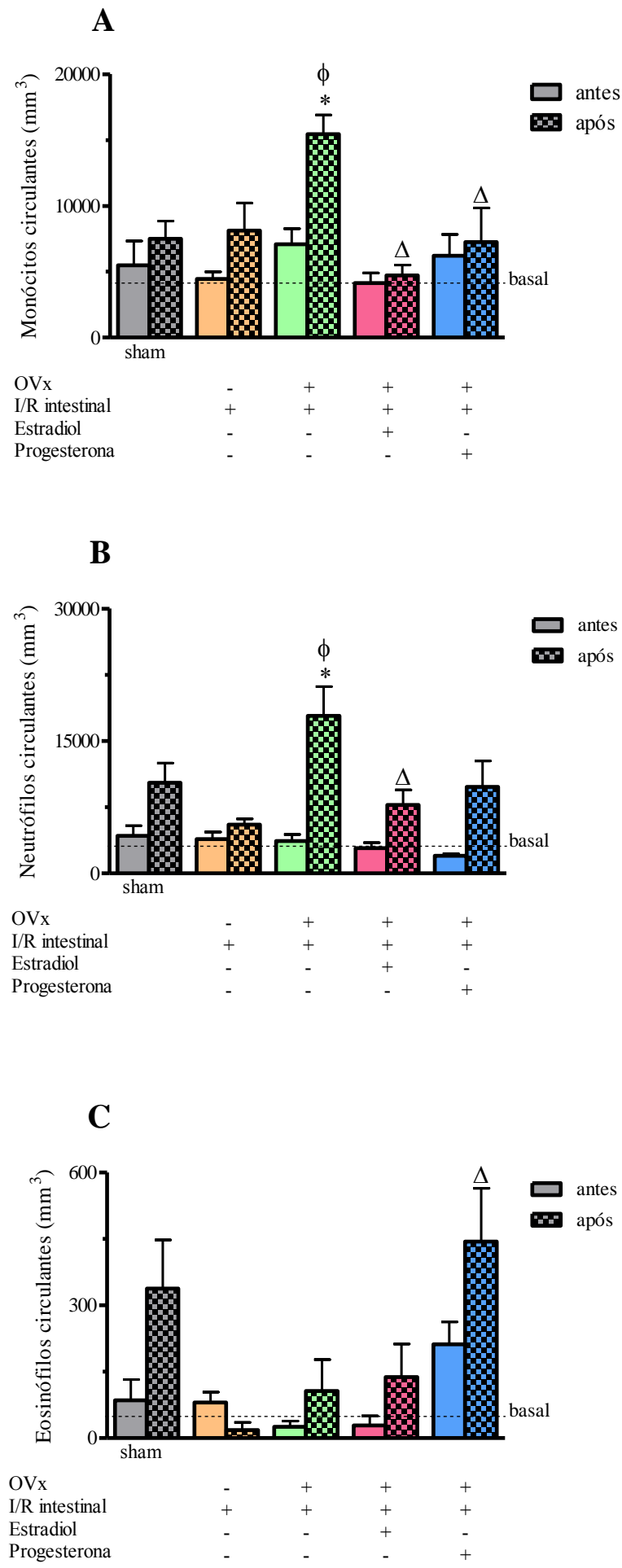


\subsubsection{Concentração sérica de TNF- $\alpha$}

A figura 24 (painel A) mostra que a I/R intestinal aumentou a concentração de TNF- $\alpha$ no soro em ratas com os ovários intactos (não-OVx). Ainda, a remoção dos ovários não alterou significativamente os valores de TNF- $\alpha$ quantificados. No painel B, observa-se que após a I/R intestinal os animais OVx apresentaram um aumento na quantificação sérica de TNF- $\alpha$ em relação ao grupo sham. Contudo, o tratamento dos animais com estradiol ou progesterona $24 \mathrm{~h}$ antes da indução da I/R intestinal não alterou a concentração de TNF- $\alpha$ em relação ao grupo Ovx.

Figura 24 - Efeito da OVx e dos hormônios sexuais femininos sobre os níveis de TNF- $\alpha$ no soro de ratas. As ratas OVx ou não foram submetidas ou não (Sham) à isquemia (45 min) e reperfusão intestinal ( 2 horas - I/R intestinal). Valores basais foram obtidos de ratas não manipuladas. Os dados representam a média $\pm E P M$ de 5 animais. No gráfico A, $* P<0,05$ em relação ao grupo basal; ${ }^{\phi} P<0,05$ em relação ao grupo I/R não-OVx. No gráfico $\mathrm{B},{ }^{*} P<0,05$ em relação ao grupo sham; ${ }^{\phi} P<0,05$ em relação ao grupo I/R OVx.

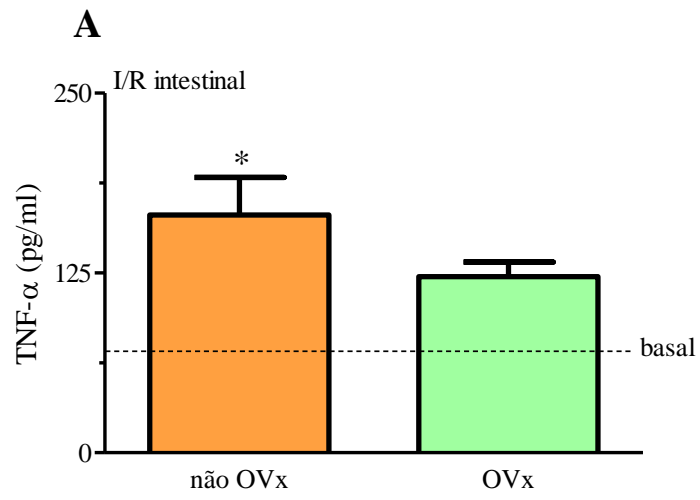

\section{B}

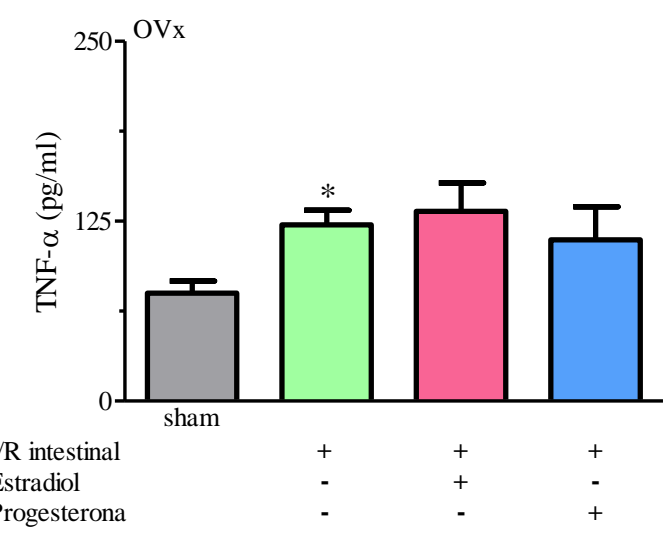




\subsubsection{Atividade da enzima lactato desidrogenase (LDH) no soro}

No painel A da figura 25 observamos que os níveis séricos de $\mathrm{LDH}$ diminuem quando os animais com ovários intactos (não-OVx) são submetidos à $\mathrm{I} / \mathrm{R}$ intestinal em relação ao grupo OVx. Quando os ovários são removidos $(\mathrm{OVx}) 7$ dias antes da indução da I/R intestinal, a concentração de LDH no soro aumenta em relação ao grupo não-OVx. Por outro lado, o tratamento prévio dos animais com estradiol ou progesterona não alterou a concentração de LDH no soro de animais submetidos à I/R intestinal (painel B).

Figura 25 - Efeito da OVx e dos hormônios sexuais femininos sobre os níveis de LDH no soro de ratas. As ratas OVx ou não foram submetidas ou não (Sham) à isquemia (45 min) e reperfusão intestinal ( 2 horas - I/R intestinal). Valores basais foram obtidos de ratas não manipuladas. Os dados representam a média \pm EPM de 5 animais. No gráfico A, $* P<0,05$ em relação ao grupo basal; ${ }^{\phi} P<0,05$ em relação ao grupo I/R não-OVx. No gráfico $\mathrm{B},{ }^{*} P<0,05$ em relação ao grupo sham; ${ }^{\phi} P<0,05$ em relação ao grupo I/R OVx.
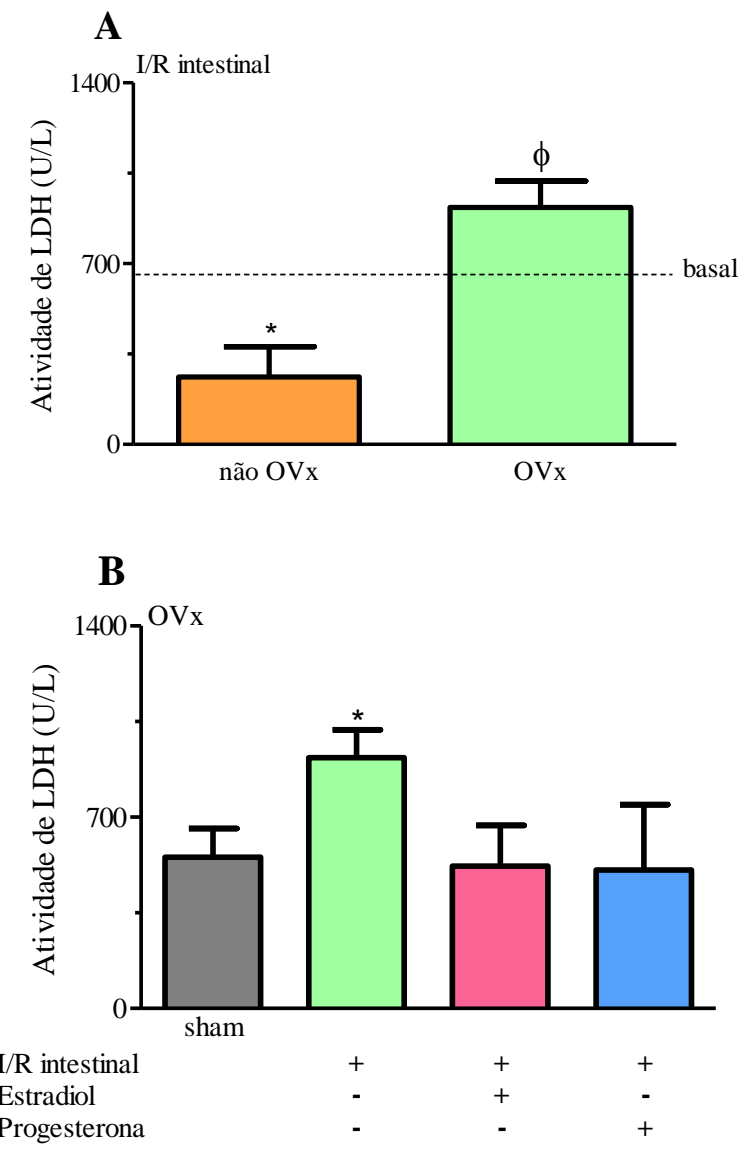


\subsubsection{Concentração de fosfatase alcalina no soro}

A figura 26 indica que a concentração de fosfatase alcalina aumenta significativamente no soro de animais do grupo OVx submetidos a I/R intestinal quando comparamos com o grupo não-OVx. Contudo, como indicado no painel B, o tratamento dos animais com estradiol ou progesterona preveniu o aumento da concentração de fosfatase alcalina no soro dos animais OVx após I/R intestinal.

Figura 26 - Efeito da OVx e dos hormônios sexuais femininos sobre os níveis de fosfatase alcalina no soro de ratas. As ratas OVx ou não foram submetidas ou não (Sham) à isquemia (45 $\mathrm{min}$ ) e reperfusão intestinal (2 horas - I/R intestinal). Valores basais foram obtidos de ratas não manipuladas. Os dados representam a média $\pm \mathrm{EPM}$ de 5 animais. No gráfico $\mathrm{A} * P<0,05$ em relação ao grupo não $\mathrm{OVx}$. No gráfico $\mathrm{B}$, . ${ }^{*} P$ $<0,05$ em relação ao grupo Sham; ${ }^{\phi} P<0,05$ em relação ao grupo OVx I/R.
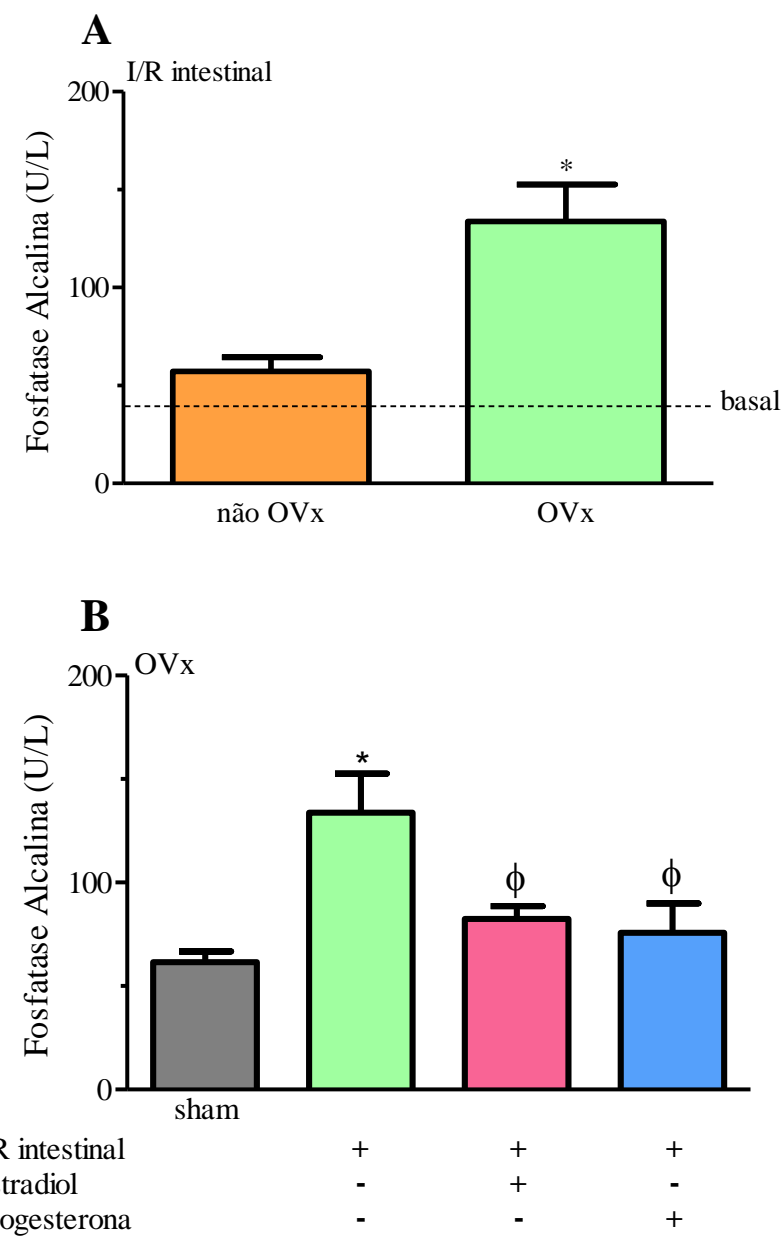


\subsubsection{Concentração de ácido úrico no soro}

No painel A da figura 27 observamos que a concentração de ácido úrico no soro aumentou significativamente no grupo de animais não-OVx, submetidos à $\mathrm{I} / \mathrm{R}$ intestinal quando comparados com o grupo basal. Por outro lado, a remoção dos ovários (OVx) não alterou a concentração de ácido úrico no soro após a I/R intestinal. Ainda, o tratamento dos animais com estradiol, mas não com progesterona, $24 \mathrm{~h}$ antes da indução da I/R intestinal diminui os níveis de ácido úrico em relação ao grupo OVx não tratado (painel B).

Figura 27 - Efeito da OVx e dos hormônios sexuais femininos sobre os níveis de ácido úrico no soro de ratas. As ratas OVx ou não foram submetidas ou não (Sham) à isquemia (45 min) e reperfusão intestinal ( 2 horas - I/R intestinal). Valores basais foram obtidos de ratas não manipuladas. Os dados representam a média \pm EPM de 5 animais. No gráfico A, $* P<0,05$ em relação ao grupo basal; ${ }^{\phi} P<0,05$ em relação ao grupo I/R não-OVx. No gráfico $\mathrm{B},{ }^{*} P<0,05$ em relação ao grupo sham; ${ }^{\phi} P<$ 0,05 em relação ao grupo I/R OVx.
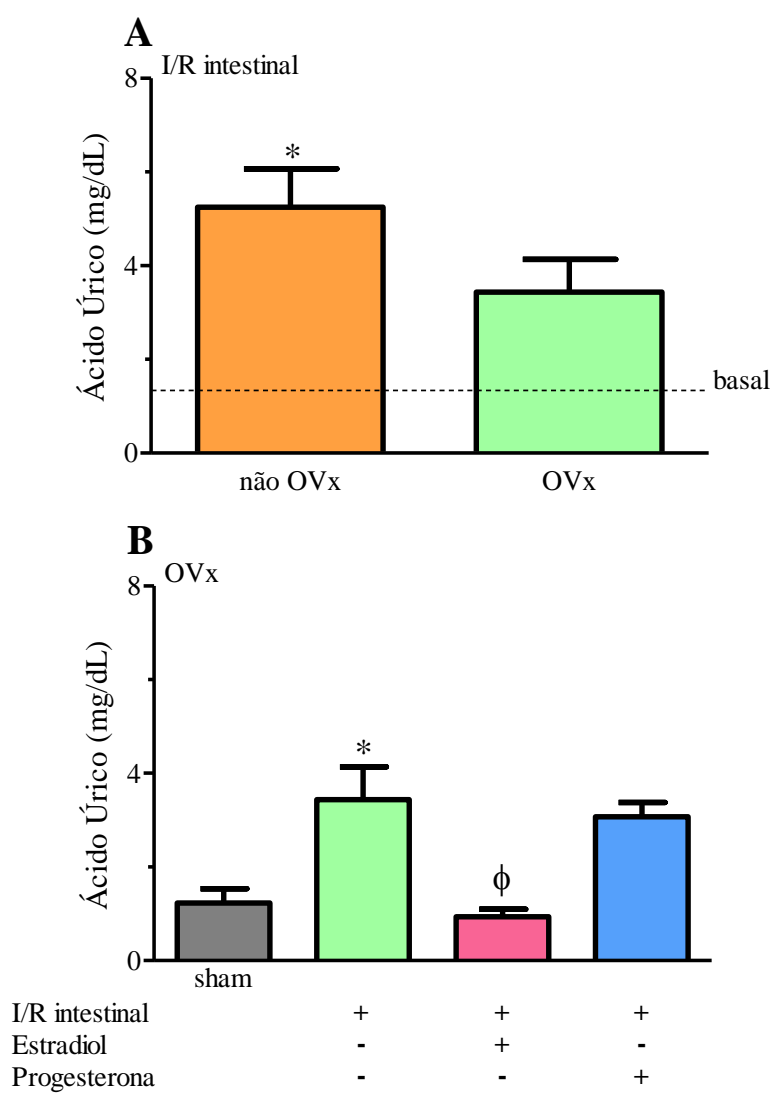


\subsubsection{Concentração de trifosfato de adenosina (ATP) no soro}

A figura 28 (painel A) representa os níveis de AMPc no soro e indica que sua concentração aumentou de forma significativa nos animais OVx após a I/R intestinal quando comparada com a obtida no grupo I/R intestinal com os ovários intactos (Não-OVx). No grupo de animais tratados com estradiol ou progesterona os níveis de AMPc não se alteram.

Figura 28 - Efeito da OVx e dos hormônios sexuais femininos sobre os níveis de AMPc no soro de ratas. As ratas OVx foram submetidas ou não (Sham) à isquemia (45 min) e reperfusão intestinal ( 2 horas - I/R intestinal). Valores basais foram obtidos de ratas não manipuladas. Os dados representam a média \pm EPM de 5 animais. No gráfico $\mathrm{A}$ $* P<0,05$ em relação ao grupo não $\mathrm{OVx}$.
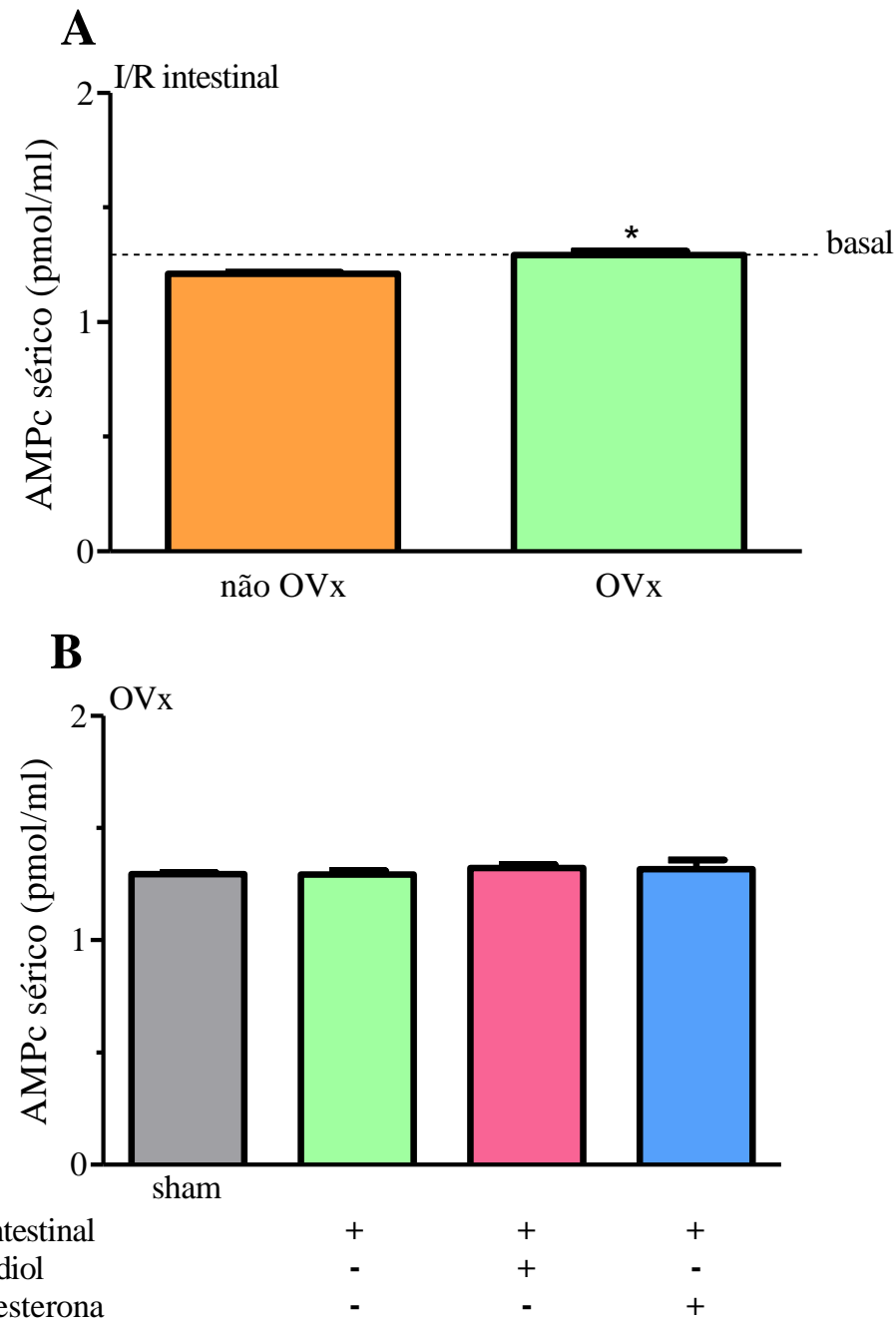

$\mathrm{I} / \mathrm{R}$ intestinal

Estradiol

Progesterona 


\subsection{Caracterização da lesão local causada pela I/R intestinal}

\subsubsection{Atividade de enzima mieloperoxidase (MPO)}

A indução da $\mathrm{I} / \mathrm{R}$ intestinal causou infiltração de neutrófilos para o intestino dos animais como observado pelo aumento da atividade da enzima MPO. Os resultados obtidos no intestino estão representados na figura 29 e revelam que após 45 minutos de isquemia e 2 horas de reperfusão intestinal os animais $\mathrm{OVx}$ apresentaram elevação significativa da atividade de MPO (painel A). Em contrapartida, quando analisamos o painel B, notamos que os animais do grupo OVx e submetidos a I/R intestinal apresentaram maior atividade de MPO que o intestino dos animais do grupo Sham (falsamente operado).

$\mathrm{O}$ tratamento dos animais com estrógeno ou progesterona $24 \mathrm{~h}$ antes da I/R intestinal determinou aumento significativo da atividade de MPO intestinal em relação à atividade observada no grupo de animais do grupo I/R OVx não tratados. 
Figura 29 - Atividade da enzima MPO em homogenatos de intestino. As ratas OVx foram submetidas ou não (Sham) à isquemia (45 min) e reperfusão intestinal (2 horas - I/R intestinal). Valores basais foram obtidos de ratas não manipuladas. Os dados representam a média \pm EPM de 5 animais. No gráfico $\mathrm{A},{ }^{*} P<0,05$ em relação ao grupo basal; ${ }^{\phi} P<0,05$ em relação ao grupo I/R não-OVx. No gráfico $\mathrm{B},{ }^{*} P<0,05$ em relação ao grupo sham; ${ }^{\phi} P<0,05$ em relação ao grupo I/R OVx.

\section{Intestino}
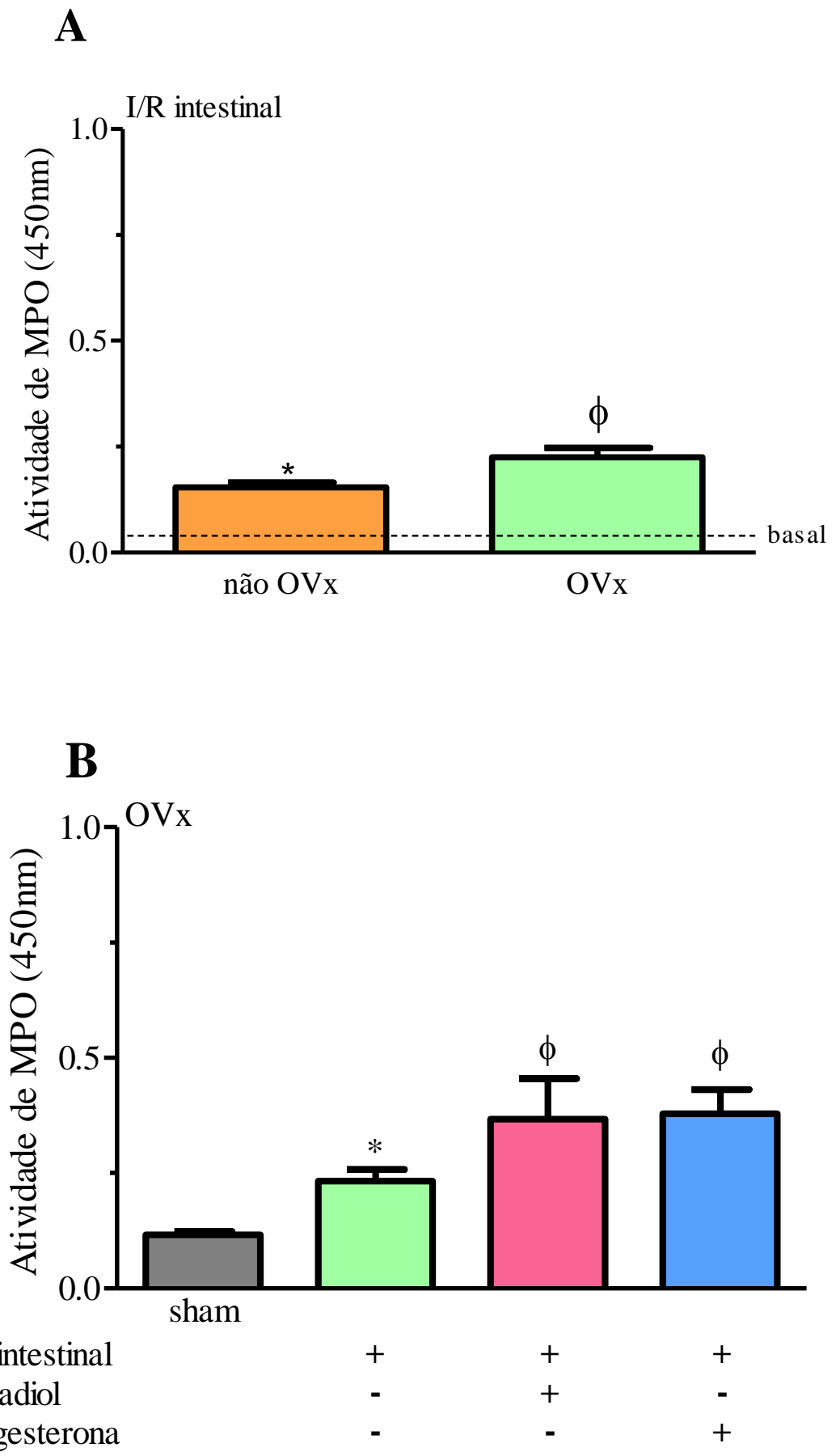


\subsubsection{Extravasamento do corante Azul de Evans (AE) no intestino}

A permeabilidade vascular em fragmentos do duodeno foi avaliada indiretamente por meio da técnica do extravasamento do corante AE. Os dados estão representados na figura 30 e indicam que a $/ / R$ intestinal causou aumento significativo do extravasamento do corante $\mathrm{AE}$ nos animais do grupo não-OVx quando comparado com o observado nos animais basais (Painel A). Contudo, a remoção dos ovários (OVx) exacerbou o extravasamento do corante $\mathrm{AE}$ no intestino quando comparado com o grupo não-OVx.

Por outro lado, o tratamento dos animais com estradiol ou progesterona $24 \mathrm{~h}$ antes da indução da $\mathrm{I} / \mathrm{R}$ intestinal, preveniu o aumento do extravasamento do corante AE de maneira que seus valores permaneceram próximos aos obtidos no grupo sham (painel B).

Figura 30 - Efeito da OVx sobre o extravasamento do corante AE intestinal. As ratas OVx ou não foram submetidas ou não (Sham) à isquemia (45 min) e reperfusão intestinal (2 horas - I/R intestinal). Valores basais foram obtidos de ratas não manipuladas. Os dados representam a média $\pm \mathrm{EPM}$ de 5 animais. No gráfico $\mathrm{A}, * P<0,05 \mathrm{em}$ relação ao grupo basal; ${ }^{\phi} P<0,05$ em relação ao grupo I/R não-OVx. No gráfico $\mathrm{B}$, ${ }^{*} P<0,05$ em relação ao grupo sham; ${ }^{\phi} P<0,05$ em relação ao grupo I/R OVx.
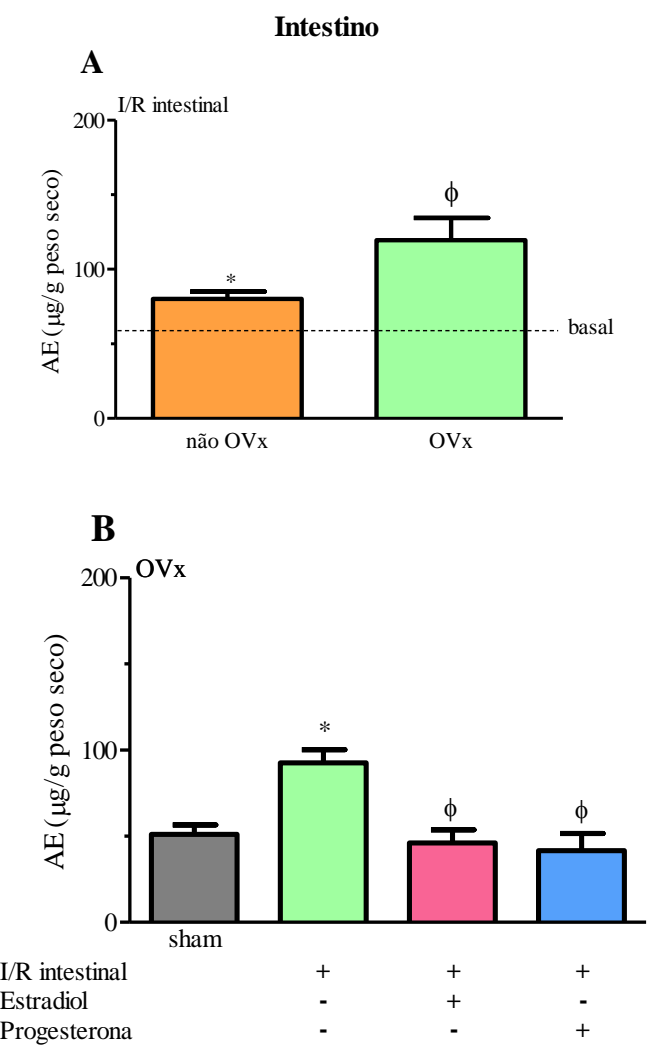


\section{DISCUSSÃO}

Os dados representados neste estudo referem-se à investigação do papel dos hormônios sexuais femininos na inflamação pulmonar causada pela $\mathrm{I} / \mathrm{R}$ intestinal experimental. Para tanto, utilizamos ratas ovariectomizadas $(\mathrm{OVx})$ e submetidas à obstrução da artéria mesentérica superior por $45 \mathrm{~min}$. Decorridas $2 \mathrm{~h}$ de reperfusão intestinal os experimentos foram conduzidos. Para efeitos de confirmação da eficiência da remoção dos ovários e do tratamento dos animais OVx com estradiol e progesterona, quantificamos as concentrações séricas de estradiol e progesterona.

A remoção dos ovários determinou redução significativa dos níveis de ambos hormônios. Adicionalmente, o tratamento dos animais OVx com $280 \mu \mathrm{g} / \mathrm{kg}$ de estradiol foi efetivo em elevar a concentração circulante deste esteroide. Por outro lado, o tratamento dos animais com $200 \mu \mathrm{g} / \mathrm{kg}$ de progesterona não foi eficaz em elevar significativamente a concentração de progesterona. É possível que tenham ocorrido falhas na metodologia de detecção da progesterona ou que a dosagem administrada não seja suficiente para elevar a concentração sérica desejada deste hormônio.

Nossos dados referem-se à caracterização das repercussões pulmonares causadas pela I/R intestinal em ratas 7 dias após a remoção dos ovários (OVx). A I/R intestinal acarretou aumento da permeabilidade vascular no pulmão das ratas OVx em relação aquele quantificado no grupo de ratas Não-OVx, bem como em relação ao grupo OVx que foi manipulado, mas não submetido à I/R intestinal (Sham). Ainda, é notável que ratas com ovários intactos (NãoOVx) uma vez submetidas à $\mathrm{I} / \mathrm{R}$ intestinal não desenvolveram significativo aumento de permeabilidade vascular no pulmão. No que se refere à diferença na resposta inflamatória de fêmeas com e sem hormônios nossos dados estão de acordo com a literatura (ANANTHAKRISHNAN et al., 2005; CARUSO et al., 2001; CHEN et al., 2008; CHILDS et al., 2010; DOUCET et al., 2010).

Neste estudo nós observamos que ratas OVx quando submetidas a I/R intestinal desenvolvem inflamação pulmonar. Contudo, ratas mantidas com ovários intactos, o mesmo não foi observado. É notável que existam estudos revelando efeito protetor do estradiol sobre o tecido pulmonar em modelo de choque hemorrágico em ratas OVx (DOUCET et al., 2010; HSU et al., 2013; KAN et al., 2008)

A resposta inflamatória aguda no pulmão após a $\mathrm{I} / \mathrm{R}$ intestinal é caracterizada por aumento da permeabilidade vascular e do extravasamento plasmático e recrutamento celular, notadamente de neutrófilos, para o sítio inflamatório (CERQUEIRA; HUSSNI; YOSHIDA, 
2005). A interação de neutrófilos com a parede vascular modifica a atividade funcional das células endoteliais. Vale lembrar que em eventos isquêmicos, tais como o utilizado neste estudo, causam aumento de aderência de neutrófilos ao endotélio pulmonar, o que pode acarretar em lesão microvascular pulmonar, a qual é um dos eventos críticos observados na I/R intestinal (CARDEN; YOUNG; GRANGER, 1993). Ainda, na vigência de uma inflamação pulmonar induzida pela I/R intestinal, neutrófilos são recrutados para o local da injúria e atravessam o endotélio das vênulas pós-capilares atingindo o sítio inflamatório (TAKAYAMA et al., 2001; TURNAGE; GUICE; OLDHAM, 1995). Uma vez no tecido, os neutrófilos são estimulados por citocinas locais ou patógenos presentes. Nessas condições passam a liberar um amplo espectro de mediadores inflamatórios e de enzimas contidas em seus grânulos (NATHAN, 2006; SALAMA; PUSEY, 2009).

No sentido de avaliar a migração neutrofílica para o tecido pulmonar, utilizamos a quantificação da atividade da enzima mieloperoxidase no pulmão dos animais como método indireto de determinar a presença de neutrófilos no pulmão. Paralelamente, quantificamos as células presentes no tecido pulmonar após a sua digestão com colagenase.

A I/R intestinal em animais OVx, causou significativo aumento da atividade pulmonar de MPO quando comparado com a atividade de MPO do grupo de ratas I/R intestinal mas com os ovários intactos (Não-OVx). Assim, os hormônios sexuais femininos de alguma forma, exercem efeito protetor destas repercussões da I/R intestinal. Basicamente, estes dados sugerem que os hormônios ovarianos, possivelmente estradiol ou progesterona, exerçam papel modulador do trânsito de neutrófilos e de alterações vasculares envolvidas com o aumento de permeabilidade vascular pulmonar. É interessante notar que estudos conduzidos por Ananthakrishnan et al. (2005) os hormônios sexuais femininos mostram efeito similar em modelo de trauma seguido por choque hemorrágico.

Considerando a proteção que as ratas Não-OVx aparentemente apresentaram no que tange à inflamação pulmonar causada pela I/R intestinal e a observação de que estudos indicam papel protetor dos hormônios sexuais femininos em modelo de choque hemorrágico em suas consequências pulmonares e sistêmicas (CHAUDRY et al., 2003; RAJU; CHAUDRY, 2008; YU; CHAUDRY, 2009), decidimos avaliar o efeito do tratamento das ratas OVx com estradiol ou progesterona previamente a indução da I/R intestinal.

Os dados obtidos permitiram sugerir que o perfil de modulação dos hormônios sexuais femininos (proteção ou exacerbação) da resposta inflamatória depende do parâmetro avaliado. Neste sentido, o tratamento com estradiol ou progesterona não protegeu contra o aumento de permeabilidade vascular pulmonar. Estes dados estão de acordo com os de Hamidi et al. 
(2011) mostrando que o estradiol protege o pulmão do edema causado pelo aumento de permeabilidade em modelo de inflamação aguda causada por paraquat, um herbicida.

Considerando o espectro de resultados obtidos no presente estudo sugerimos que o aumento da permeabilidade vascular pulmonar é modulado pelos hormônios sexuais femininos por meio da ativação das moléculas de adesão, síntese de mediadores inflamatórios como o TNF e o VEGF e síntese de óxido nítrico.

Uma vez que nossos dados comprovam a ação do óxido nítrico na permeabilidade vascular (BREITHAUPT-FALOPPA et al., 2009), quantificamos nitritos em sobrenadante de explante pulmonar $(24 \mathrm{~h}$ ) de ratas após a I/R intestinal. Nossos dados revelaram que o pulmão de animais do grupo Não-OVx submetidos à I/R intestinal apresentaram aumento significativo na quantidade de nitritos comparação o observado no pulmão dos animais do grupo $\mathrm{OVx}$ submetidos à I/R intestinal e ao grupo de animais não manipulados (Basal). Ainda, nossos dados mostraram que o hormônio responsável por este aumento é o estradiol, uma vez que somente o tratamento com estradiol exerceu este efeito. É possível que o estradiol exerça efeito protetor por meio do aumento da expressão da eNOS (óxido nítrico sintase). Neste sentido sugerimos que variações na quantidade de estradiol circulante pode influenciar a expressão de eNOS e desta forma interferir na quantidade de NO disponível. Dados recentes gerados em nosso laboratório comprovam que o tratamento de ratas OVx com estradiol reduz a inflamação pulmonar após a I/R intestinal. De acordo com os nossos estudos esta modulação ocorre por meio da expressão de eNOS no tecido pulmonar.

Com o intuito de confirmar e elucidar os dados encontrados na quantificação indireta da presença de neutrófilos no tecido pulmonar (atividade de MPO), o pulmão dos animais foi digerido com colagenase. A partir das amostras digeridas, e quantificamos as células presentes neste tecido. Nossos dados confirmaram a presença exacerbada de neutrófilos no tecido pulmonar de ratas $\mathrm{OVx}$ submetidas à $\mathrm{I} / \mathrm{R}$ intestinal comparadas aos outros grupos analisados. E mais este aumento foi prevenido pelo tratamento dos animais com os hormônios sexuais. Um dado interessante desta análise foi a observação do aumento do número de eosinófilos nos animais OVx tratados previamente à indução de I/R intestinal com progesterona.

É interessante notar que o estradiol e a progesterona foram administrados para os animais separadamente. Desta forma pode ser que um desequilíbrio entre as concentrações de estrógeno/progesterona exerça algum tipo de efeito pró-inflamatório na I/R intestinal. Além disto, é notável que a administração exógena dos hormônios acarretou no aumento da concentração circulante de estradiol e de progesterona a qual difere daquela encontrada 
fisiologicamente. Diante da remoção dos ovários a quantidade de hormônio encontrada no soro dos animais reduziu-se pela metade. A concentração de estradiol utilizada para o tratamento dos animais foi capaz de triplicar a quantidade de estradiol nos animais OVx em comparação com a encontrada nos animais com ovários intactos. Todavia, a administração de progesterona apresentou valores semelhantes ao grupo OVx. Disso resulta a percepção de que é possível haver uma relação ideal entre os níveis circulantes de estradiol/progesterona que possam exercer efeito protetor no organismo com os ovários intactos.

Levando em consideração os dados citados até o presente momento, podemos afirmar que estão em linha com os dados da literatura sugerindo que fêmeas com ovários intatos (portanto com concentrações fisiológicas dos hormônios sexuais) são menos sensíveis à injúria pulmonar devido, em parte, a uma resistência do tecido intestinal a desenvolver a lesão por causa da isquemia (ADAMS et al., 2000). De acordo com estes autores no modelo de inflamação pulmonar causada pelo trauma seguido de choque hemorrágico, as fêmeas apresentam menor lesão comparadas aos machos e isto reduz a inflamação pulmonar. Neste mesmo estudo os autores também concluíram que a lesão pulmonar é causada pelo choque hemorrágico e a origem dos problemas pulmonares é lesão intestinal. Ainda Adams et al. (2000) consideram que fatores tóxicos gerados no intestino podem ser carreados pela linfa. Outro ponto importante acerca do papel dos hormônios sexuais no recrutamento celular é que o estradiol estimula a imunidade celular e humoral (GROSSMAN, 1989) e interaja com os neutrófilos, reduzindo sua quimiotaxia e ativação (MIYAGI et al., 1992).

Tomados em conjunto os dados obtidos neste estudo corroboram com a visão de que os hormônios sexuais femininos tenham efeito protetor no modelo de $\mathrm{I} / \mathrm{R}$ intestinal, notadamente sobre e o aumento de permeabilidade vascular e o recrutamento de neutrófilos para o pulmão. É interessante ressaltar uma vez mais que enquanto o tratamento com estradiol preveniu a atividade de MPO no pulmão o mesmo não foi não foi observado quando investigamos a permeabilidade vascular. Assim, é interessante mencionar que estes achados dizem respeito ao período de isquemia (45 min) e reperfusão intestinal ( 2 h) estabelecidos em nosso modelo. Se tempos maiores de isquemia ou de reperfusão intestinal podem modificar o padrão de modulação dos hormônios sexuais femininos sobre a permeabilidade microvascular ou do recrutamento de neutrófilos nossos estudos não permitem avaliar.

Os neutrófilos representam talvez a primeira linha de defesa do organismo frente a estímulos lesivos. Estas fagócitos são de extrema importância para as repercussões inflamatórias observadas no modelo de inflamação pulmonar causada pela I/R intestinal. O aumento de neutrófilos no pulmão ocorre através dos capilares (ZHOU; DAI; HUANG, 
2012). Como conhecido esta migração inclui o rolar destas células ao longo do endotélio microvascular, sua aderência ao endotélio e a migração transendotelial para o tecido pulmonar. Após a ligação às células endoteliais, os neutrófilos tornam-se ativados e liberam diversos mediadores inflamatórios, que estão envolvidos com a indução do aumento de permeabilidade vascular. Este processo é iniciado e mantido por interações dos leucócitos circulantes e por interações dos neutrófilos com o endotélio por meio do aumento da expressão de moléculas de adesão específicas (BOLDT et al., 1995).

As células endoteliais possuem funções metabólicas e sintéticas que influenciam outras células, como os linfócitos. As ligações entre as células endoteliais e os linfócitos servem como transporte e barreira entre o sangue e os tecidos e vice-versa (GALLEY; WEBSTER, 2004). Na junção intracelular a transmigração do leucócito aderido ao endotélio é regulada pela PECAM-1 (DELISSER; BALDWIN; ALBEDA, 1997). Esta molécula de adesão é da família das IgGs (NEWMAN et al., 1990) e exerce papel importante na passagem de neutrófilos e monócitos através das células endoteliais para o tecido (MULLER et al., 1993). Outra molécula de adesão expressa por células endoteliais e algumas subpopulações de células da medula óssea durante a resposta inflamatória é a VCAM (ELICES et al., 199089; OSBORN et al., 1989).

Uma das moléculas mais importantes para a adesão de neutrófilos ao endotélio vascular e para sua migração e interação com o epitélio pulmonar é a ICAM-1 (LIN et al., 2007). Em condições fisiológicas, a ICAM-1 tem expressão basal nas células endoteliais e epiteliais (ALBELDA et al., 1994) e constitutiva na superfície de células alveolares (INOUE et al., 1996). Além disto, a ICAM-1 também exerce papel fundamental na resposta inflamatória (GOLIAS et al., 2007; ROLAND et al., 2007). Com isto, é interessante a percepção de que a redução da expressão de ICAM-1 no epitélio pulmonar possa ser considerada como um novo enfoque terapêutico pra o tratamento de doenças respiratórias (YEN et al., 2013).

Com base na importância destas moléculas de adesão na migração dos neutrófilos, investigamos o papel dos hormônios sexuais femininos na migração de células para o tecido pulmonar por meio da análise da expressão das moléculas de adesão. Para tanto, avaliamos a expressão de PECAM-1, ICAM-1, e VCAM no endotélio vascular pulmonar dos grupos de animais estudados.

Nossos dados revelaram que a expressão de PECAM-1 se encontra reduzida nos animais OVx submetidos à $\mathrm{I} / \mathrm{R}$ intestinal. Dados da literatura mostram que a redução da expressão de PECAM-1 no pulmão de coelhos expostos ao paraquat, um herbicida, está 
relacionada ao aumento da fibrose tecidual (GAO et al., 2011). Ainda, no leito mesentérico de ratos, o estímulo com inibidor da NO (LNAME) causou acúmulo de neutrófilos, mas não houve aumento de expressão de PECAM-1 (SCALIA; LEFER, 1998). Portanto, no conjunto nossos dados aparentemente estão em linha com aqueles da literatura os a quais evidenciam que a expressão reduzida de PECAM-1 está relacionada com uma maior inflamação pulmonar. De interesse é que em nossos estudos os hormônios sexuais femininos podem participar desse mecanismo. Ainda, nossos dados revelaram que o tratamento prévio dos animais OVx com estradiol ou progesterona aumentou a expressão de PECAM-1 no endotélio vascular pulmonar de animais submetidos à $\mathrm{I} / \mathrm{R}$ intestinal. Por outro lado, a remoção dos ovários não interferiu com a expressão de ICAM-1 e VCAM nos vasos pulmonares após a I/R intestinal. Contudo, a indução da I/R intestinal no grupo Não-OVx aumentou a expressão de ICAM-1 em comparação ao grupo basal. Agressões ao tecido pulmonar, como por exemplo as que ocorrem por causa de ventilação mecânica, aumentam a expressão de ICAM-1 (AMADORODRÍGUEZ et al., 2013). Estudos revelam que células epiteliais pulmonares humanas aumentam a expressão de ICAM-1 após o tratamento com TNF- $\alpha$ (YEN et al., 2013). É interessante notar que em nossos estudos detectamos esta citocina em concentrações elevadas no soro de animais com ovários intactos submetidos à $\mathrm{I} / \mathrm{R}$ intestinal. De maneira a estabelecer conexão entre os nossos resultados, consideramos razoável que o TNF- $\alpha$ possa induzir aumento da expressão de ICAM-1 no tecido pulmonar dos animais submetidos a I/R intestinal. Entre os potenciais candidatos a mediar este aumento a NOX (enzima produtora de espécies reativas de oxigênio), através da IL-1 $\beta$, e o AP-1, através do TNF- $\alpha$ (CHI et al., 2012; LIANG et al., 2011; YEN et al., 2013), poderiam ser candidatos potenciais.

Animais submetidos à lesão pulmonar aguda por estímulo com ácido oleico ou LPS, apresentam aumento da expressão de VCAM (WU et al., 2012; LIU et al., 2013). A expressão de VCAM também se encontra aumentada no pulmão de animais submetidos ao trauma seguido por choque hemorrágico (PATI et al., 2011). Apesar dos dados literários evidenciarem que diante de um estímulo inflamatório há um aumento na expressão de VCAM no tecido pulmonar, nossos dados mostraram que nem a remoção dos ovários ou a I/R intestinal foram capazes de aumentar a expressão desta molécula, nos tempos estudados. Eventualmente neste modelo, esta molécula pode participar de fases mais tardias da inflamação pulmonar, as quais não foram alvo do nosso estudo.

Apesar da remoção dos ovários não ter interferido na expressão de ICAM-1, o tratamento prévio dos animais OVx com estradiol ou progesterona resultou na redução da expressão de ICAM-1 no endotélio vascular pulmonar. Contudo, com relação à VCAM o 
tratamento prévio dos animais OVx com progesterona teve o efeito oposto, isto é aumentou sua expressão. Esta molécula não sofreu alteração diante do tratamento prévio com estradiol. Nossos dados mostram que, possivelmente, nossas concentrações administradas de estradiol e progesterona interferiram na expressão destas moléculas diferenciaram das concentrações basais.

Estudo avaliando a expressão de ICAM-1 e VCAM em células endoteliais ilíacas humanas revelou que o tratamento prévio com estradiol ou progesterona reduziu os níveis de IL-1 $\beta$ o que levou a uma redução, não estatística, destas moléculas. Contudo, o tratamento com estradiol e progesterona reduziu a expressão dessas moléculas (PIERCY et al., 2002). Diante disto, sugerimos a importância, não somente do estradiol, como importante modulador da expressão de moléculas de adesão no endotélio vascular pulmonar. Assim, em condições onde ocorra redução dos hormônios sexuais, pode haver o recrutamento de neutrófilos para o pulmão e consequentemente, a inflamação pulmonar aguda como observada em nosso modelo de I/R intestinal nos animais OVx.

Alguns estudos indicam que a progesterona aumenta a expressão de VCAM no endotélio vascular (FU et al., 2012; OTSUKI et al., 2001; WANG et al., 2011). Estes dados vão de encontro ao que encontramos. De fato, em nosso modelo, a expressão de VCAM no endotélio vascular pulmonar encontra-se aumentada nos animais tratados com progesterona. Isto nos parece interessante visto que pode sugerir que a migração de leucócitos para o pulmão através da ativação de VCAM é modulada pela progesterona.

Neste trabalho também investigamos a expressão do receptor $\mathrm{P} 2 \mathrm{X}_{7}$ no endotélio vascular pulmonar. Este receptor purinérgico (NORTH, 2012) possui uma alta afinidade pelo ATP. Sabe-se que durante o processo de isquemia as células por consequência da hipóxia liberam ATP. Este, ao se ligar ao receptor purinérgico, inicia uma resposta inflamatória resultando em dano tecidual (MCDONALD et al., 2010). Além disto, a ativação destes receptores pode induzir ações, tais como agregação de plaquetas, apoptose, migração celular e liberação de citocinas (BURNSTOCK, 2002; HECHLER et al., 2003). Estudo envolvendo camundongos, foi observado que células epiteliais alveolares sob estresse mecânico liberam ATP. Este pode ativar o P2X $X_{7}$ o qual medeia o aumento da secreção de surfactante (MISHRA et al., 2011). Baseados nestas informações e associando a liberação de ATP com a indução de migração celular e liberação de citocinas, investigamos sua expressão no endotélio vascular pulmonar dos animais OVx submetidos a I/R intestinal.

É importante destacar que dados da literatura mostram a presença deste receptor no endotélio vascular de muitos tecidos tais como coração, pulmão e intestino. Estes dados se 
associam a estudos envolvendo inflamação tecidual (CHIAO et al., 2008; NOWAKMACHEN et al., 2013; SOUZA et al., 2012; TUTTOLOMONDO et al., 2009). Este receptor também é encontrado em células do sistema imune, plaquetas e macrófagos (DI et al., 2011). Ainda, existem dados indicando que os receptores $\mathrm{P} 2 \mathrm{X}_{7}$, quando ativados induzem a liberação de IL-1 $\beta$ por células da microglia estimuladas por endotoxina bacteriana (FERRARI et al., 1997). Estudos conduzidos posteriormente por Riteau et al. (2010) concluíram que o ATP liberado pelas células epiteliais de pulmão durante injuria se acopla a receptores $\mathrm{P} 2 \mathrm{X}_{7}$. Nessas condições deflagra uma cascata de eventos culminando na ativação de células presentes no pulmão. Ainda, existem dados indicando que por meio de efeitos não-genômicos (via rápida) o estradiol modula a atividade dos receptores $\mathrm{P} 2 \mathrm{X}_{7}$. Assim, sugere-se que o estradiol altere propriedades funcionais tanto de monócitos e macrófagos, quanto do endotélio vascular pulmonar.

Em nossos estudos, notamos que a I/R intestinal aumentou a expressão deste receptor ao compararmos com o grupo basal. Por outro lado, a remoção dos ovários preveniu este aumento após a I/R intestinal. O que nos indicou que a remoção dos ovários preveniu o aumento da expressão dos receptores $\mathrm{P} \mathrm{X}_{7}$ no endotélio vascular pulmonar após a $\mathrm{I} / \mathrm{R}$ intestinal. É interessante notar que tal expressão retoma índices elevados após o tratamento dos animais OVx com progesterona. Dados da literatura mostram que a expressão do $\mathrm{P} 2 \mathrm{X}_{7}$ em animais submetidos à I/R cerebral se encontra reduzida no hipocampo (LI et al., 2012). Diante do exposto, aparentemente nossos dados sugerem que a expressão dos receptores $\mathrm{P} 2 \mathrm{X}_{7}$ no pulmão, após a I/R intestinal, pode influenciar na geração de citocinas, sendo regulada positivamente pela progesterona.

Evidências experimentais mostram a participação dos hormônios sexuais femininos no controle das repercussões causadas pelo trauma seguido de choque hemorrágico (ANGELE et al., 2000; ANGELE; FRANTZ; CHAUDRY, 2006; CHAUDRY et al., 2003; FRINK et al., 2007; HILDEBRAND et al., 2006; KNOFERL et al., 2001; KNOFERL et al., 2002; MELDRUM, 2006; MOEINPOUR et al., 2007) e estudos também mostram que o gênero feminino sob trauma, produz menores concentrações de IL-6 e IL-8 (DEITCH et al., 2007; YU et al., 2007). Com base nisso, avaliamos alguns mediadores inflamatórios reconhecidamente envolvidos nestes eventos no sobrenadante de meio de cultura de explantes pulmonares. A percepção desses estudos foi a de averiguar se o controle dos hormônios sexuais sobre a inflamação poderia ser diretamente sobre o pulmão, uma vez que o estímulo primário da inflamação neste caso é o intestino e não o pulmão. 
A IL-1 $\beta$ é uma citocina pró-inflamatória que ativa células e induz síntese de outras citocinas e quimiocinas, além de induzir a expressão de moléculas de adesão nas células endoteliais, facilitando assim, o recrutamento de células inflamatórias (DINARELLO, 2000). A IL-1 $\beta$ ativa e recruta neutrófilos para o tecido lesionado (EL ETER et al., 2007). A IL-1 $\beta$ exerce papel importante na lesão local e em órgão distante após a isquemia e reperfusão de membros posteriores em ratos (SEEKAMP; WARD, 1993). Além disso, dados do nosso grupo e de outros mostraram que a concentração sérica de IL-1 $\beta$ está elevada em ratos submetidos à I/R intestinal (CAVRIANI, 2007; HATO et al., 2001; MARDI; KAUSHAL, 2012; NARITA; KUWABARA; FUJII, 2004), e que sua neutralização previne a hiporreatividade brônquica induzida pela I/R intestinal (COELHO et al., 2007). No presente estudo, mostramos que ratas do grupo OVx submetidas à I/R intestinal apresentaram concentrações elevadas desta citocina no explante pulmonar quando comparadas com as do grupo falso operado (Sham). Contudo, a concentração de IL-1 $\beta$ em ratas Não-OVx submetidas à I/R intestinal não foi alterada. Desta forma, a síntese pulmonar de IL-1 $\beta$ pode ser modulada pelos hormônios sexuais femininos. Ao avaliar individualmente os hormônios, percebemos que os tratamentos dos animais com estradiol ou progesterona foram eficazes em prevenir o aumento da síntese de IL-1 $\beta$. Chen et al. (2007), demonstraram que a progesterona reduz a geração de IL-1 $\beta$ no intestino de ratos submetidos à trauma craniano. Outros autores confirmaram o efeito do estradiol em reduzir os níveis de IL-1 $\beta$ em modelos de inflamação pulmonar experimental (CUZZOCREA et al., 2001; ESPOSITO et al., 2005; SPEYER et al., 2005).

É interessante ressaltar que o padrão de síntese e liberação das citocinas inflamatórias pode ser regulado por complexa rede de mediadores com efeitos anti-inflamatórios, na qual a IL-10 pode participar (MOSSSER; ZHANG, 2008). Um aspecto interessante acerca da resposta inflamatória é que sua magnitude é fator limitante para que o organismo possa responder ao estimulo inflamatório e paralelamente recompor a homeostasia e mantendo as atividades vitais. Portanto, é relevante a percepção de um controle endógeno da inflamação. A IL-10 é descrita como potente citocina anti-inflamatória e entre suas ações está a inibição da síntese de diversas citocinas e quimiocinas proinflamatórias como o TNF- $\alpha$ (ZEMSE et al., 2010).

A IL-10 também participa da regulação da resposta imune humoral, atenua o recrutamento de neutrófilos para o pulmão em modelo de I/R intestinal (SOUZA et al., 2000). Stallion et al. (2002) utilizando camundongos "knockout" para IL-10 demonstraram que apesar de regular a produção de outras citocinas, a IL-10 endógena não protege o animal 
contra o dano tecidual intestinal e a inflamação sistêmica em modelo de $\mathrm{I} / \mathrm{R}$ intestinal. No presente estudo quantificamos as concentração de IL-10 em amostras de sobrenadante de explantes pulmonares. Nossos dados mostraram que os pulmão dos animais Não-OVx submetidos à I/R intestinal geraram elevadas concentração de IL-10. Ainda a remoção dos ovários reduziu a produção de IL-10. É interessante notar que apesar destes efeitos após a remoção dos ovários, os hormônios administrados in vivo isoladamente não foram eficazes em restaurar a menor geração de IL-10 nos pulmão dos animais OVx. De interesse, o tratamento dos animais com estradiol reduziu ainda mais os níveis encontrados na fêmeas OVx. Esses resultados sugerem que o controle da inflamação nas ratas está sob interferência dos hormônios sexuais femininos e que nas ratas Não-OVx a IL-10 produzida no pulmão poderia ser responsável por diminuir os efeitos causados no pulmão pela I/R intestinal. Em nosso modelo de I/R intestinal o tratamento dos animais OVx com progesterona aumentou a geração de IL-10 no explante de tecido pulmonar, diferentemente do observado quando os animais OVx foram tratados com estradiol. Apesar de ser modelo distinto do utilizado no presente estudo, Yates et al. (2010), mostraram em células isoladas do baço de animais tratados com progesterona, aumento da geração de IL-10. Neste contexto, estudos visando o tratamento dos animais por via intranasal ou incubação de explante de pulmão com progesterona podem ser de interesse para compreensão de mecanismos e efeitos dos hormônios sexuais femininos na lesão pulmonar causada pela I/R intestinal.

Outro mediador que pode participar da modulação da lesão pulmonar causada pela I/R intestinal é o VEGF. Este fator merece destaque por sua participação na regulação da permeabilidade microvascular e na manutenção da integridade do endotélio na lesão pulmonar decorrente da I/R intestinal (MURA et al., 2006). Ainda, o VEGF pode contribuir para o desenvolvimento de edema pulmonar. Em nosso estudo, o perfil de geração de VEGF no explante pulmonar foi similar ao da IL-1 $\beta$. Isto é, a concentração de VEFG aumentou nos explante pulmonar dos animais $\mathrm{OVx}$ submetidos à $\mathrm{I} / \mathrm{R}$ intestinal em comparação ao grupo Não-OVx. Considerando o potencial efeito do VEGF sobre a permeabilidade vascular (KOH et al., 2007), é possível, portanto que o aumento do extravasamento do corante azul de Evans nos animais OVx possa se relacionar com o aumento da geração e de VEGF no pulmão causada pela I/R intestinal. Esta hipótese é reforçada pela percepção de que o VEGF é até 20.000 vezes mais potente que a histamina em aumentar a permeabilidade microvascular (DVORAK et al., 1995). Ainda, o tratamento dos animais OVx com estradiol resultou na redução da concentração de VEGF no sobrenadante dos explantes de pulmão e como já observado, também preveniu o aumento de permeabilidade microvascular pulmonar. 
Tomados em conjunto estes dados indicam uma vez mais, a potencial existência de um controle hormonal da permeabilidade microvascular, neste caso mediada pelo VEGF. Em nossos dados o estradiol reduziu a concentração de VEFG, o que corrobora com os dados de Mueller et al. (2000) que mostra o estradiol regulando a transcrição gênica do VEGF em cultura de células endometriais. Sabe-se também que o VEGF é secretado em resposta a estímulos pró-inflamatórios que medeiam a indução da SDRA, como o LPS e a elastase de neutrófilos (KOYAMA et al., 2002). Ainda, estudos clínicos indicam redução da concentração de VEGF intrapulmonar nas primeiras fases da SDRA (ABADIE et al., 2005; MAITRE et al., 2001; THICKETT; ARMSTRONG; MILLAR, 2002). Realizando uma comparação dos nossos dados com a literatura, é possível considerar que o VEGF possa estar exercendo efeito pró-inflamatório no modelo de I/R intestinal.

Entre as diversas ações da IL-6 destacam-se aquelas envolvendo sua participação na hematopoiese durante a resposta inflamatória modulando, por exemplo, a proliferação celular, diferenciação de leucócitos e apoptose (FAN et al., 2007). Os estudos sugerem que a IL-6 é um marcador de gravidade e precedente da SDRA quando esta é desencadeada, por exemplo, pela sepse (REMICK et al., 2002) ou pancreatite aguda (LESER et al., 1991).

Apesar de mencionado, sua concentração no explante de pulmão nos grupos investigados não diferiu dos valores observados nos grupos basais. De fato, nessas condições é possível que, em fêmeas, esta citocina pode não ser um marcador da lesão pulmonar causada pela I/R intestinal. Se estes dados forem confirmados em outro compartimento como no soro obtido de fêmeas após a I/R intestinal, esta informação pode ser de relevância clínica adicional. Uma vez que, na clínica o soro é um material mais fácil de ser recolhido do paciente do que a cultura de tecido pulmonar. Também devemos relevar que nosso modelo envolve uma lesão intestinal que culmina em uma inflamação sistêmica, sendo o sistema circulatório o primeiro a carregar esta citocina.

Contudo, Kleemann et al. (2008) relataram que a IL-6 regula vários aspectos da resposta imune, porém, pode exercer efeito positivo ou negativo na resposta imune inata. Isto implica que os efeitos da IL-6 podem depender do modelo investigado, gênero, idade e dieta. Vale salientar que, apesar da IL-6 ser uma citocina indicadora de lesão no modelo de I/R intestinal em machos, talvez em fêmeas esta indicação pode não ser verdadeira.

Dados da literatura mostram que durante eventos inflamatórios, existe expressão tecidual de IFN- $\gamma$. Pacientes portadores da doença de Crohn apresentam alta concentração de IFN- $\gamma$ no intestino (KALLEL et al., 2005). Em modelo de I/R renal observa-se aumento da concentração de IFN- $\gamma$ no soro dos animais (AWAD; EL-SHARIF, 2011). No presente 
estudo, não detectamos alterações nos valores de IFN- $\gamma$ gerados pelo pulmão decorrentes da remoção dos ovários ou por causa da I/R intestinal. É interessante notar que Braun et al. (2004) usando modelo de I/R intestinal em suínos mostraram que o IFN- $\gamma$ é expresso na primeira hora de reperfusão intestinal. Assim, considerando que o tecido pulmonar foi coletado após $2 \mathrm{~h}$ de reperfusão intestinal, e mais, permaneceu sob cultura por 48 h, é razoável supor que nossos estudos foram realizados em períodos não apropriados à quantificação desta citocina.

Ao analisar o efeito do tratamento prévio com estradiol e progesterona na concentração de INF- $\gamma$ no explante pulmonar de ratas OVx submetidas a I/R intestinal. Observamos que o tratamento com estradiol apresentou níveis elevados de INF- $\gamma$. Até onde pudemos observar não existe relato na literatura relacionando os efeitos do estradiol com a geração pulmonar de INF- $\gamma$.

De forma geral os dados apresentados neste estudo indicam que os hormônios sexuais femininos exercem efeito modulador da inflamação pulmonar aguda causada pela I/R intestinal. Vale também lembrar que em condições como a I/R intestinal ocorre inflamação sistêmica e mobilização de significativa de leucócitos circulantes e como consequência há mobilização das células da medula óssea. Neste sentido, ao investigarmos a quantidade de leucócitos presentes na medula óssea dos grupos de animais observamos que os animais com ovários intactos (Não-OVx) após a I/R intestinal apresentaram a redução no número total de células quando comparado com o número determinado na medula óssea dos animais do grupo basal e do grupo OVx submetido à I/R intestinal. Sifri et al. (2007) analisaram a medula óssea de fêmeas OVx e em fêmeas em proestro submetidas ao trauma seguido de choque hemorrágico. Sugerindo que os hormônios sexuais exercem efeito protetor nas células presentes na medula óssea.

De fato, animais tratados com progesterona tiveram redução do número de células presentes na medula óssea. Esses dados mostram que a progesterona media o recrutamento celular medular. Por outro lado, quando avaliamos o número de leucócitos circulantes antes e após a indução da I/R intestinal, observamos que animais OVx apresentam aumento significativo após a indução da I/R intestinal. Tal aumento foi prevenido pelo tratamento dos animais com estradiol ou progesterona.

Ainda, investigando a geração de inflamação sistêmica após $\mathrm{I} / \mathrm{R}$ intestinal e de maneira a tentar associa-la à modulação da inflamação pulmonar orquestrada pelos hormônios sexuais femininos, quantificamos a concentração de TNF- $\alpha$. No soro dos animais. A base para a quantificação desta citocina é que sua presença é confirmada na inflamação sistêmica. 
Ainda, o TNF- $\alpha$ é gerado por macrófagos ativados, bem como por linfócitos CD4+, células "natural killers" e neurônios. Além disto, o TNF- $\alpha$ causa aumento da inflamação no sistema cardiovascular (CAO et al., 2013) e no pulmão pode causar disfunção do epitélio alveolar (PATEL et al., 2013).

Em modelo murino de I/R intestinal em machos notou-se que após 60 minutos de reperfusão intestinal os macrófagos presentes no pulmão se encontram ativados sintetizando TNF- $\alpha$ e $\mathrm{H}_{2} \mathrm{O}_{2}$ (SOUZA et al.,2000). Estudos realizados por Cavriani et al. (2004) revelaram a presença de TNF- $\alpha$ em modelo de I/R intestinal em ratos machos. Dados recentemente publicados por Banerjee et al. (2013) mostraram que a solução salina hipertônica reduz a adesão de células humanas endoteliais dos vasos pulmonares em pacientes acometidos de choque hemorrágico. Nossos dados revelaram que a I/R intestinal em fêmeas com ovário intacto aumentou as concentrações desta citocina no soro dos animais. Contudo, no grupo de animais com os ovários removidos (OVx) não observamos tal aumento. Vale ressaltar que o tratamento dos animais com estrógeno ou progesterona separadamente não alterou a concentração de TNF- $\alpha$ em relação aos animais OVx submetidos à I/R intestinal.

A lesão tecidual causada pela $\mathrm{I} / \mathrm{R}$ intestinal leva à perda da integridade celular $\mathrm{e}$ liberação da enzima LDH. Em situações de hipoxia esta enzima converte o piruvato em ácido lático. Estudos usando ratos machos mostraram que após a I/R intestinal ocorre aumento da atividade sérica de LDH, indicando a presença de lesão a tecidual (ITOH et al., 2002; SOZEN et al., 2011). Resultados similares também foram observados por Cavriani et al. (2005) usando também modelo de I/R intestinal. No presente estudo mostramos que a I/R intestinal causou aumento significativo da atividade de LDH tanto em ratas OVx como em ratas com os ovários intactos (Não-OVx). Ainda, os tratamentos com os hormônios não modificaram o perfil dos valores obtidos de atividade de LDH. Com isso, concluímos que em nosso modelo de I/R intestinal em fêmeas há um aumento do marcador de lesão tecidual (LDH), possivelmente no intestinal e os hormônios sexuais femininos não medeiam esta lesão. Assim, o controle feito pelos hormônios sexuais femininos pode ser em outro nível.

Além da atividade de $\mathrm{LDH}$, outro marcador utilizado no diagnóstico precoce da isquemia é a fosfatase alcalina (HEREK et al., 2003). Nossos resultados indicaram que a concentração de fosfatase alcalina no soro não se alterou nos animais com ovários intactos após a I/R intestinal. Contudo, observamos aumento nos seus valores no soro dos animais OVx após a I/R intestinal. Desta forma, podemos sugerir a existência de uma conexão entre os efeitos dos hormônios ovarianos e o aumento deste marcador. De fato, o tratamento dos 
animais OVx com estradiol e progesterona foi eficaz em reduzir a concentração sérica de fosfatase alcalina.

Outra substância que pode ser utilizada como indicador de inflamação é o ácido úrico sérico. Este surge por meio da quebra das moléculas de purina por ação da xantina oxidase. A geração aumentada de ácido úrico por longos períodos pode acarretar na formação de cristais de urato de sódio. Em modelo de inflamação pulmonar causada pela instilação nasal de bleomicina observou-se a produção de ácido úrico local a qual ativa o inflamassoma gerador de IL-1 $\beta$ (GASSE et al., 2009). Nossos dados revelaram que a I/R intestinal elevou a concentração de ácido úrico nos animais Não-OVx ao comparar com os animais basais. Contudo, a remoção dos ovários não alterou a concentração de ácido úrico no soro dos animais submetidos à I/R intestinal. Por outro lado, a administração de estradiol 24 h antes da indução da I/R intestinal nos animais OVx resultou na redução da concentração sérica de ácido úrico. Desta forma, nossos dados sugerem que o estradiol tenha um efeito protetor na geração de sinais de perigo, pelo menos no que se refere à geração de ácido úrico.

A lesão tecidual também pode gerar ATP, que juntamente com o ácido úrico podem exercer efeitos moduladores da resposta imune no contexto dos sinais de perigo (TAGER et al., 2008). O ATP é também sintetizado nas células como parte dos mecanismos de armazenamento de energia. Uma vez em hipóxia, ocorre redução da fosforilação oxidativa e da produção de ATP pelas mitocôndrias. Nestas condições, pode ocorrer indução de apoptose. É interessante notar que durante a I/R intestinal ocorre liberação de ATP (CHEKENI et al., 2010; ELTZCHIG et al., 2006; ELTZCHIG et al., 2009). Baseados nestas informações, quantificamos a concentração de ATP no soro por meio de seu derivado, o AMPc. Nossos dados revelaram que animais com ovários intactos (Não-OVx) tiveram redução da concentração de AMPc sérico após a I/R intestinal. Ainda, a remoção dos ovários (OVx) aumenta a expressão dos receptores de $\mathrm{P} 2 \mathrm{X}_{7}$ no endotélio vascular pulmonar em relação ao grupo com ovários intactos. Por fim, não encontramos mudanças nos valores no soro dos grupos de animais tratados com estrógeno ou progesterona. Um aspecto que merece destaque refere-se ao período em que o ATP foi quantificado. Uma vez que pode ser liberado após início da lesão, talvez o período utilizado em nosso estudo tenha sido tardio. Assim, a avaliação da sua concentração em período mais precoce, por exemplo, imediatamente após os 45 min de isquemia, poderia gerar dados mais evidentes sobre o papel da I/R intestinal na geração deste sinal de perigo.

Como já mencionado a I/R intestinal determina inflamação local e nesse sentido para fins de comprovação da agressão gerada no intestino determinamos o extravasamento do 
corante azul de Evans e a atividade de MPO no tecido intestinal. Nossos dados revelaram que animais OVx apresentaram aumento do extravasamento do corante e da atividade de MPO em comparação com os animais Não-OVx. Indicando que a $\mathrm{I} / \mathrm{R}$ intestinal nestes animais determinou aumento de permeabilidade microvascular intestinal e de recrutamento de neutrófilos. Vale lembrar que o tratamento dos animais OVx com estradiol ou progesterona foram eficazes em proteger o tecido intestinal do aumento de permeabilidade microvascular mas não alterou o perfil do aumento de atividade de MPO. Um estudo recente mostrou o efeito protetor do estradiol sobre a microcirculação mesentérica em modelo experimental de sepse em ratos (SHARAWY et al., 2011). De acordo com estes autores, o tratamento de animais (machos ou fêmeas) com estradiol causa redução da quimiotaxia e na microcirculação intestinal havendo uma melhor tolerância a sepse do que os animais não tratados (SHARAWY et al., 2011).

Diversos mediadores podem estar envolvidos na indução do aumento de permeabilidade após a I/R intestinal, seja ele local ou no pulmão. Assim estímulos no endotélio com VEGF, TNF- $\alpha$, histamina, entre outros podem mediar este evento (MEHTA; MALIK, 2006). Estudo em humanos caracterizou que em períodos prolongados de $I / R$ intestinal há perda da integridade da barreira intestinal com exposição dos patógenos intraluminal e conteúdos intracelulares dos enterócitos, resultando na ativação do sistema complemento e transmigração de neutrófilos do endotélio, também ativo (GROOTJANS et al., 2010). A I/R intestinal causa danos e inflamação na musculatura longitudinal do intestinal delgado e isto pode gerar em longo prazo déficit na motilidade intestinal (PONTELL et al., 2011).

Tomados em conjunto os dados gerados neste estudo, mostram que os hormônios sexuais femininos podem exercer efeito protetor sobre a inflamação pulmonar aguda induzida pela I/R intestinal. Tal efeito é mediado pelo controle da geração de citocinas, da expressão de receptores purinérgicos e moléculas de adesão. Embora não tenhamos avaliado a correlação entre a geração de ATP e a magnitude da resposta inflamatória. 


\section{CONCLUSÕES}

$\rightarrow$ Os hormônios sexuais femininos protegem o pulmão das repercussões inflamatórias induzidas pela $\mathrm{I} / \mathrm{R}$ intestinal visto que a remoção dos ovários se relacionou com o aumento de recrutamento celular e da permeabilidade microvascular pulmonar.

$\rightarrow$ É possível que os efeitos protetores dos hormônios sexuais femininos sejam resultantes de sua modulação na geração pulmonar de IL-1 $\beta$, IL-10 e VEGF.

$\rightarrow$ A redução da geração pulmonar de nitritos e das citocinas IL-1 $\beta$ e VEGF depende da presença de estradiol circulante.

$\rightarrow$ A administração de progesterona induz aumento nos níveis de IL-10 e altera expressão de VCAM e do receptor $\mathrm{P}_{2} \mathrm{X}_{7}$ no endotélio vascular pulmonar, além de prevenir o aumento de células na medula óssea.

$\rightarrow$ Sugere-se que a geração de sinais perigo (fosfatase alcalina e LDH) e a expressão de ICAM-1 e PECAM-1 em modelo de I/R intestinal depende da ação em conjunto do estradiol e progesterona. Enquanto que a concentração de ácido úrico parece ser modulada apenas pelo estradiol.

Os dados gerados neste estudo apontam para uma possível utilização dos estradiol oi progesterona como moduladores da resposta inflamatória decorrente de eventos isquêmicos intestinais. 


\section{REFERÊNCIAS*}

ABADIE, Y.; BREGEON, F.; PAPAZIAN, L.; LANGE, F.; CHAILLEY-HEU, B.; THOMAS, P.; DUVALDESTIN, P.; ADNOT, S.; MAITRE, B.; DELCLAUX, C. Decreased VEGF concentration in lung tissue and vascular injury during ARDS. Eur. Respir. J., v. 25, p. 139-146, 2005.

ABRAHAM, E. Neutrophils and acute lung injury. Crit. Care Med., v. 31, p. S195-S199, 2003.

ADAMS, C. A.; MAGNOTTI, L. J.; XU, D. Z.; LU, Q.; DEITCH, E. A. Acute lung injury after hemorrhagic shock is dependent on gut injury and sex. Am. Surg., v. 66, p. 905-912, 2000 .

ALBELDA, S. M.; SMITH, C. W.; WARD, P. A. Adhesion molecules and inflammatory injury. FASEB J., v. 8, p. 504-512, 1994.

AMADO-RODRÍGUEZ, L.; GONZÁLEZ-LÓPEZ, A.; LÓPEZ-ALONSO, I.; AGUIRRE, A.; ASTUDILLO, A.; BATALLA-SOLÍS, E.; BLAZQUEZ-PRIETO, J.; GARCÍA-PRIETO, E.; ALBAICETA, G. M. Anti-inflammatory effects of clarithromycin in ventilator-induced lung injury. Respir. Res., v. 14, p. 52, 2013.

ANNATHAKRISHNAN, P.; COHEN, D. B.; XU, D. Z.; LU, Q.; FEKETEOVA, E.; DEITCH, E. A. Sex hormones modulate distant organ injury in both a trauma/hemorrhagic shock model and a burn model. Surgery, v. 137, p. 56-65, 2005.

ANGELE, M. K.; FRANTZ, M. C.; CHAUDRY, I. H. Gender and sex hormone influence the response to trauma and sepsis - potential therapeutic approaches. Clinics, v. 61, p. 479-488, 2006.

ANGELE, M. K.; SCHWACHA, M. G.; AYALA, A.; CHAUDRY, I. H. Effect of gender and sex hormones on immune responses following shock. Shock, v. 14, p. 81-90, 2000.

AWAD, A. S.; EL-SHARIF, A. A. Curcumin immune-mediated and anti-apoptotic mechanisms protect against renal ischemia/reperfusion and distant organ induced injuries. Int. Immunopharmacol., v. 11, p. 992-998, 2011.

BANERJEE, A.; MOORE, E. E.; MCLAUGHLIN, N. J.; LEE, L.; JONES, W. L.; JOHNSON, J. L.; NYDAM, T. L.; SILLIMAN, C. C. Hyperosmolarity attenuates TNF- $\alpha-$ mediated proinflammatory activation of human pulmonary microvascular endothelial cells. Shock, v. 39, p. 366-372, 2013.

BARAJA-LÓPEZ，C.; HUIZINGA，J. D.; GERZANICH， V.; ESPINOSA-LUNA，R.; PERES, A. L. P2X-purinoceptors ununsual pharmacological neurones from the guinea-pig ileum and their unusual pharmacological properties. Br. J. Plarmacol., v.119, p. 1341-1548, 1996. 
BAUMANN, H.; GAULDIE, J. The acute phase response. Immunol. Today, v. 15, p. 74-80, 1994.

BARON, P.; TRABER, L. D.; TRABER, D. L.; NGUYEN, T.; HOLLYOAK, M.; HEGGERS, J. P.; HERNDON, D. N. Gut failure and translocation following burn and sepsis. J. Surg. Res., v. 57, p. 197-204, 1994.

BERG, R. D.; OWENS, W. E. Inhibition of translocation of viable Escherichia coli from the gastrointestinal tract of mice by bacterial antagonism. Infect. Immun., v. 25, p. 820-827, 1979.

BERNARD, G. R. Acute respiratory distress syndrome: a historical perspective. Am. J. Respir. Crit. Care Med., v. 172, n. 7, p. 798-806, 2005.

BERNARD, G.R.; ARTIGAS, A.; BRIGAM, K. L.; CARLET, J.; FALKE, L.; HUDSON, L.; LAMY, M.; LEGALL, J. R.; MORRIA, A.; SPRAGG, R. The American-European Consensus Conference on ARDS. Definitions, mechanisms, relevant outcomes, and clinical trial coordination. Am. J. Respir. Crit. Care Med., v. 149, p. 818-824, 1994.

BERTHIAUME, Y.; LESUR, O.; DAGENAIS, A. Treatment of adult respiratory distress syndrome: plea for rescue therapy of the alveolar epithelium. Thorax, v. 54, p. 150-160, 1999.

BIAN, X. C.; BERTRAND, P. P.; BORNSTEIN, J. C. Descending inhibitory reflexes involve $\mathrm{P} 2 \mathrm{X}$ receptor-mediated transmission from interneurons to motor neurons in guinea-pig ileum. J. Physiol., v. 528, p. 551-560, 2000.

BIANCHI, M. E. DAMPs, PAMPs and alarmins: all we need to know about danger. J. Leukoc. Biol., v. 81, p. 1-5, 2007.

BIANCHI, M. E. HMGB1 loves company. J. Leukoc. Biol., v. 86, p. 273-276, 2009.

BIFFL, W. L.; MOORE, E. E. Splanchnic ischaemia/reperfusion and multiple organ failure. Br. J. Anaesth., v. 77, p. 59-70, 1996.

BOLDT, J.; OSMER, C.; LINKE, L. C.; DAPPER, F.; HEMPELMANN, G. Circulating adhesion molecules in pediatric cardiac surgery. Anesth. Analg., v. 81, p. 1129-1135, 1995.

BOONYARATANAKORNKIT, V.; EDWARDS, D. P. Receptor mechanisms mediating non-genomic actions of sex steroids. Semin. Reprod. Med., v. 25, p. 139-153, 2007.

BOOTH, J. W.; TAM, F. W.; UNWIN, R. J. P2 purinoceptors: Renal pathophysiology and therapeutic potential. Clin. Nephrol., v. 78, p. 154-163, 2012.

BORJESSON, A.; NORLIN, A.; WANG, X.; ANDERSSON, R.; FOLKESSON, H. G. TNFalpha stimulates alveolar liquid clearance during intestinal ischemia-reperfusion in rats. Am. J. Physiol. Lung Cell Mol. Physiol., v. 278, p. L3-12, 2000. 
BJORNSTROM, L.; SJOBERG, M. Mechanisms of estrogen receptor signaling: convergence of genomic and nongenomic actions on target genes. Mol. Endocrinol., v. 19, p. 833-842, 2005.

BRAUN, F.; HOSSEINI, M.; WIELAND, E.; SATTLER, B.; MÜLLER, A. R.; FÄNDRICH, F.; KREMER, B.; RINGE, B. Kinetics and localization of interleukin-2, interleukin-6, heat shock protein 70, and interferon gamma during intestinal-reperfusion injury. Transplant. Proc., v. 36, p. 267-269, 2004.

BRAUNE, S.; KLUGE, S. ARDS - an update. Dtsch. Med. Wochenschr., v. 138, p 10191022, 2013.

BREITHAUPT-FALLOPA, A. C.; VITORETTI, L. B.; CAVRIANI, G.; LINO-DOSSANTOS-FRANCO, A.; SUDO-HAYASHI, L. S.; OLIVEIRA-FILHO, R.. M.; VARGAFTIG, B. B.; TAVARES-DE-LIMA, W. Intestinal lymph-borne factors induce lung release of inflammatory mediators and expression of adhesion molecules after an intestinal ischemic insult. J. Surg. Res., v. 176, p. 195-201, 2012.

BREITHAUPT-FALOPPA, A. C.; VITORETTI, L. B.; COELHO, F. R.; DOS SANTOS FRANCO, A. L.; DOMINGOS, H. V.; SUDO-HAYASHI, L. S.; OLIVEIRA-FILHO, R. M.; TAVARES DE LIMA, W. Nitric oxide mediates lung vascular permeability and lymph-borne IL-6 after an intestinal ischemic insult. Shock, v. 32, p. 55-61, 2009.

BURNSTOCK, G.; BROUNS, I.; ADRIAENSEN, D.; TIMMERMANS, J. P. Purinergic signaling in the airways. Phamacol. Rev., v. 64, 2012.

BURNSTOCK, G. Purinergic signaling and vascular cell proliferation and death. Arterioscler. Thromb. Vasc. Biol., v. 22, p. 364-373, 2002.

CAO, Y.; TANG, J.; YANG, T.; MA, H.; YI, D.; GU, C.; YU, S. Cardioprotective effect of ghrelin in cardiopulmonary bypass involves a reduction in inflammatory response. PloS One, v. 8, p. 55021, 2013.

CAVRIANI, G.; DOMINGOS, H. V.; OLIVEIRA-FILHO, R. M.; SUDO-HAYASHI, L. S.; VARGAFTIG, B. B.; DE LIMA, W. T. Lymphatic thoracic duct ligation modulates the serum levels of il-1beta and il-10 after intestinal ischemia/reperfusion in rats with the involvement of tumor necrosis factor alpha and nitric oxide. Shock, v. 27, p. 209-213, 2007.

CAVRIANI, G.; DOMINGOS, H. V.; SOARES, A. L.; TREZENA, A. G.; LIGEIROOLIVEIRA, A. P.; OLIVEIRA-FILHO, R. M.; SUDO-HAYASHI, L. S.; TAVARES DE LIMA, W. Lymphatic system as a path underlying the spread of lung and gut injury after intestinal ischemia/reperfusion in rats. Shock, v. 23, p. 330-6, 2005.

CAVRIANI, G.; OLIVEIRA-FILHO, R. M.; TREZENA, A. G.; DA SILVA, Z. L.; DOMINGOS, H. V.; DE ARRUDA, M. J.; JANCAR, S.; TAVARES, D. L. Lung microvascular permeability and neutrophil recruitment are differently regulated by nitric oxide in a rat model of intestinal ischemia-reperfusion. Eur. J. Pharmacol., v. 494, p. 241249, 2004. 
CAVRIANI, G. Avaliação do envolvimento do sistema linfático na inflamação pulmonar decorrente de trauma esplâncnico. 2007. 150 f. Tese. (Doutorado em Farmacologia) Instituto de Ciências Biomédicas, Universidade de São Paulo, São Paulo, 2007.

CARDEN, D. L.; YOUNG, J. A.; GRANGER, D. N. Pulmonary microvascular injury after intestinal ischemia reperfusion: role of P-selectin. J. Appl. Physiol., v. 75, n. 6, p. 2529-2534, 1993.

CARUSO, J. M.; XU, D. Z.; LU, Q.; DAYAL, S. D.; DEITCH, E. A. The female gender protects against pulmonary injury after trauma hemorrhagic shock. Sug. Infect. (Larchmt), v. 2, p. 231-240, 2001.

CATY, M. G.; GUICE, K. S.; OLDHAM, K. T.; REMICK, D. G.; KUNKEL, S. I. Evidence for tumor necrosis factorinduced pulmonary microvascular injury after intestinal ischemiareperfusion injury. Ann. Surg., v. 212, n. 6, p. 694-700, 1990.

CERQUEIRA, N. F.; HUSSNI, C. A.; YOSHIDA, W. B. Pathophysiology of mesenteric ischemia/reperfusion: a review. Acta. Cir. Bras., v. 20, p. 336-343, 2005.

CHAUDRY, I. H.; SAMY, T. S.; SCHWACHA, M. G.; WANG, P.; RUE, L. W.; BLAND, K. I. Endocrine targets in experimental shock. The Journal of Trauma, v. 54, p. 118-25, 2003.

CHEKENI, F. B.; RAVICHANDRAN, K. S. The role of nucleotides in apoptotic cell clearance: implications for disease pathogenesis. J. Mol. Med. (Berl.), v. 89, p. 13-22, 2010.

CHEN, G.; SHI, J.; DING, Y.; YIN, H.; HANG, C. Progesterone prevents traumatic brain injury-induced intestinal nuclear factor kappa B activation and proinflammatory cytokines expression in male rats. Mediators of Inflammation, v. 2007, p. 1-7, 2007.

CHEN, J.; YANG, S.; HU, S.; CHOUDHRY, M. A.; BLAND, K. I.; CHAUDRY, I. H. Estrogen prevents intestinal inflammation after trauma-hemorrhage via downregulation of angiotensin II and angiotensin II subtype I receptor. Am. J. Physiol. Gastrointest. Liver Physiol., v. 295, p. 1131-1137, 2008.

CHEN, L. W.; EGAN, L.; LI, Z. W.; GRETEN, F. R.; KAGNOFF, M. F.; KARIN, M. The two faces of IKK and NF-kappaB inhibition: prevention of systemic inflammation but increased local injury following intestinal ischemia-reperfusion. Nat. Med., v. 9, p. 575-581, 2003.

CHI, P. L.; CHEN, Y. W.; HSIAO, L. D.; CHEN, Y. L.; YANG, C. M. HO-1 attenuates IL1beta-induced cPLA(2) expression via a decrease in NADPH oxidase/ROS/AP-1 activation in human rheumatoid arthritis synovial fibroblasts. Arthritis Rheum., v. 63, p. 2905-2917, 2012.

CHIAO, C. W.; TOSTES, R. C.; WEBB, R. C. P2X7 receptor activation amplifies lipopolysaccharide-induced vascular hyporeactivity via interleukin-1 beta release. $\mathbf{J}$. Pharmacol. Exp. Ther., v. 326, p. 864-870, 2008. 
CHILDS, E. W.; THARAKAN, B.; HUNTER, F. A.; SMYTHE, W. R. 17beta-estradiol mediated protection against vascular leak after hemorrhagic shock: role of estrogen receptors and apoptotic signaling. Shock, v. 34, p. 229-235, 2010.

CHOPRA, M. REUBEN, J. S.; SHARMA, A. C. Acute lung injury: apoptosis and signaling mechanisms. Exp. Biol. Med., v. 234, p. 361-371, 2009.

COELHO, F. R.; CAVRIANI, G.; SOARES, A. L.; TEIXEIRA, S. A.; ALMEIDA, P. C.; SUDO-HAYASHI, L. S.; MUSCARA, M. N.; OLIVEIRA-FILHO, R. M.; VARGAFTIG, B. B.; TAVARES-DE-LIMA, W. Lymphatic-borne IL-1beta and the inducible isoform of nitric oxide synthase trigger the bronchial hyporesponsiveness after intestinal ischemia/reperfusion in rats. Shock, v. 28, p. 694-699, 2007.

COHEN, M. J.; BROHI, K.; CALFEE, C. S.; RAHN, P.; CHESEBRO, B. B.; CHRISTIAANS, S. C.; CARLES, M.; HOWARD, M.; PITTET, J. F. Early release of high mobility group box nuclear protein 1 after severe trauma in humans: role of injury severity tissue hypoperfusion. Crit. Care, v. 13, p. R174, 2009.

CUZZOCREA, S.; RILEY, D. P.; CAPUTI, A. P.; SALVEMINI, D. Antioxidant therapy: a new pharmacological approach in shock, inflammation, and ischemia/reperfusion injury. Pharmacol Rev., v. 53, p. 135-159, 2001.

DAVIDSON, M. T.; DEITCH, E. A.; LU, Q.; OSBAND, A.; FEKETEOVA, E.; NEMETH, Z. H.; HASKO, G.; XU, D. Z. A study of the biologic activity of trauma-hemorrhagic shock mesenteric lymph over time and the relative role of cytokines. Surgery, v. 136, p. 32-41, 2004.

DE LIMA, F. M.; VITORETTI, L.; COELHO, F.; ALBERTINI, R.; BREITHAUPTFALOPPA, A. C.; DE-LIMA, W. T.; AIMBIRE, F. Suppressive effect of low-level laser therapy on tracheal hyperresponsiveness and lung inflammation in rat subjected to intestinal ischemia and reperfusion. Lasers Med. Sci., v. 28, p. 551-564, 2013.

DE MARCO, R.; LOCATELLI, F.; SUNYER, J.; BURNEY, P. Differences in incidence of reported asthma related to age in men and women. A retrospective analysis of the data of the European Respiratory Health Survey. Am. J. Respir. Crit. Care Med., v. 162, p. 68-74, 2000.

DE OLIVEIRA, A. P. L.; DOMINGOS, H. V.; CAVRIANI, G.; DAMAZO, A. S.; DOS SANTOS FRANCO, A. L.; OLIANI, S. M.; OLIVEIRA-FILHO, R. M.; VARGAFTIG, B. B.; DE LIMA, W. T. Cellular recruitment and cytokine generation in a rat model of allergic lung inflammation are differentially modulated by progesterone and estradiol. American Journal of Physiology. Cellular Physiology, v. 293, p. 1120-8, 2007.

DELISSER, H.; BALDWIN, H. S.; ALBELDA, S. M. PECAM-1/CD31 - A multifunctional vascular cell adhesion molecule. Trends. Cardiovasc. Med., v. 151, p. 671-677, 1997.

DEITCH, E. A.; ADAMS, C.; LU, Q.; XU, D. Z. A time course study of the protective effect of mesenteric lymph duct ligation on hemorrhagic shock-induced pulmonary injury and the toxic effects of lymph from shocked rats on endothelial cell monolayer permeability. Surgery, v. 129, p. 39-47, 2001. 
DEITCH, E. A.; CHU, H.; XU DA, Z. Organ blood flow and the central hemodynamic response are better preserved in female, as opposed to the male rats, after trauma-hemorrhagic shock. J. Trauma, v. 65, p. 566-572, 2008a.

DEITCH, E. A.; FEKETEOVA, E.; LU, Q.; ZAETS, S.; BEREZINA, T. L.; MACHIEDO, G. W.; HAUSER, C. J.; LIVINGSTON, D. H.; XU, D. Z. Resistance of the female, as opposed to the male, intestine to I/R-mediated injury is associated with increased resistance to gutinduced distant organ injury. Shock, v. 29, p. 78-83, 2008b.

DEITCH, E. A.; LIVINGSTON, D. H.; LAVERY, R. F.; MONAGHAN, S. F.; BONGU, A.; MACHIEDO, G. W. Hormonally active women tolerate shock-trauma better than do men: a prospective study of over 4000 trauma patients. Ann. Surg., v. 246, p. 447-53, 2007.

DI. W. L.; LACHELIN, G. C.; MCGARRIGLE, H. H.; THOMAS, N. S.; BECKER, D. L. Oestriol and oestradiol increase cell to cell communication and connexin43 protein expression in human myometrium. Mol. Hum. Reprod., v. 7, p. 671-679, 2001.

DINARELLO, C. A. The role of the interleukin-1-receptor antagonist in blocking inflammation mediated by interleukin-1. N. Engl. J. Med. , v. 343, p. 732-734, 2000.

DOUCET, D.; BADAMI, C.; PALANGE, D.; BONITZ, R. P.; LU, Q.; ZU, D. Z.; KANNAN, K. B.; COLORADO, I.; FEINMAN, R.; DEITCH, E. A. Estrogen receptor hormone agonists limit trauma hemorrhage shock-induced gut and lung injury in rats. PloS One, v. 25, p. 9421, 2010.

DVORAK, H.F.; BROWN, L.F.; DETMAR, M.; DVORAK, A. M. Vascular permeability factor/vascular endothelial growth factor, microvascular hyperpermeability, and angiogenesis.Am. J. Pathol., v. 146, p. 1029-1039, 1995.

EL ETER, E.; AL TUWAIJIRI, A.; HAGAR, H.; ARAFA, M. In vivo and in vitro antioxidant activity of ghrelin: Attenuation of gastric ischemic injury in the rat. $\mathbf{J}$ Gastroenterol. Hepatol., v. 22, p. 1791-1799, 2007.

ELICES, M. J.; OSBORN, L.; TAKADA, Y.; CROUSE, C.; LUHOWSKYJ, S.; HEMLER, M. E.; LOBB, R. R. VCAM-1 on activated endothelium interacts with the leukocyte integrin VLA-4 at a site distinct from the VLA-4/fibronectin binding site. Cell, v. 60, p. 577-584, 1990.

ELTZCHIG, H. K.; CARMELIET, P. Hypoxia and inflammation. N. Engl. J. Med., v. 364, p. 656-665, 2011.

ESPOSITO, G.; FILOSA, A.; CANTELLI, L.; MAGLIONE, F.; NIOLA, R.Chronic intestinal bleeding because of aneurysm of superior pancreaticoduodenal artery: embolization during angiography. J. Pediatr. Surg., v. 40, p. 59-61, 2005.

FAN, Y.; YE, J.; SHEN, F.; ZHU, Y.; YEGHIAZARIANS, Y.; ZHU, W.; CHEN, Y.; LAWTON, M. T.; YOUNG, W. L.; YANG, G. Y.Interleukin-6 stimulates circulating bloodderived endothelial progenitor cell angiogenesis in vitro. J. Cereb. Blood Flow Metab., v. 28, p. 90-98, 2008. 
FERGUSON, N. D.; FRUTOS-VIVAR, F.; ESTEBAN, A.; GORDO, F.; HONRUBIA, T.; PEÑUELAS, O.; ALGORA, A.; GARCÍA, G.; BUSTOS, A.; RODRÍGUEZ, I. Clinical risk conditions for acute lung injury in the intensive care unit and hospital Ward: a prospective observational study. Crit. Care, v. 3, p. R96, 2007.

FERRARI, D.; CHIOZZI, P.; FALZONI, S.; HANAU, S.; DI VIRGILIO, F. Purinergic modulation of interleukin-1 beta release from microglial cells stimulated with bacterial endotoxin. J. Exp. Med., v. 185, p. 579-682, 1997.

FISH, E. N. The X-files in immunity: sex-based differences predispose immune responses. Nature Reviews Immunology, v. 8, p. 737-744, 2008.

FOEX, B. Bacterial translocation in hemorrhagic shock: are we any wiser? Crit. Care Med., v. 33, p. 1166-1167, 2005.

FRINK, M.; THOBE, B. M.; HSIEH, Y. C.; CHOUDHRY, M. A.; SCHWACHA, M. G.; BLAND, K. I.; CHAUDRY, I. H. 17beta-estradiol inhibits keratinocyte-derived chemokine production following trauma-hemorrhage. American Journal of Physiology. Lung Cellular and Molecular Physiology, v. 292, p. 585-91, 2007.

FU, X. D.; GARIBALDI, S.; GOPAL, S.; POLAK, K.; PALLA, G.; SPINA, S.; MANNELLA, P.; GENAZZANI, A. R.; GENAZZANI, A. D.; SIMONCINI, T. Dydrogesterone exerts endothelial anti-inflammatory actions decreasing expression of leukocyte adhesion molecules. Mol. Hum. Reprod., v. 18, p. 44-51, 2012.

FURNESS, J. B. Types of neurons in the enteric nervous system. J. Autonom. Nerv. Syst., v. 81, p. 87-96, 2000.

FURNESS, J. B. The enteric nervous system. Melbourne: Blackwell, 2006.

GALLEY, H. F.; WEBSTER, N. R. Physiology of the endothelium. Br. J. Anaesth., v. 93, p. 105-113, 2004.

GALLIGAN, J. J.; LEPARD, K. J.; SCHNEIDER, D. A.; ZHOU, X. Multiple mechanisms of fast excitatory synaptic transmission in the enteric nervous system. J. Auton. Nerv. Syst., v. 81, p. 97-103, 2000.

GALLIGAN, J. J. Ligand-gated ion channels in the enteric nervous system. Neurogastroenterol. Motil., v. 14, p. 611-623, 2002.

GALLUCCI, S.; MATZINGER, P. Danger signals: SOS to the immune system. Curr. Opin. Immunol., v. 13, p. 114-119, 2001.

GALHARDO, F. P. L.; MARTINEZ, J. A. B. Síndrome do desconforto respiratório agudo. Medicina, Ribeirão Preto. v. 36, p. 248-256, 2003.

GAO, Y. L.; HU, C. L.; SHI, J.; LIAO, X. X. Pulmonary platelet endotelial cell adhesion molecule-1 (PECAM-1) in rabbits after acute paraquat (PQ) poisoning. Zhongguo Wei Zhong Bing Ji Jiu Yi Xue, v. 23, p. 585-587, 2011. 
GASSE, P.; RITEAU, N.; CHARRON, S.; GIRRE, S.; FICK, L.; PÉTRILLI, V.; TSCHOPP, J.; LAGENTE, V.; QUESNIAUX, V. F.; RYFFEL, B.; COUILLIN, I. Uric acid is a danger signal activating NALP3 inflammasome in lung injury inflammation and fibrosis. Am. J. Respir. Crit. Care Med., v. 179, p. 904-913, 2009.

GIANNATTASIO, G., OHTA, S.; BOYCE, J. R.; ZING, W.; BALESTRIERI, B.; BOYCE, J. A.The purinergic $\mathrm{G}$ protein-coupled receptor 6 inhibits effector $\mathrm{T}$ cell activation in allergic pulmonary inflammation. J. Immunol., v. 187, p. 1486-1497, 2011.

GIRN, H. R. S.; AHILATHIRUNAYAGAM, S.; MAVOR, A. I. D.; HOMERVANNIASINKAM, S. Reperfusion syndrome: cellular mechanisms of microvascular dysfunction and potential therapeutic strategies. Vascular and Endovascular Surgery, v. 41, p. 277-293, 2007.

GOLIAS, C.; TSOUTSI, E.; MATZIRIDIS, A.; MAKRIDIS, P.; BATISTATOU, A.; CHARALADOPOULOS, K. Leukocyte and endotelial cell adhesion molecules in inflammation focusing on inflammatory heart disease. In Vivo, v. 21, p. 757-769, 2007.

GONG, J.; LI, H. B.; GOU, S.; SHANG, Y.; YAO, S. L. Lipoxin receptor agonist, may be a potential treatment for hemorrhagic shock-induced acute lung injury. Med. Hypotheses, v. 79, p. 92-94, 2012.

GOODMAN; GILMAN. Estrogênios e progestinas. Manual de famacologia e terapêutica. AMGH Editora Ltda, v. 9, p. 993-1012, 2010.

GRACE, P. A. Ischaemia-reperfusion injury. Br. J. Surg., v. 81, p. 637-647, 1994.

GRANGER, D. N.; KORTHUIS, R. J. Physiologic mechanisms of postischemic tissue injury. Annu. Rev. Physiol., v. 57, p. 311-332, 1995.

GROOTJANS, J.; LENAERTS, K.; DERIKX, J. P. M.; MATTHIJSEN, R. A.; VAN DAM, R. M.; DEJONG, C. H. C.; BUURMAN, W. A. Human intestinal ischemia-reperfusioninduced inflammation characterized. The American Journal of Pathology, v. 176, p. 22832292, 2010.

GROSSMAN, C. J. Interactions between the gonadal steroids and the immune system. Science, v. 227, p. 257-261, 1985.

HAMIDI, S. A.; DICKMAN, K. G.; BERISHA, H.; SAID, S. I.17 $\beta$-estradiol protects the lung against acute injury: possible mediation by vasoactive intestinal polypeptide. Endocrinology, v. 152, p. 4729-4737, 2011.

HARWARD, T R.; BROOKS, D. L.; FLYNN, T. C.; SEEGER, J. M. Multiple organ dysfunction after mesenteric artery revascularization. J. Vasc. Surg., v. 18, n .3, p. 459-467, 1993.

HATO, S.; URAKAMI, A.; YAMANO, T.; UEMURA, T.; OTA, T.; HIRAI, R.; SHIMIZU, N. Attenuation of liver and lung injury after hepatic ischemia and reperfusion by a cytokinesuppressive agent, FR167653. Eur. Surg. Res., v. 33, p. 202-209, 2001. 
HE, G. Z.; ZHOU, K. G.; ZHANG, R.; WANG, Y. K.; CHEN, X. F. Impact of intestinal ischemia/reperfusion and lymph drainage on distante organs in rats. World $\mathbf{J}$. Gastroenterol., v.18, p. 7271-7278, 2012.

HECHLER, B.; LENAIN, N.; MARCHESE, P.; VIAL, C.; HEIM, V.; FREUND, M.; CAZENAVE, J. P.; CATTANEO, M.; RUGGERI, Z. M.; EVANS, R.; GACHET, C. A role of the fast ATP-gated P2X1 cation channel in thrombosis of small arteries in vivo. J. Exp. Med., v. 198, p. 661-667, 2003.

HEREK, O.; YILMAZ, M.; DEMIR, S.; AKBULUT, M. The effects of intestinal ischemia on the levels of serum immunoglobulin A in rats. Pediatr. Surg. Int., v. 18, p. 601-604, 2003.

HILDEBRAND, F.; HUBBARD, W. J.; CHOUDHRY, M. A.; THOBE, B. M.; PAPE, H. C.; CHAUDRY, I. H. Effects of 17beta-estradiol and flutamide on inflammatory response and distant organ damage following trauma-hemorrhage in metaestrus females. Journal of Leukocyte Biology, v. 80, p. 759-765, 2006.

HILL, J.; LINDSAY, T. F.; ORTIZ, F.; YEH, C. G.; HECHTMAN H. B.; MOORE F. D. JR. Soluble complement receptor type 1 ameliorates the local and remote organ injury after intestinal ischemia-reperfusion in the rat. J. Immunol., v. 149, p. 1723-1728, 1992.

HOGG, M. E.; VAVRA, A. K.; BANERJEE, M. N.; MARTINEZ, J.; JIANG, Q.; KEERFER, L. K.; CHAMBON, P.; KIBBE, M. R. The role of estrogen receptor $\alpha$ and $\beta$ in regulating vascular smooth muscle cell proliferation is based on sex. J. Surg. Res., v. 173, p. $1-10,2012$.

HSIEH, Y. H.; MCCARTNEY, K.; MOORE, T. A.; THUDYIL, J.; GELDERBLOM, M.; MANZANERO, S.; ARUMUGAM, T. V. Intestinal ischemia-reperfusion injury leads to inflammatory changes in the brain. Shock, v. 36, p. 424-430, 2011.

HSU, J. T.; YEH, H. C.; CHEN, T. H.; KOU, C. J.; LIN, C. J.; CHIANG, K. C.; YEH, T. S.; HWANG, T. L.; CHAUDRY, I. I. Role of Akt/OH-1 pathway in estrogen-mediated attenuation of trauma-hemorrhage-induced lung injury. J. Surg. Res., v. 182, p. 319-329, 2013.

HUDSON, L. D.; MILBERG, J. A.; ANARDI, D; MAUNDER, R. J. Clinical risks for development of the acute respiratory distress syndrome. Am. J. Respir. Crit. Care Med., v. 151, n. 2, p. 293-301, 1995.

IKAI, M.; ITOH, M.; JOH, T.; YOKOYAMA, Y.; OKADA, N.; OKADA, H. Complement plays an essential role in shock following intestinal ischaemia in rats. Clin. Exp. Immunol., v. 106, p. 156-159, 1996.

INOUE, S.; NAKAO, A.; KISHIMOTO, W.; MURAKAMI, H.; HARADA, A.; NONAMI, T.; TAKAGI, H. LFA-1 (CD11a/CD18) and ICAM-1 (CD54) antibodies attenuate superoxide anion release from polymorphonuclear leukocytes in rats with experimental acute pancreatitis. Pancreas, v. 12. p. 183-188, 1996. 
ITOH, H.; YAGI, M.; HASEBE, K.; FUSHIDA, S.; TANI, T.; HASHIMOTO, T.; SHIMIZU, K.; MIWA, K.Regeneration of small intestinal mucosa after acute ischemia-reperfusion injury. Dig. Dis. Sci., v. 47, p. 2704-2710, 2002.

IWASAKI, A.; MEDZHITOV, R. Regulation of adaptive immunity by the innate imune system. Science, v. 327, p. 291-295, 2010.

JAESCHKE, H.; WOOLBRIGHT, B. L. Current strategies to minimize hepatic ischemiareperfusion injury by targeting reactive oxygen species. Transplant. Rev., v.26, p. 103-114, 2012.

JAMES, I. A.; CHEN, C. L.; HUANG, G.; ZHANG, H. Y.; VENTEL, M.; BESNER, G. E. HB-EGF protects the lungs after intestinal ischemia/reperfusion injury. J. Surg. Res., v. 163, p. 86-95, 2010.

KALLEL, L.; BOUBAKER, J.; LOUZIR, H.; BEN AHMED, M.; SASSI, A.; BOUBAKER, S.; ZOUARI, B.; FILALI, A. Colonic expression of gamma-interferon and interleukin-10 in Crohn's disease and ulcerative colitis. Presse. Med., v. 34, p. 8-12, 2005.

KAN, W. H.; HSU, J. T.; SHAWACHA, M. G.; CHOUDHRY, M. A.; BLAND, K. L.; CHAUDRY, I. H. Estrogen ameliorates trauma-hemorrhage-induced lung injury via endothelial nitric oxide synthase-dependent activation of protein kinase G. Ann. Surg., v. 248, p. 294-302, 2008.

KLEEMANN, R.; ZADELAAR, S.; KOOISTRA, T. Cytokines and atherosclerosis: a comprehensive review of studies in mice. Cardiovascular Research, v. 79, p. 360-376, 2008.

KNÖFERL, M. W.; ANGELE, M. K.; DIODATO, M. D.; SCHWACHA, M. G.; AYALA, A.; CIOFFI, W. G.; BLAND, K. I.; CHAUDRY, I. H. Female sex hormones regulate macrophage function after trauma-hemorrhage and prevent increased death rate from subsequent sepsis. Annals of Surgery, v. 235, p. 105-112, 2002.

KNÖFERL, M. W.; JARRAR, D.; ANGELE, M. K.; AYALA, A.; SCHWACHA, M. G.; BLAND, K. I.; CHAUDRY, I. H. 17beta-estradiol normalizes immune responses in ovariectomized females after trauma-hemorrhage. American Journal of Physiology. Cellular Physiology, v. 281, p. 1131-1138, 2001.

KOH, H.; TASAKA, S.; HASEGAWA, N.; YAMADA, W.; SHIMIZU, M.; NAKAMURA, M.; YONEMARU, M.; IKEDA, E.; ADACHI, Y.; FUJISHIMA, S.; YAMAGUCHI, K.; ISHIDA, A. Protective role of vascular endothelial growth factor in endotoxin induced acute lung injury in mice. Resp. Res., v. 8, p. 60, 2007.

KOIKE, K.; MOORE, F. A.; MOORE, E. E.; READ, R. A.; CARL, V. S.; BANERJEE, A. gut ischemia mediates lung injury by a xanthine oxidase-dependent neutrophil mechanism. J. Surg. Res., v. 54, p. 469-473, 1993.

KOIKE, K.; YAMAMOTO, Y.; HORI, Y.; ONO, T. Group iia phospholipase a2 mediates lung injury in intestinal ischemia-reperfusion. Ann. Surg., v. 232, p. 90-97, 2000. 
KOYAMA, S.; TAKAGI, H.; OTANI, A.; OH, H.; NISHIMURA, K.; HONDA, Y. Inhibitory mechanism of vascular endothelial growth factor (VEGF) by bucillamine. Br. J. Pharmacol., v. 137, p. 901-909, 2002.

KÜCÜKAYDIN, M.; KOCAOGLU, C.; KÖKSAL, F.; KONTAS, O. Detection of intestinal bacterial translocation in subclinical ischemia-reperfusion using the polymerase chain reaction technique. J. Pedriatr. Surg., v. 35, p. 41-43, 2000.

LAPCHAK, P. H.; IOANNOU, A.; KANNAN, L.; RANI, P.; DALLE LUCCA, J. J.; TSOKOS, G. C. Platelet-associated cd40/cd154 mediates remote tissue damage after mesenteric ischemia/reperfusion injury. PLoS ONE, v. 7, p. e32260, 2012.

LASKIN, D. L.; SUNIL, V. R.; GARDNER, C. R.; LASKIN, J. D. Macrophages and tissue injury: agents of defense or destruction? Annu. Rev. Pharmacol. Toxicol. v. 51, p. 267-288, 2011.

LESER, H. G.; GROSS, V.; SCHEIBENBOGEN, C.; HEINISCH, A.; SALM, R.; LAUSEN, M.; RÜCKAUER, K.; ANDREESEN, R.; FARTHMANN, E. H.; SCHÖLMERICH, J. Elevation of serum interleukin-6 concentration precedes acute-phase response and reflects severity in acute pancreatitis. Gastroenterology, v. 101, p. 782-785, 1991.

LI, H. B.; WANG, G. Z.; GONG, J.; WU, Z. Y.; GOU, S.; LI, B.; LIU, M.; JI, Y. D.; TANG, M.; YUAN, S. Y.; SHANG, Y.; YAO, S. L. BML-111 attenuates hemorrhagic shock-induced acute lung injury through inhibiting activation of mitogen-activated protein kinase pathway in rats. J. Surg. Res., 2013. [Epub ahead of print]

LI, X. J.; HE, R. F.; LI, S.; LI, X. J.; LI, D. L. Effects of progesterone on learning and memory and P2X7 receptor expression in the hippocampus after global cerebral ischemia/reperfusion injury in rats. Zhongguo Ying Yong Sheng Li Xue Za Zhj., v. 28, p. 472-475, 2012.

LIANG, C. J.; WANG, S. H.; CHEN, Y. H.; CHANG, S. S.; HWANG, T. L. Viscolin reduces VCAM-1 expression in TNF-alpha-treated endothelial cells via the JNK-NF-kappaB and ROS pathway. Free Radic. Biol. Med., v. 51, p. 1337-1346, 2011.

LIN, C. C.; LEE, C. W.; CHU, T. H.; CHENG, C. Y.; LUO, S. F. Transactivation of Src. PDGF receptor, and Akt is involved in IL-1beta-induced ICAM-1 expression in A549 cells. J. Cell Physiol., v. 211, p. 771-780, 2007.

LINDESTROM, L.; EKBLAD, E. Structural and neuronal changes in rat ileum after ischemia with reperfusion. Dig. Dis. Sci., v. 49, p. 1212-1222, 2004.

LIGEIRO DE OLIVEIRA, A. P.; OLIVEIRA-FILHO, R. M.; DA SILVA, Z. L.; BORELLI, P.; TAVARES DE LIMA, W. Regulation of allergic lung inflammation in rats: interaction between estradiol and corticosterone. Neuroimmunomodulation, v. 11, p. 20-27, 2004.

LIU, C.; ZHANG, H.; CHENG, P. Y.; ZHOU, F. C. The influence of pre-B-cell colony enhancing factor on adhesive molecule in pulmonary cells in rats with acute lung injury/acute respiratory distress syndrome. Zhonghua Wei Zhong Bing Ji Jiu Yi Xue, v. 25, p. 159-163, 2013. 
LOONEY, M. R.; NGUYEN, J. X.; HU, Y.; VAN ZIFFLE, J. A.; LOWELL, C. A.; MATTHAY, M. A. Platelet depletion and aspirin treatment protect mice in a two-event model of transfusion-related acute lung injury. J. Clin. Invest., v, 119, p. 3450-3461, 2009.

LU, Y. Z.; WU, C.C; HUANG, Y. C.; HUANG, C. Y.; YANG, C. Y.; LEE, T. C.. CHEN, C. F.; YU, L. C.; Neutrophil priming by hypoxic preconditioning protects against epithelial barrier damage and enteric bacterial translocation in intestinal ischemia/reperfusion. Lab. Invest., v. 92, p. 783-796, 2012.

LUHR, O.R.; ANTONSEN, K.; KARLSSON, M.; AARDAL, S.; THORSTEINSSON, A.; FROSTELL, C.G.; BONDE, J. Incidence and mortality after acute respiratory failure and acute respiratory distress syndrome in Sweden, Denmark, and Iceland. The ARF Study Group. Am. J. Respir. Crit. Care Med., v.159, p. 1849-1861, 1999.

LUTZ, J.; THURMEL, K.; HEEMANN, U. Anti-inflammatory treatment strategies for ischemia/reperfusion injury in transplantation. Journal of Inflammation, v.7, p. 1-8, 2010.

MA, X. L.; GAO, F.; CHEN, J.; CHRISTOPHER, T. A.; LOPEZ, B. L.; OHLSTEIN, E. H.; YUE, T. Endothelial protective and antishock effects of a selective estrogen receptor modulator in rats. Am. J. Physiol. Heart Circ. Physiol., v. 280, p. 876-884, 2001.

MAÎTRE, B.; MEKONTSO-DESSAP, A.; HABIBI, A.; BACHIR, D.; PARENT, F.; GODEAU, B.; GALACTEROS, F. Pulmonary complications in adult sickle cell disease. Rev. Mal. Respir., v. 28, p.129-137, 201.

MARDI, K.; KAUSHAL, V. Cryptococcal mesenteric lymphadenitis in an immunocompromised host. Indian J. Sex Transm. Dis., v. 33, p. 60-61, 2012.

MATSUO, S.; YANG, W. L.; AZIZ, M.; JACOB, A.; WANG, P. Cyclic arginine-glycineaspartate attenuates acute lung injury in mice after intestinal ischemia/reperfusion. Crit. Care, v. 29, p. 17-19, 2013.

MAXWELL, S. R.; LIP, G. Y. Reperfusion injury: a review of the pathophysiology, clinical manifestations and therapeutic options. Int. J. Cardiol., v. 58, p. 95-117, 1997.

MCCORD, J. M. Oxygen-derived free radicals in post ischemic tissue injury. N. Engl. J. Med., v. 312, p. 159-163, 1985.

MCDONALD, B.; PITTMAN, K.; MENEZES, G. B.; HIROTA, S. A.; SLABA, I.; WATERHOUSE, C. C.; BECK, P. L.; MURUVE, D. A.; KUBES, P. Intravascular danger signals guide neutrophils to sites of sterile inflammation. Science, v. 330, p. 362-566, 2010.

MEES, S. T.; GWINNER, M.; MARX, K.; FAENDRICH, F.; SCHROEDER, J.; HAIER, J.; KAHLKE, V. Influence of sex and age on morphological organ damage after hemorrhagic shock. Shock, v. 29, p. 670-674, 2008.

MEHTA, D.; MALIK, A. B. Signaling mechanisms regulating endothelial permeability. Physiol. Rev., v. 86, p. 279-367, 2006. 
MELDRUM, D. R. Estrogen increases protective proteins following trauma and hemorrhage. American Journal of Physiology. Regulatory, Integrative and Corporative Physiology, v. 290, p. 809-811, 2006.

MENGER, M. D.; RÜCKER, M.; VOLLMAR, B. Capillary dysfunction in striated muscle ischemia/reperfusion: on the mechanisms of capillary "no-reflow". Shock, v. 8, p. 2-7, 1997.

MEYER, M. R.; HAAS, E.; BARTON, M. Gender differences of cardiovascular disease: new perspectives for estrogen receptor signaling. Hypertension, v. 47, p. 1019-1026, 2006.

MILBERG, J. A.; DAVIS, D. R.; STEINBERG, K. P.; HUDSON, L. D. Improved survival of patients with acute respiratory distress syndrome (ARDS): 1983-1993. JAMA, v. 273, p. 306309, 1995.

MISHRA, A.; CHINTAGARI, M. R.; GUO, Y.; WENG, T.; SU, L.; LIU, L. Purinergic P2X 7 receptor regulates lung surfactant secretion in a paracrine manner. J. Cell Science, v. 124, p. 657-668, 2011.

MIYAGI, M.; AOYAMA, H.; MORISHITA, M.; IWAMOTO, Y. Effects of sex hormones on chemotaxis of human peripheral polymorphonuclear leukocytes and monocytes. $\mathbf{J}$. Periodontol., v. 63, p. 28-32, 1992.

MOEINPOUR, F.; CHOUDHRY, M. A.; KAWASAKI, T.; TIMARES, L.; SCHWACHA, M. G.; BLAND, K. I.; CHAUDRY, I. H.17beta-estradiol normalizes Toll receptor 4, mitogen activated protein kinases and inflammatory response in epidermal keratinocytes following trauma-hemorrhage. Molecular Immunology, v. 44, p. 3317-3323, 2007.

MOLLEN, K. P.; ANAND, R. J.; TSUNG, A.; PRINCE, J. M.; LEVY, R. M.; BILLIAR, T. R. Emerging paradigm: toll-like receptor 4-sentinel for the detection of tissue damage. Shock, v. 26, p. 430-437, 2006.

MOORE, F. A.; MOORE, E. E.; POGGETTI, R.; MCANENA, O. J.; PETERSON, V. M.; ABERNATHY, C. M.; PARSONS, P. E. Gut bacterial translocation via the portal vein: a clinical perspective with major torso trauma. J. Trauma, v. 31, p. 629-636, 1991.

MOORE, F. A.; MOORE, E. E.; POGGETTI, R. S.; READ, R. A. Postinjury shock and early bacteremia. A letal combination. Arch. Surg., v. 127, p. 893-897, 1992.

MORAES, L. B.; MURAKAMI, A. H. F.; FONTES, B.; POGGETTI, R. S.; ROOIJEN, N.; YOUNES, R. N.; HEIMBECKER, A. M. C. BIROLINI, D. Gut ischemia/reperfusion induced acute lung injury is an alveolar macrophage dependent event. The Journal of Trauma, v. 64, p. 1196-1201, 2008.

MOSSER, D. M.; ZHANG, X. Interleukin-10: new perspectives on an old cytokine. Immunol. Rev., v. 226, p. 205-218, 2008.

MUELLER, M. D.; VIGNE, J. L.; MINCHENKO, A.; LEBOVIC, D. I.; LEITMAN, D. C.; TAYLOR, R. N. Regulation of vascular endothelial growth factor (VEGF) gene transcription by estrogen receptors alpha and beta.Proc. Natl. Acad. Sci. USA, v. 97, p. 10972-10977, 2000 . 
MULLER, W. A.; WEIGL, S. A.; DENG, X.; PHILLIPS, D. M. PECAM-1 is required for transendothelial migration of leukocytes. J. Exp Med., v. 178, p. 449-460, 1993.

MURA, M.; HAN, B.; ANDRADE, C. F.; SETH, R.; HWANG, D.; WADDELL, T. K.; KESHAVJEE, S.; LIU, M. The early responses of VEGF and its receptors during acute lung injury: implication of VEGF in alveolar epithelial cell survival.Crit. Care, v.10, p. 130, 2006.

MUKUNDAN, C.; GURISH, M. F.; AUSTEN, K. F.; HECHTMAN, H. B.; FRIEND, D. S. Mast cell mediation of muscle and pulmonary injury following hindlimb ischemiareperfusion. J. Histochem. Cytochem., v. 49, p. 1055-1056, 2001.

NARITA, K.; KUWABARA, Y.; FUJII, Y. Lung injury after intestinal ischemia-reperfusion may be avoided by the reduced absorption of locally produced cytokines. Surg. Today, v. 34, p. 937-942, 2004.

NATHAN, C. Role of iNOS in human host defense. Science, v. 30, p. 1874-1875, 2006.

NEWMAN, P. J.; BERNDT, M. C.; GORSKI, J.; WHITE, J. C.; LYMAN, S.; PADDOCK, C.; MULLER, W. A. PECAM-1 (CD31) cloning and relation to adhesion molecules of the immunoglobulin gene superfamily. Science, v. 247, p. 1219-1222, 1990.

NEWTON, K.; DIXIT, .V. M. Signaling in innate immunity and inflammation. Cold. Spring Harb. Perspect. Biol., v. 4, 2012.

NORTH, A. R. Molecular physiology of P2X receptors. Physiol. Rev., v. 82, p. 1013-1067, 2002 .

NOWAK-MACHEN, M.; SCHMELZLE, M.; HANIDZIAR, D.; JUNGER, W.; EXLEY, M.; OTTERBEIN, L.; WU, Y.; CSIZMADIA, E.; DOHERTY, G.; SITKOVSKY, M.; ROBSON, S. C. Pulmonary natural killer T cells play an essential role in medianting hyperoxic acute lung injury. Am. J. Respir. Cell Mol. Biol., v. 48, p. 601-609, 2013.

O'SULLIVAN, B.; THOMAS, R. Recent advances on the role of CD40 and dendritic cells in immunity and tolerance. Current Opinion in Hematology, v. 10, p. 272-278, 2003.

OHKUBO, H.; ITO, Y.; MINAMINO, T.; MISHIMA, T.; HIRATA, M.; HOSONO, K.; SHIBUYA, M.; YOKOMIZO, T.; SHIMIZU, T.; WATANABE, M.; MAJIMA, M.; Leukotriene B4 type-1 receptor signaling promotes liver repair after hepatic ischemia/reperfusion injury through the enhancement of macrophage recruitment. FASEB J., 2013.

OLSEN, N. J.; KOVACS, W. J. Gonadal steroids and immunity. Endocr. Rev., v. 17, p. 369384, 1996.

OSBORN, L.; HESSION, C.; TIZARD, R.; VASSALLO, C.; LUHOWSKYJ, S.; CHIROSSO, G.; LOBB, R. Direct expression cloning of vascular cell adhesion molecule 1, a cytokine-induced endothelial protein that binds to lymphocytes. Cell, v. 59, p. 1203-1211, 1989. 
OTSUKI, M.; SAITO, H.; XU, X.; SUMITANI, S.; KOUHARA, H.; KISHIMOTO, T.; KASAYAMA, S. Progesterone, but not medroxyprogesterone, inhibits vascular cell adhesion molecule-1 expression in human vascular endothelial cells. Arterioscler. Thromb. Vasc. Biol., v. 21, p. 243-248, 2001.

PAMUK, O. N.; LAPCHAK, P. H.; RANI, P.; PINE, P.; DALLE LUCCA, J. J.; TSOKOS, G. C. Spleen tyrosine kinase inhibition prevents tissue damage after ischemia-reperfusion. Am. J. Physiol. Gastrointest. Liver Physiol., v. 299, p. 391-399, 2010.

PATEL, B. V.; WILSON, M. R.; O’DEAK, P.; TAKATA, M. TNF-induced death signaling triggers alveolar epithelial dysfunction in acute lung injury. J. Immunol., v. 190, p. 274-282, 2013.

PATI, S.; GERBER, M. H.; MENGE, T. D.; WATAHA, K. A.; ZHAO, Y.; BAUMGARTNER, J. A.; ZHAO, J.; LETORNEAU, P. A.; HUBY, M. P.; BAER, L. A.; SALSBURY, J. R.; KOZAR, R. A.; WADE, C. E.; WALKER, P. A.; DASH, P. K.; COX, C. S. Jr.; DOURSOUT, M. F.; HOLCOMB, J. B. Bone marrow derived mesenchymal stem cells inhibit inflammation and preserve vascular endothelial integrity in the lungs after hemorrhagic shock. PloS One, v. 6, p. 25171, 2011.

PAULINO, A. S.; PALOMBIT, K.; CAVRIANI, G.; DE LIMA, W. T.; MIZUNO, M. S.; MAROSTI, A. R.; DA SILVA, M. V.; GIROTTI, P. A.; LIBERTI, E. A.; CASTELUCCI, P. Effects of ischemia and reperfusion on P2X2 receptor expressing neurons of the rat ileum enteric nervous system. Digestive Diseases and Sciences, 2011.

PARKS, D. A.; GRANGER, D. N. Contributions if ischemia and reperfusion to mucosal lesion formation. Am. J. Physiol., v.250, p.G749-G753, 1986.

PIAO, D. X.; JIANG, H. C.; KOSAKA, M.; SHIBATA, T.; OHTSUKA, A.; MURAKAMI, T. Cytoplasmic delayed neuromal death in the myenteric plexus of the rat small intestine after ischemia. Archives of histology and Cytology, v. 62, p. 383-392, 1999.

PIERCY, K. T.; DONNELL, R. L.; KIRKPATRICK, S. S.; TIMARAN, C. H.; STEVENS, S. L.; FREEMAN, M. B.; GOLDMAN, M. H. Effects of estrogen, progesterone, and combination exposure on interleukin-1 beta-induced expression of VCAM-1, ICAM-1, PECAM, and E-selectin by human female iliac artery endothelial cells. J. Surg. Res., v. 105, p. 215-219, 2002.

PITTMAN, K.; KUBES, P. Damage-associated molecular patterns control neutrophil recruitment. J. Innate Immun., 2013. [Epub ahead of print]

PONTELL, L.; SHARMA, P.; RIVERA, L. R.; THACKER, M.; TAN, Y. H.; BROCK, J. A.; FURNESS, J. B. Damaging effects of ischemia/reperfusion on intestinal muscle. Cell. Tissue Res., v. 343, p. 411-419, 2011.

POULTER, L. W.; JANOSSY, G.; POWER, C.; SREENAN, S.; BURKE, C. Immunological/Physiological Relationships in Asthma: Potential Regulation by Lung Macrophages. Immunol. Today, v. 15, p. 258-261, 1994. 
RAJAMÄKI, K.; NORDSTRÖM, T.; NURMI, K.; AKERMAN, K. E.; KOVANEN, P. T.; OÖRNI, K.; EKLUND, K. K.; Extracellular acidosis is a novel danger signal alerting innate immunity via the NLRP3 inflammasome. J. Biol. Chem., 2013. [Epub ahead of print]

RAJU, R.; CHAUDRY, I. H. Sex steroids/receptor antagonist: their use as adjuncts after trauma-hemorrhage for improving immune/cardiovascular responses and for decreasing mortality from subsequent sepsis Anesth. Analg., v. 107, p. 159-166, 2008.

REMICK, D. G.; BOLGOS, G. R; SIDDIQUI, J.; SHIN, J.; NEMZEK, J. A. Six at six: interleukin- 6 measured $6 \mathrm{~h}$ after the initiation of sepsis predicts mortality over 3 days. Shock., v. 17, p. 462-467, 2002.

ROLAND, C. L.; HARKEN, A. H.; SARR, M. G.; BARNETT, C. C. ICAM-1 expression determines malignant potential of cancer. Surgery, v. 141, p. 705-707, 2007.

RITEAU, N.; GASSE, P.; FAUCONNIER, L.; GOMBAULT, A.; COUEGNAT, M.; FICK, L.; KANELLOPOULOS, J.; QUESNIAUX, V. F.; MARCHAND-ADAM S; CRESTANI, B.; RYFFEL, B.; COUILLIN, I. Extracellular ATP is a danger signal activating P2X7 receptor in lung inflammation and fibrosis. Am. J. Respir. Crit. Care Med., v. 182, p. 774-783, 2010.

RUBENFELD, G. D.; CALDWELL, E.; PEABODY, E.; WEAVER , J.; MARTIN, D. P.; NEFF, M.; STERN, E. J.; HUDSON, L. D. Incidence and outcomes of acute lung injury. N. Engl. J. Med., v. 353, p. 1685-1693, 2005.

SALAMA, A. D.; PUSEY, C. D. Shining a LAMP on pauci-immune focal segmental glomerulonephritis. Kidney Int., v. 76, p. 15-17, 2009.

SAllUSTO, F.; CELlA, M.; DANIELI, C.; LANZAVECCHIA, A. Dendritic cells use macropinocytosis and the mannose receptor to concentrate macromolecules in the major histocompatibility complex class II compartment: downregulation by cytokines and bacterial products. J. Exp. Med., v. 182, p. 389-400, 1995.

SCALIA, R.; LEFER, A. M. In vivo regulation of PECAM-1 activity during acute endotelial dysfunction in the rat mesenteric microvasculature. J. Leukoc. Biol., v. 64, p. 163-169, 1998.

SCARABELLI, T. M.; PASINI, E.; STEPHANOU, A.; COMINI, L.; CURELLO, S.; RADDINO, R.; FERRARI, R.; KNIGHT, R.; AND LATCHMAN, D. S. Urocortin promotes hemodynamic and bioenergetic recovery and improves cell survival in the isolated rat heart exposed to ischemia/reperfusion. J. Am. Coll. Cardiol., v. 40, p. 155-161, 2002.

SCHNURR, M.; THEN, F.; GALAMBOS, P.; SCHOLZ, C.; SIEGMUND, B.; ENDRES, S.; EIGLER, A. Extracellular ATP and TNF-alpha synergize in the activation and maturation of human dendritic cells. J. Immunol., v. 165, p. 4704-4709, 2000.

SCHRODER, J.; KAHLKE, V.; BOOK, M.; STUBER, F. Gender differences in sepsis: genetically determined? Shock, v. 14, p. 307-310, 2000.

SEEKAMP, A.; WARD, P. A. Ischemia-reperfusion injury. Agents Actions Suppl., v. 41, p. 137-152, 1993. 
SERHAN, C. N.; CHIANG, N.; VAN DYKE, T. E. Resolving inflammation: dual antiinflammatory and pro-resolution lipid mediators. Nat. Rev. Immunol., v. 8, p. 349-61, 2008

SHARAWY, N.; PAVLOVIC, D.; WENDT, M.; CERNY, V.; LEHMANN, C. Evaluation of the effects of gender and estradiol treatment on the intestinal microcirculation during experimental sepsis. Microvasc. Res., v. 82, p. 397-403, 2011.

SHIMIZU, T.; YU, H. P.; SUZUKI, T.; SZALAY, L.; HSIEH, Y. C.; CHOUDHRY, M. A.; BLAND, K. I.; CHAUDRY, I. H. The role of estrogen receptor subtypes in ameliorating hepatic injury following trauma-hemorrhage. J. Hepatol., v. 46, p. 1047-54, 2007.

SIFRI, C. Z.; COHEN, D.; ANANTHAKRISHNAN, P.; WANG, L.; KAISER, V. L. Sex hormones affect bone marrow dysfunction after trauma and hemorrhagic shock. Crit. Care Med., v. 35, p. 864-869, 2007.

SOUZA, A. L. JR.; POGGETTI, R. S.; FONTES, B.; BIROLINI, D. Gut ischemia/reperfusion activates lung macrophages for tumor necrosis factor and hydrogen peroxide production. J. Trauma, v.49, p.232-236, 2000.

SOUZA, C. O.; SANTORO, G. F.; FIGLIUOLO, V. R.; NANINI, H. F.; DE SOUZA, H. S.; CASTELO-BRANCO, M. T.; ABALO, A. A; PAIVA, M. M.; COUTINHO, C. M.; COUTINHO-SILVA, R. Extracellular ATP induces cell death in human intestinal epitelial cells. Biochim. Biophys. Acta., v. 1820, p. 1867-1878, 2012.

SOUZA, J. A.; POGGETTI, R. S.; FONTES, B.; BIROLINI, D. Gut ischemia and reperfusion activates lung macrophage for TNF and $\mathrm{H}_{2} \mathrm{O}_{2}$ production. J. Trauma, v. 49, p. 232-236, 2000 .

SPERRY, J. L.; NATHENS, A. B.; FRANKEL, H. L; VANEK, S. L.; MOORE, E. E.; MAIER, R. V.; MINEI, J. P. Characterization of the gender dimorphism after injury and hemorrhagic shock: are hormonal differences responsible? Crit. Care Med., v. 36, p. 1838$1845,2008$.

SPEYER, C. L.; RANCILIO, N. J.; MCCLINTOCK, S. D.; CRAWFORD, J. D.; GAO, H.; SARMA, J. V.; WARD, P. A.Regulatory effects of estrogen on acute lung inflammation in mice. Am. J. Physiol. Cell Physiol., v. 288, p. 881-890, 2005.

STALLION, A.; KOU, T. D.; MILlER, K. A.; DAHMS, B. B.; DUDGEON, D. L.; LEVINE, A. D. IL-10 is not protective in intestinal ischemia reperfusion injury. J. Surg. Res., v. 105, p. 145-152, 2002.

STANGL, V.; BAUMANN, G.; STANGL, K. Coronary atherogenic risk factors in women. Eur. Heart. J., v. 23, p. 1738-1752, 2002.

STEINBERG, K. P.; HUDSON, L. D. Acute lung injury and acute distress syndrome. the clinical syndrome. Clin. Chest. Med., v. 21, p. 401-417, 2000.

SÖZEN, S.; KISAKÜREK, M.; YILDIZ, F.; GÖNÜLTAS, M.; DINÇEL, A. S. The effects of glutamine on hepatic ischemia reperfusion injury in rats. Hippokratia, v. 15, p. 160-166, 2011. 
SUN, Z., WANG, X., LASSON, A., BORJESSON, A., LEVEAU, P., HARALDSEN, P., ANDERSSON, R. Roles of platelet-activating factor, interleukin-1 beta and interleukin- 6 in intestinal barrier dysfunction induced by mesenteric arterial ischemia and reperfusion. $\mathbf{J}$. Surg. Res., v. 87, p. 90-100, 1999.

TAGER, A. M.; LACAMERA, P.; SHEA, B. S.; CAMPANELLA, G. S.; SELMAN, M.; ZHAO, Z.; POLOSUKHIN, V.; WAIN, J.; KARIMI-SHAH, B. A.; KIM, N. D.; HART, W. K.; PARDO, A.; BLACKWELL, T. S.; XU, Y.; CHUN, J.; LUSTER, A. D. The lysophosphatidic acid receptor LPA1 links pulmonary fibrosis to lung injury by mediating fibroblast recruitment and vascular leak. Nat. Med., v. 14, p. 45-54, 2008.

TAKAYAMA, M.; ISHIBASHI, M.; ISHII, H.; KURAKI, T.; NISHIDA, T.; YOSHIDA, M. Effects of neutrophil elastase inhibitor (ONO-5046) on lung injury after ischemia-reperfusion. J. Appl. Physiol., v. 91, p. 1800-1807, 2001.

THAUNAT, O. Sterile inflammatory response to ischemia-reperfusion injury: immediate and long term consequences on graft function. Bull. Acad. Natl. Med., v. 195, p. 847-859, 2011.

THICKETT, D. R.; ARMSTRONG, L.; MILLAR, A. B. A role for vascular endothelial growth factor in acute and resolving lung injury. Am. J. Respir. Crit. Care Med., v. 166, p. 1332-1337, 2002.

TUTTOLOMONDO, A.; DI SCIACCA, R.; DI RAIMONDO, D.; RENDA, C.; PINTO, A.; LICATA, G. Inflammation as a therapeutic target in acute ischemic stroke treatment. Curr. Top. Med. Chem., v. 9, p. 1240-1260, 2009.

TURNAGE, R.H.; GUICE, K. S.; OLDHAM, K. T. Endotoxemia and remote organ injury following intestinal reperfusion. J. Surg. Res., v. 56, p. 571, 1994.

TÜRÜT, H.; KURUTAS, E. B.; BULBULOGLU, E.; YASIM, A.; OZKAYA, M.; ONDER, A.; IMREK, S. S. Zinc aspartate alleviates lung injury induced by intestinal ischemiareperfusion in rats. J. Surg. Resp., v.151, p. 62-67, 2009.

VICTONI, T.; COELHO, F. R.; SOARES, A. L; DE FREITAS, A.; SECHER, T.; GUABIRABA, R.; ERARD, F.; DE OLIVEIRA-FILHO, R. M.; VARGAFTIG, B. B.; LAUVAUX, G.; KAMAL, M. A.; RYFFEL, B.; MOSER, R.; TAVARES-DE-LIMA, W. Local and remote tissue injury upon intestinal ischemia and reperfusion depends on the TLR/MyD88 signaling pathway. Med. Microbiol. Immunol., v. 199, p. 35-42, 2010.

VOLLMAR, B.; MENGER, M. B. Intestinal ischemia/reperfusion: microcirculatory pathology and functional consequences. Langenbecks Arch. Surg., v. 396, p. 13-29, 2011.

WANG, H.; ZHANG, W.; LUGEN, Z.; ZHU, W.; LI, Q.; LI, J. Bifidobacteria may be beneficial to intestinal microbiota and reduction of bacterial translocation in mice following ischaemia and reperfusion injury. British Journal of Nutrition, p. 1-9, 2012.

WANG, J.; ZHAO, Y.; LIU, C.; JIANG, C.; ZHAO, C.; ZHU, Z. Progesterone inhibits inflammatory response pathways after permanent middle cerebral artery occlusion in rats.

Mol. Med. Rep., v. 4, p. 319-324, 2011. 
WARD, D. T.; LAWSON, S. A.; GALlAGHER, C. M.; CONNER, W. C.; SHEADONOHUE, T. Sustained Nitric Oxide Production Via L-Arginine Administration Ameliorates Effects of Intestinal Ischemia-Reperfusion. J. Surg. Res., v. 89, p. 13-19, 2000.

WARE, L. B.; MATTHAY, M. A. The acute respiratory distress syndrome. N. Engl. J. Med., v. 342, p. 1334-1349, 2000.

WAREHAM, K.; VIAL, C.; WYKES, R. C.; BRADDING, P.; SEWARD, E. P. Functional evidence for the expression of $\mathrm{P} 2 \mathrm{X} 1, \mathrm{P} 2 \mathrm{X} 4$ and $\mathrm{P} 2 \mathrm{X}_{7}$ receptors in human lung mast cells. Br. J. Pharmacol., v. 157, p. 1215-1224, 2009.

WAXMAN, K. Shock: ischemia, reperfusion, and inflammation. New Horiz., v. 4, p. 153$160,1996$.

WU, Y. H.; CHUANG, S. Y.; HONG, W. C.; LAI, Y. J.; CHANG, G. J.; PANG, J. H. Berberine reduces leukocyte adhesion to LPS-stimulated endothelial cells and VCAM-1 expression both in vivo and in vitro. Int. J. Immunopathol. Pharmacol., v. 25, p. 741-750, 2012.

XIA, Y. C.; REDHU, N. S.; MOIR, L. M.; KOZIOL-WHITE, C.; AMMIT, A. J.; ALALWAN,L.; CAMORETTI-MERCADO, B., CLIFFORD, R. L. Pro-inflammatory and immunomodulatory functions of airway smooth muscle: emerging concepts. Pulmonary Pharmacology \& Therapeuthics, 2012.

XIA, G.; MARTIN, A. E.; BESNER, G. E. Heparin-binding EGF-like growth factor downregulates expression of adhesion molecules and infiltration of inflammatory cells after intestinal ischemia/reperfusion injury. J. Pediatr. Surg, v. 38, p. 434-439, 2003.

XIAO, X.; LIU, D.; ZHENG, S.; FU, J.; ZHANG, H.; CHEN, L. Protective effect of estrogen on intestinal ischemia-reperfusion injury in pubertal rats. J. Pediatr. Surg., v. 39, p. 1828-31, 2004.

XING, H. C.; LI, L. J.; XU, K. J.; SHEN, T.; CHEN, Y. B.; SHENG, J. F.; YU, Y S.; CHEN, Y. G. Intestinal microflora in rats with ischemia/reperfusion liver injury. J. Zhejiang. Univ. Sci. B., v. 6, p. 14-21, 2005.

YATES, M. A.; LI, Y.; CHLEBECK, P.; PROCTOR, T.; VANDENBARK, A. A.; OFFNER, $\mathrm{H}$. Progesterone treatment reduces disease severity and increases IL-10 in experimental autoimmune encephalomyelitis. J. Neuroimmunol., v. 220, p. 136-139, 2010.

YEN. F. L.; TSAI, M. H.; YANG, C. M.; LIANG, C. J.; LIN, C. C.; CHIANG, Y. C.; LEE, H. C.; KO, H. H.; LEE, C. W. Curcumin nanoparticles ameliorate ICAM-1 expression in TNF- $\alpha$-treated lung epithelial cells through p47 (phox) and MAPKs/AP-1 pathways. PloS One, v. 8, p. 63845, 2013.

YU, H. P.; CHAUDRY, I. H. The role of estrogen and receptor agonists in maintaining organ function after trauma-hemorrhage. Shock, v. 31, p. 227-237, 2009. 
YU, H. P.; HSIEH, Y. C.; SUZUKI, T.; CHOUDHRY, M. A.; SCHWACHA, M. G.; BLAND, K. I.; CHAUDRY, I. H. Mechanism of the nongenomic effects of estrogen on intestinal myeloperoxidase activity following trauma-hemorrhage: up-regulation of the PI3K/Akt pathway. J. Leukoc. Biol., v. 82, p. 774-780, 2007.

ZEMSE, S. M.; CHIAO, C. W.; HILGERS, R. H.; WEBB, R. C. Interleukin-10 inhibits the in vivo and in vitro adverse effects of TNF-alpha on the endothelium of murine aorta. Am. J. Physiol. Heart Circ. Physiol., v. 299, p. 1160-1167, 2010.

ZHANG, Q.; RAOOF, M.; CHEN, Y.; SUMI, Y.; SURSAL, T.; JUNGER, W.; CROHI, K.; ITAGAKI, K.; HAUSER, C. J. Circulating mitochondrial DAMPs cause inflammatory responses to injury. Nature, v. 464, p. 104-107, 2010.

ZHOU, X.; DAI, Q.; HUANG, X. Neutrophils in acute lung injury. Front. Biosci., v. 17, p. 2278-2283, 2012. 